\author{
Universidade de São Paulo \\ Escola Superior de Agricultura "Luiz de Queiroz"
}

\title{
Uma abordagem econômica das causas da criminalidade: evidências para a cidade de São Paulo
}

Marcelo Justus dos Santos

Tese apresentada para obtenção do título de Doutor em Ciências. Área de concentração: Economia Aplicada

Piracicaba

2012 
Marcelo Justus dos Santos

Economista

Uma abordagem econômica das causas da criminalidade: evidências para a cidade de São Paulo

Orientadora:

Profa. Dra. AnA Lúcia KASSOUF

Tese apresentada para obtenção do título de Doutor em Ciências. Área de concentração: Economia Aplicada

Piracicaba

2012 


\section{Dados Internacionais de Catalogação na Publicação}

DIVISÃO DE BIBLIOTECA - ESALQ/USP

Santos, Marcelo Justus dos

Uma abordagem econômica das causas da criminalidade: evidências para a cidade de São Paulo / Marcelo Justus dos Santos.- - Piracicaba, 2012.

$93 \mathrm{p}$ : il.

Tese (Doutorado) - - Escola Superior de Agricultura "Luiz de Queiroz", 2012.

1. Análise de intervenção 2. Análise de séries temporais 3. Crime 4. Criminalidade 5. Desarmamento 6. Riqueza 7. Vitimização I. Título

CDD 364

$\mathrm{S} 237 \mathrm{a}$

"Permitida a cópia total ou parcial deste documento, desde que citada a fonte - 0 autor" 



\section{DEDICO}

À minha esposa Daiane, o grande amor da minha vida. Dedico esta conquista a essa mulher maravilhosa e reforço a promessa de amála e respeitá-la por toda a minha vida. Prometo que nenhum sucesso na vida será mais grandioso do que a felicidade do nosso lar. 


\section{AGRADECIMENTOS}

Esta tese de doutorado representa a conclusão de um longo processo de aprendizado. Nesse caminho muitas pessoas foram importantes, sendo justo agradecer a todas elas. Deixo aqui registrado os meus sinceros agradecimentos a todos aqueles que, direta ou indiretamente, contribuíram para a minha formação pessoal, educacional e profissional. Imensurável é o tamanho da minha dívida com meus amados pais, Cirlei Justus e Dejalma dos Santos, sobretudo pelos esforços e recursos dispensados para a minha criação. Incluo aqui, também, um agradecimento especial a Edilene Scheidt, minha sogra, por todo o carinho e atenção. Também serei eternamente grato ao Professor Eziquiel Guerreiro pela ajuda nos primeiros passos no campo da pesquisa científica, por seus valiosos conselhos e por ter me estendido a mão em muitos momentos difíceis de minha vida. Aproveito para agradecer a todos os verdadeiros mestres que tive desde a educação fundamental. Entre eles incluo o querido Professor Estanislau Rodrigues de Almeida. De modo especial, sempre terei profunda gratidão, respeito e admiração pela minha orientadora, tanto durante o mestrado como durante o doutorado, Profa. Dra. Ana Lúcia Kassouf. Não tenho dúvida de que, a partir das relações de trabalho, uma grande amizade foi construída. Incluo aqui a minha gratidão também a Maria Aparecida Maielli, secretária do Programa de Pós-Graduação em Economia Aplicada, desejando que todo funcionário público seja igual a ela em solicitude e presteza. Agradeço a todos que se dispuseram a comentar, criticar e sugerir melhorias às versões preliminares dos artigos que compõem esta tese. Particular agradecimento faço aos doutores Tulio Kahn, Humberto Francisco Spolador, Geraldo Sant'Ana de Camargo Barros e Mirian Rumenos Piedade Bacchi. Aos três últimos, ainda, sou grato pelas valiosas críticas e sugestões que recebi no exame de qualificação desta tese. À Profa. Mirian declaro, ainda, a minha imensa gratidão por ter sanado tantas dúvidas que tive sobre as metodologias de análise de séries temporais. Agradeço ao Centro de Políticas Públicas (CPP) do Insper - Instituto de Ensino e Pesquisa, em particular ao seu coordenador, Dr. Naercio Aquino Menezes Filho, pelos dados utilizados no terceiro artigo que compõe esta tese. Agradeço a todos os colegas de pós-graduação com os quais tive a honrosa oportunidade de conviver, em especial, ao Henrique Coelho Kawamura pelo grande apoio nos momentos finais desta tese. Preciso reconhecer, também, que, mesmo com tanta ajuda, sobretudo a recebida de meus pais, não poderia ter estudado se não fosse o investimento que recebi da sociedade brasileira desde o primeiro ano do ensino fundamental. Especificamente, esta tese só foi possível porque recebi fomento do Conselho Nacional de Desenvolvimento Científico e Tecnológico - CNPq, entidade governamental brasileira promotora do desenvolvimento científico e tecnológico. Sinceramente, trabalharei muito para devolver, na forma de ensino e pesquisa, tudo aquilo que recebi da sociedade, pois sei que muitos não tiveram as mesmas oportunidades que eu tive. Ainda, sou muito grato à Universidade Estadual de Ponta Grossa pela liberação integral para doutoramento durante aproximadamente dois anos, tempo suficiente para que eu pudesse completar todos os créditos referentes às disciplinas e para escrever a primeira versão desta tese. Reconheço que, sem o afastamento integral de minhas atividades docentes, tudo ficaria muito mais difícil. Por fim, ressalto minha gratidão a Deus Pai, a Deus Filho e a Deus Espírito Santo, pelo dom da vida, da fé e da sabedoria. Todas as vezes em que eu disse "isso é impossível", Deus disse "tudo é possível" (Lucas 18:27); quando eu disse "já estou cansado", Deus disse "eu te darei repouso" (Mateus 11:28-30); quando eu disse "não tenho condições, Deus disse "minha graça é suficiente" (II Coríntios 12:9); quando eu disse "eu não posso fazer", Deus disse "você pode tudo" (Filipenses 4:13); quando eu disse "não vale a pena", Deus disse "tudo vale a pena" (Romanos 8:28); quando eu disse "não vou conseguir", Deus disse "eu suprirei todas as suas necessidades" (Filipenses 4:19); quando eu disse "eu não tenho sabedoria suficiente", Deus disse "eu te dou sabedoria" (I Coríntios 1:30). Muito obrigado, Pai Celestial! 
"Mais vale uma resposta aproximada para a pergunta certa que uma resposta exata para a pergunta errada".

John Tukey 


\section{SUMÁRIO}

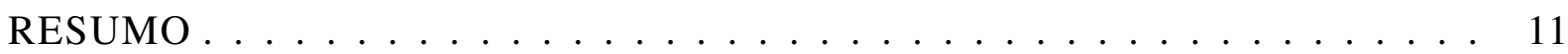

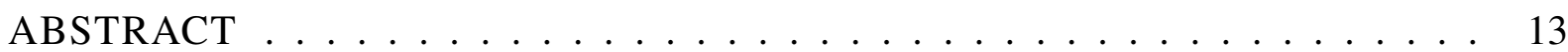

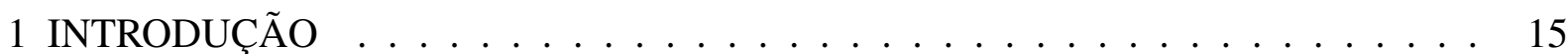

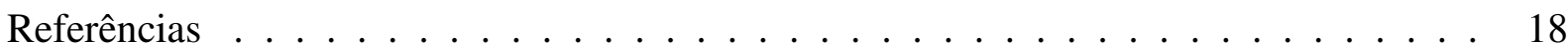

2 AVALIAÇÃO DE IMPACTO DO ESTATUTO DO DESARMAMENTO NA CRIMINALIDADE: UMA ABORDAGEM DE SÉRIES TEMPORAIS APLICADA À CIDADE DE SÃO PAULO . . . . . . . . . . . . . . . . . . . . . . . . . . . 21

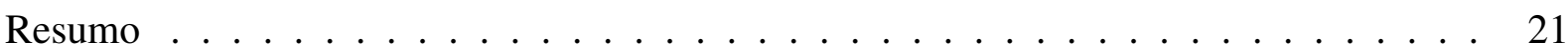

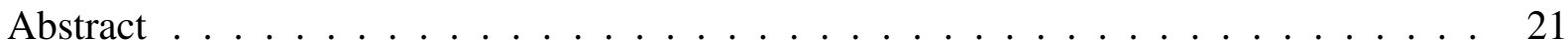

2.1 Introdução . . . . . . . . . . . . . . . . . . . . . 21

2.2 Dados e Amostra . . . . . . . . . . . . . . . . . . . . . 24

2.3 Escolha do Indicador de Criminalidade . . . . . . . . . . . . . . . . . . . . . . . . . . . . . . . . . . . . . .

2.4 Metodologia Empírica . . . . . . . . . . . . . . . . . . . . 27

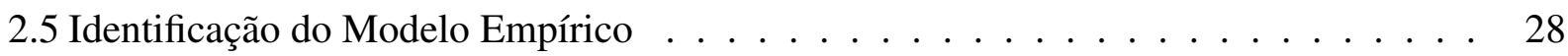

2.6 Resultados e Discussões . . . . . . . . . . . . . . . . . . . . . . . . . 30

2.7 Considerações Finais . . . . . . . . . . . . . . . . . . . . . 34

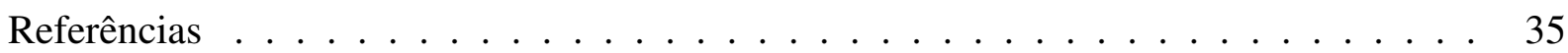

3 RELAÇÕES DE LONGO PRAZO ENTRE ATIVIDADE ECONÔMICA, DISSUAS ÃO E CRIME: EVIDÊNCIAS PARA A CIDADE DE SÃO PAULO . . . . . . . . . . . 41

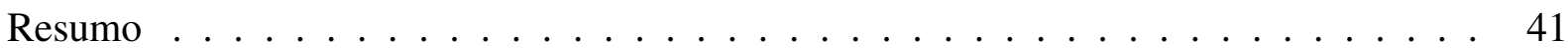

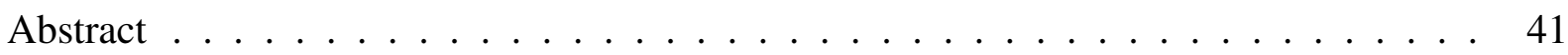

3.1 Introdução . . . . . . . . . . . . . . . . . . . . . . . . . . 41

3.2 Estrutura do Modelo . . . . . . . . . . . . . . . . . . . . . . . . . 43

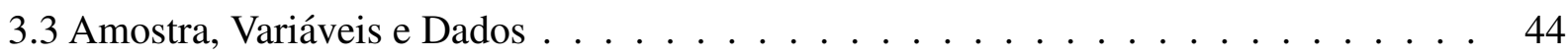

3.4 Identificação do Modelo . . . . . . . . . . . . . . . . . . . . . . . . . . . . 48

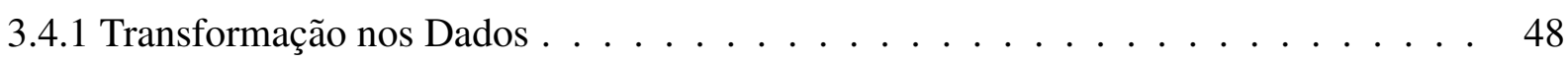

3.4.2 Testes de Raiz Unitária . . . . . . . . . . . . . . . . . . . . . . . . . . . . . . 49

3.4 .3 Análises de Cointegração . . . . . . . . . . . . . . . . . . . . . . . . . . . . . . . . . . . .

3.5 Resultados e Discussões . . . . . . . . . . . . . . . . . . . . . . . . . . 56

3.6 Considerações Finais . . . . . . . . . . . . . . . . . . . . . 61 . . . . . . . . . . . . 63

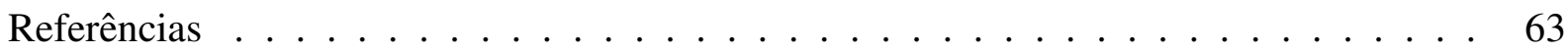

4 EFEITOS DA RIQUEZA NO RISCO DE VITIMIZAÇÃO CRIMINAL: EVIDÊNCIAS

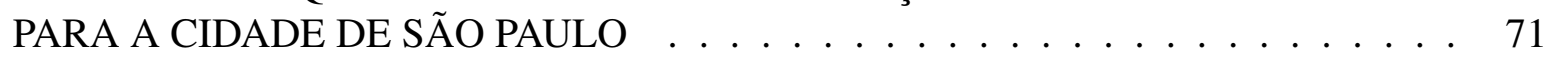

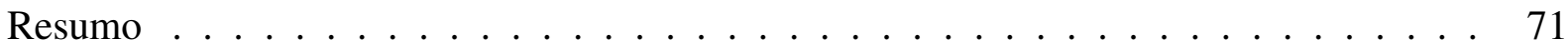

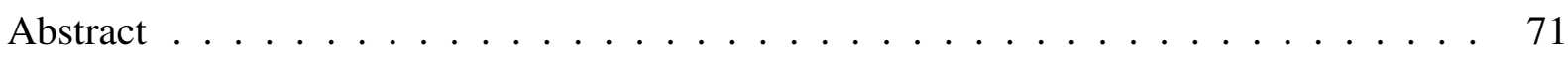

4.1 Introdução . . . . . . . . . . . . . . . . . . . . . . . . . 71

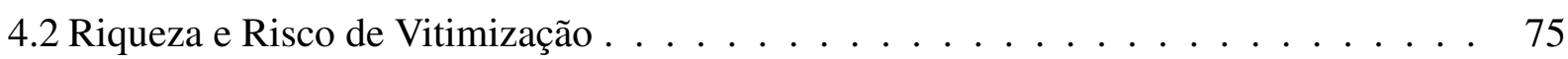

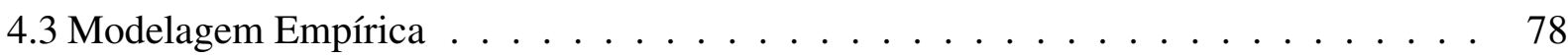

4.3.1 Tipos de Crimes, Dados e Amostra . . . . . . . . . . . . . . . . . . 78

4.3.2 Modelo e Metodologia de Estimação . . . . . . . . . . . . . . . . . . . . 78 
4.4 Análises Preliminares . . . . . . . . . . . . . . . . . . . . . . . 81

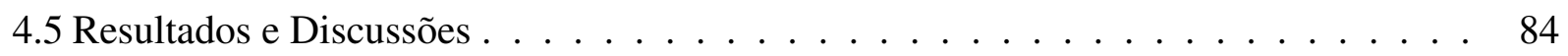

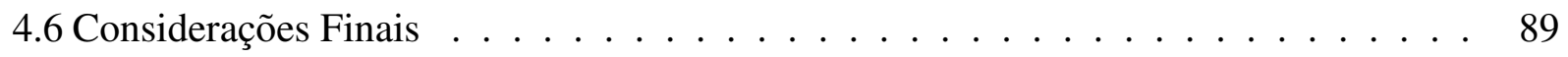

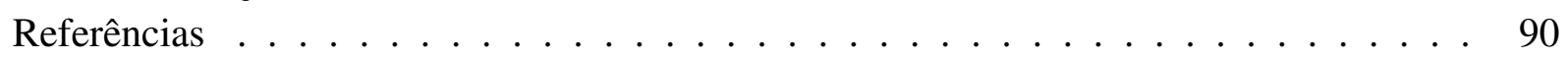




\section{RESUMO}

\section{Uma abordagem econômica das causas da criminalidade: evidências para a cidade de São Paulo}

O objetivo geral desta tese, composta por três artigos, é analisar as causas da criminalidade. As análises são feitas sob a ótica da Economia do Crime. Os dois primeiros artigos são independentes, mas complementares. Neles se busca lançar luz sobre as possíveis causas da queda do crime na cidade São Paulo. A ênfase recai na política de desarmamento dos cidadãos, no desempenho da Polícia e nas condições econômicas, em particular do mercado de trabalho. No primeiro deles, o objetivo é avaliar o efeito do Estatuto do Desarmamento sobre a criminalidade letal. Para isso foram utilizados dados de séries temporais da cidade de São Paulo na aplicação de uma metodologia de análise de intervenção. A hipótese de que a política de desarmamento causou redução na taxa de crimes letais não é rejeitada. Partindo dessa evidência, no segundo artigo o principal objetivo é investigar possíveis causas da significativa redução da criminalidade na cidade de São Paulo. Por meio de uma análise de cointegração evidenciaram-se relações de longo prazo entre crime, atividade econômica e desempenho da Polícia. Os resultados indicam que a taxa de crimes letais é positivamente relacionada ao desemprego, negativamente relacionada ao salário real e negativamente relacionada aos resultados das atividades de polícia, especificamente prisões e apreensão de armas de fogo. Ademais, não é rejeitada a hipótese de que o Estatuto do Desarmamento causou redução na taxa de crimes letais, reforçando a conclusão feita no primeiro artigo desta tese. No terceiro artigo, o foco das análises passa a ser os determinantes do risco de vitimização criminal. O objetivo é investigar os efeitos da riqueza dos indivíduos no risco de serem vítimas de crimes contra a propriedade, em particular crimes de furto/roubo a residência e furto/roubo a pessoa. Em termos específicos, o intuito é investigar se a relação entre risco de vitimização e riqueza pode ser descrita por uma parábola com concavidade voltada para baixo. São utilizados os dados de duas pesquisas domiciliares de vitimização realizadas na cidade de São Paulo na estimação de modelos probit. Os resultados das estimações indicaram que a riqueza dos indivíduos é um dos determinantes do risco de vitimização criminal a propriedade. Ademais, evidenciou-se que o risco de vitimização cresce com a riqueza, mas atinge um ponto de máximo, a partir do qual se reduz para níveis de riqueza mais elevados.

Palavras-chave: Crime; Criminalidade; Análise de intervenção; Estatuto do Desarmamento; Cointegração; Séries de tempo; Vitimização; Riqueza 


\begin{abstract}
An economic approach of the criminality: evidences for the city of São Paulo
\end{abstract}

This three-article PhD thesis aims to investigate the causes of crime using an economic approach. The first two articles are independent, but complementary. In these articles, the objective is to shed light on possible causes of reductions in the crime rate in São Paulo city, focusing on the citizen disarmament policy, police performance, economic conditions and, particularly, the labor market. In the first article, the objective is assessing the effect of the Disarmament Statute on lethal crime rates. For this purpose, we used time-series data for São Paulo city in applying an intervention analysis methodology. The hypothesis that the disarmament policy led to a decline in the lethal crime rate is not rejected. Based on this evidence, the main objective of the second article is to investigate possible causes for the significant reduction observed in crime rates in São Paulo city. By applying a cointegration analysis, we observed long-run relationships between crime, economic activity and police performance. The results indicate that the lethal crime rate is positively related to unemployment and negatively related to real wages and to the results of law-enforcement activities, specifically arrests and seizure of firearms. Moreover, the hypothesis that the Disarmament Statute led to a reduction in the lethal crime rate is not rejected, reinforcing the conclusion arrived at in the first article of this thesis. In the third article, the focus of the analysis shifts to the determinants of criminal victimization. In this study, the objective is to investigate the effects of the wealth of individuals on the risk of becoming victims of property crimes, particularly crimes of theft/robbery of residence and theft/robbery of person. Specifically, its aim is to investigate whether the relationship between wealth and victimization risk can be described by a concave down parabola. Data from two household surveys on victimization held in São Paulo were used to estimate probit models. It became evident that the wealth of individuals is one of the determinants of victimization risk. And it was found that criminal victimization risk increases with wealth, but that it reaches a maximum point from which it decreases as wealth levels increase.

Keywords: Crime; Criminality; Intervention analysis; Disarmament Statute; Cointegration; Time series; Victimization; Wealth 


\section{INTRODUÇÃO}

A criminalidade, embora presente desde a Antiguidade, é um dos maiores problemas que afligem as sociedades contemporâneas. Fundamentalmente, o crime é uma anomalia social causadora de fortes efeitos negativos sobre a vida dos cidadãos. A criminalidade influi direta e indiretamente na qualidade de vida das pessoas, sobretudo por causar insegurança e medo. Infelizmente, porém, os seus efeitos negativos sobre a sociedade são bem maiores do que isso. Há efeitos negativos estritamente econômicos e que, portanto, afetam a economia dos países. Crimes letais, por exemplo, reduzem a quantidade de capital humano. Sendo esse fator, o capital humano, imprescindível para o crescimento e desenvolvimento econômico, intui-se que o crime reduz o bem-estar social. Um exemplo desses prejuízos à sociedade foi visto por Carvalho et al. (2007) para o caso brasileiro. Segundo suas estimativas, somente em 2001 os homicídios reduziram em mais de nove bilhões de reais o estoque de capital humano disponível ao país, mensurado monetariamente.

Além de causar a perda desse importante fator produtivo, o capital humano, há várias outras consequências negativas do crime ao país. Em Santos e Kassouf (2008a) listaram-se as principais: as perdas materiais das vítimas, os gastos públicos e privados na prevenção e combate ao crime, a redução na atividade turística e a perda de atratividade de novos investimentos produtivos e/ou a expulsão dos existentes. No que diz respeito ao convívio social, pesquisas de vitimização ${ }^{1}$ têm recorrentemente apontado que a criminalidade tem alterado os hábitos cotidianos e reduzido as relações interpessoais. Fatos que também resultam em menor bem-estar social.

Se por uma lado não se pode rejeitar que o crime causa prejuízos à economia, por outro lado, a hipótese de que condições econômicas e criminalidade são estreitamente relacionadas é bastante plausível. Diante disso, a Ciência Econômica também tem se dedicado à análise dos fatores, econômicos e não econômicos, que determinam o comportamento criminoso. Nessa direção foram pioneiros os estudos feitos por Fleisher (1963, 1966), Smigel-Leibowistz (1965) e Ehrlich (1967). ${ }^{2}$ Mas, foi somente a partir da publicação da teoria da racionalidade econômica do criminoso (BECKER, 1968) e, posteriormente, da relevante contribuição teórica e empírica de Ehrlich (1973), que os estudos econômicos das causas da criminalidade puderam ser apoiados em um sólido referencial teórico. Desde então, os economistas têm ininterruptamente se dedicado à identificação e análise econômica das causas do comportamento criminoso.

No Brasil, infelizmente as estatísticas criminais, em particular sobre homicídios, mostram que a criminalidade cresce ininterruptamente por todo o território brasileiro. Áreas que no passado eram consideradas seguras para se viver, ou pelo menos pouco violentas, hoje são fortemente afetadas pela criminalidade (SANTOS; SANTOS FILHO, 2011). Felizmente, embora

\footnotetext{
${ }^{1}$ Trata-se de pesquisas por amostra de domicílios com perguntas específicas sobre ocorrências de crimes.

${ }^{2}$ Os dois últimos estudos foram citados por Ehrlich (1973).
} 
poucas, há exceções a essa tendência. É o caso, por exemplo, da cidade de São Paulo. Nessa localidade a taxa de homicídios, por exemplo, caiu de forma intensa e ininterruptamente a partir de 1999, depois de décadas de acentuado crescimento. Em 2009, a taxa de homicídios foi de 14,7 por cem mil habitantes, nível visto pela última vez na segunda metade da década de $1970 .^{3}$ Tal fato, inédito na história da segurança pública brasileira, tornou notório o caso da cidade de São Paulo, colocando-a ao lado das poucas cidades no mundo onde também houve queda semelhante nos níveis de criminalidade.

Mas, qual foi ou quais foram as causas da significativa queda do crime na cidade de São Paulo? Essa questão, ainda sem reposta, se impôs desafiadoramente aos pesquisadores do tema, especialmente àqueles que têm se dedicado a estudar as causas do crime no Brasil. Nesse contexto, a questão em epígrafe norteou a primeira parte desta tese, que se constitui pelos dois primeiros artigos.

Mesmo sem evidências empíricas específicas sobre o assunto, muitos especialistas intuem que a queda do crime em São Paulo resultou da política de desarmamento, executada no estado desde 2001 e ampliada pelo Estatuto do Desarmamento, sancionado em dezembro de 2003 e regulamentado em julho de 2004. Outros, embora não rejeitem essa hipótese, defendem que o melhor desempenho da Polícia é a principal causa. Há, ainda, aqueles que creem que a queda do crime ocorreu devido à melhoria nas condições econômicas, em particular devido à significativa redução do desemprego e aumento real dos salários. Como dito, porém, não há evidências empíricas dando respaldo a tais conclusões. A única evidência empírica sobre o assunto, embora indireta, foi encontrada no estudo feito por Cerqueira (2010) analisando a suposta relação causal entre armas de fogo e crime com dados dos municípios de São Paulo observados entre 2001 e 2009. Mas, segundo o próprio autor, explicar a queda na taxa de crimes em São Paulo não era pretensão do estudo realizado. Souza et al. (2007), Goertzel e Kahn (2009) e Peres et al. (2011) também discutem possíveis causas, mas sem respaldo empírico. No entanto, todos esses estudos foram fundamentais para a estruturação dos dois primeiros artigos desta tese, composta por três artigos.

No primeiro artigo, o objetivo é avaliar o efeito da Lei Federal 10.826, de 22 de dezembro de 2003, conhecida por Estatuto do Desarmamento, sobre o crime na cidade de São Paulo. Partindo da evidência observada nesse artigo, no segundo investigam-se os papéis exercidos por outros supostos causadores da redução dos níveis de criminalidade na capital paulista: maior desempenho da Polícia e maior nível de atividade econômica. Em suma, o objetivo principal desses dois artigos, de natureza investigativa, é testar as hipóteses enunciadas no parágrafo anterior concernentes às causas da queda do crime na cidade de São Paulo.

Ressalte-se que, tanto na literatura nacional quanto na internacional, os estudos econômicos sobre as causas do crime são geralmente feitos utilizando dados em painel, de estados ou municípios. Aqui, a modelagem empírica é feita com dados e metodologias de séries temporais,

\footnotetext{
${ }^{3}$ Dados publicados no jornal "O Estado de São Paulo”, em 10 de novembro de 2010. As estatísticas referentes a outros períodos estão apresentados na introdução do segundo capítulo.
} 
abordagem metodológica que diferencia este estudo da maioria dos estudos anteriores.

No primeiro artigo aplica-se uma metodologia de análise de intervenção (BOX; TIAO, 1975) à série temporal trimestral de crimes letais, nos moldes da análise feita por Zimring (1975) para avaliar o efeito da lei de controle de armas sobre o crime nos Estados Unidos, e por Enders et al. (1990) na avaliação dos efeitos de políticas anti-terroristas. No segundo artigo desta tese utiliza-se a metodologia de análise de cointegração de Johansen (JOHANSEN, 1991, 1992a, 1992b). Esta não é a primeira tentativa de identificar uma relação de cointegração em sistemas de equações compostos, entre outras variáveis, por indicadores de crime. Na literatura internacional, a propriedade de cointegração nesse contexto foi avaliada por Hale (1998), Scorcu e Celline (1998), Corman e Mocan (2000), Saridakis (2004, 2011), entre outros. Na literatura brasileira, porém, trata-se de uma aplicação inédita da análise de cointegração de Johansen na identificação dos efeitos de longo prazo dos determinantes da criminalidade.

Note-se que os dois primeiros artigos desta tese são independentes, mas complementares. Neles abordamos questões teóricas e empíricas relevantes em relação à literatura econômica das causas do crime. Especificamente, investigam-se os efeitos sobre o crime decorrentes do desarmamento dos cidadãos, do desempenho da Polícia e do nível de atividade econômica. $\mathrm{O}$ estudo traz mais evidências sobre as propriedades de estacionariedade e de cointegração da taxa de crimes, em particular os de natureza letal, propriedades que ainda foram pouco estudadas na literatura. Observe-se, também, que todos os estudos empíricos sobre as causas da criminalidade, supracitados, foram feitos sob a tendência de agravamento do problema. Nesse sentido, este estudo enriquece a literatura empírica sobre as causas do crime ao analisar uma localidade onde a criminalidade há anos apresenta forte tendência de queda. Por fim, de forma sucinta, no primeiro artigo discute-se a qualidade dos indicadores de criminalidade, sensível ao fenômeno do sub-registro de crimes (crimes não registrados). ${ }^{4}$ Segundo MacDonald (2000), mesmo na literatura internacional, que é muito mais densa, há pouquíssimas discussões sobre a qualidade dos indicadores de criminalidade que compõem a especificação dos modelos empíricos. O autor destaca a importância do assunto evidenciando que a taxa de sub-registro de crimes contra a propriedade é sensível às condições econômicas, mas na direção oposta à da sensibilidade da própria criminalidade. Em outras palavras, a taxa de sub-registro de crimes aumenta durante períodos de recessão econômica e diminui em períodos de crescimento econômico. Nesse contexto, é possível que a taxa de sub-registro de crimes contra a propriedade tenha diminuído na cidade de São Paulo no período analisado. Por esse motivo e pelos demais motivos que serão expostos no primeiro artigo, optou-se, neste estudo, pela taxa de crimes letais por cem mil habitantes como indicador do nível de criminalidade.

Nesses dois artigos focou-se o lado da oferta da atividade criminosa, ou seja, o lado composto pelos criminosos. Predominantemente esse tem sido o foco das análises empíricas, sobretudo na literatura nacional, realizadas na maioria das vezes com dados agregados por países, estados ou municípios. Mas, análises dessa natureza não permitem inferências sobre o lado

\footnotetext{
${ }^{4}$ Uma discussão específica sobre as causas e consequências do sub-registro é feita em Santos e Kassouf (2008b).
} 
da demanda de crimes, ou seja, o lado formado pelas potenciais vítimas do crime. ${ }^{5}$ Por esse motivo pouco se conhece sobre os fatores que influem no risco de um indivíduo ser vitimizado. Análises desse tipo só podem ser feitas utilizando dados obtidos por meio de pesquisas de vitimização $^{6}$. Dispondo de microdados de duas pesquisas de vitimização realizadas na cidade de São Paulo, no terceiro artigo o foco das análises passa a ser o lado da demanda por crimes. Analisam-se os efeitos da riqueza sobre o risco de vitimização criminal a propriedade, especificamente furto/roubo a residência e furto/roubo a pessoa. Esse assunto não foi especificamente abordado e aprofundado pelos estudos empíricos anteriores feitos com dados de pesquisas de vitimização realizadas no Brasil. Especificamente, o objetivo é investigar se a relação entre risco de vitimização e riqueza pode ser descrita por uma parábola com concavidade voltada para baixo.

Após essa introdução geral, o estudo tem a seguinte estrutura: no capítulo 2, apresentase o primeiro artigo "Avaliação de impacto do Estatuto do Desarmamento na criminalidade: uma abordagem de séries temporais aplicada à cidade de São Paulo"; no capítulo 3, apresentase o segundo artigo "Relações de longo prazo entre atividade econômica, dissuasão e crime: evidências para a cidade de São Paulo"; no capítulo 4, apresenta-se o último artigo que compõe esta tese, intitulado "Efeitos da riqueza no risco de vitimização criminal: evidências para a cidade de São Paulo".

\section{Referências}

BECKER, G. S. Crime and punishment: an economic approach. The Journal of Political Economy, Chicago, v. 76, n. 2, p. 169-217, 1968.

BOX, G. E. P.; TIAO G. C. Intervention analysis with applications to economic and environmental problems. Journal of the American Statistical Association, Alexandria, v. 70, n. 349 , p. 70-79, 1975.

CARVAlHO, A. X.; CERQUEIRA, D. R. C.; RODRIGUES, R. I.; LOBÃO, W. J. A. Custos das mortes por causas externas no Brasil. Texto de Discussão - IPEA, Brasília, n. 1268, 2007.

CERQUEIRA, D. R. C. Causas e consequências do crime no Brasil. 2010, 168 p. Tese (Doutorado em Economia) - Pontifícia Universidade Católica do Rio de Janeiro, Rio de Janeiro, 2010.

\footnotetext{
${ }^{5}$ Embora sejam estranhos, termos como "oferta de crimes" e "demanda de crimes" são recorrentemente utilizados nos estudos econômicos das causas do crime. A origem desses termos está no clássico trabalho de Becker (1968).

${ }^{6}$ Trata-se de pesquisas realizadas com uma amostra aleatória de determinada população, à qual se pergunta sobre ocorrências de determinados tipos de crimes em determinado período de tempo.
} 
CORMAN, H; MOCAN, H. N. A time-series analysis of crime, deterrence and drug abuse in New York city. The American Economic Review, Nashville, v. 90, n. 3, p. 584-604, 2000.

EHRLICH, I. Participation in illegitimate activities: a theoretical and empirical investigation. Journal of Political Economy, Chicago, v. 81, n. 3, p. 526-536, 1973.

ENDERS, W.; SANDLER, T.; CAULEY, J. Assessing the impact of terrorist-thwarting policies: an intervention time series approach. Defense Economics, United Kingdom, v. 2, n. 1, p. 1-18, 1990.

GOERTZEL, T.; KAHN, T. The Great São Paulo homicide drop. Homicide Studies, Thousand Oaks, v. 13 , n. 4, p. 398-410, 2009.

HALE, C. Crime and the business cycle in post-war Britain revisited. British Journal of Criminology, Oxford, v. 38, p. 681-698, 1998.

JOHANSEN, S. Estimation and hypothesis testing of cointegration vectors in Gaussian vector autorregressive models. Econometrica, Oxford, v. 59, n.6, p. 1551-1580, 1991.

JOHANSEN, S. Cointegration and partial systems and the efficiency of single-equation analysis. Journal of Econometrics, Amsterdam, v. 52, n. 3, p. 389-402, 1992a.

JOHANSEN, S. Determination of cointegration rank in the presence of a linear trend. Oxford Bulletin of Economics and Statistics, Malden, v. 54, n.3, p. 383-397, 1992.

MacDONALD, Z. The impact of under-reporting on the relationship between unemployment and property crime. Applied Economics Letters, Oxfordshire, v. 7, n. 10, p. 659-663, 2000.

PERES, M. F. T.; VICENTIN, D.; NERY, M. B.; LIMA, R. S.; SOUZA, E. R.; CERDA, M.; CARDIA, N.; ADORNO, S.. Queda dos homicídios em São Paulo, Brasil: uma análise descritiva. Rev Panam Salud Publica, Washington, v. 29, n. 1, p. 17-26, 2011.

SANTOS, M. J. dos; KASSOUF, A. L. Estudos Econômicos das causas da criminalidade no Brasil: Evidências e Controvérsias. Economia, Brasília, v. 9, n. 2, p. 343-373, 2008a.

SANTOS, M. J. dos; KASSOUF, A. L. Existe explicação econômica para o sub-registro de crimes contra a propriedade? Economia Aplicada, Ribeirão Preto, v. 12, n. 1, p. 5-27, 2008b. 
território brasileiro. Economia, Brasília, v. 12, n. 1, p. 131-147, 2011.

SARIDAKIS, G. Violent crime in the United States of America: a time-series analysis between 1960-2000. European Journal of Law and Economics, New York, v. 18, n. 2, p. 203-221, 2004.

SARIDAKIS, G. Violent crime and incentives in the long-run: evidence from England and Wales. Journal of Applied Statistics, Oxon, v. 38, n. 4, p. 647-660, 2011.

SCORCU, A.; CELLINE, R. Economic activity and crime in the long run: An empirical investigation on aggregate data from Italy, 1951-1994. International Review of Law and Economics, New York, v. 18, n. 3, p. 279-292, 1998.

SJOQUIST, D. L. Property crime and economic behavior: Some empirical results. The American Economic Review,Chicago, v. 63, n. 3, p. 439-446, 1973.

SOUZA, M. F. M.; MACINKO, J.; ALENCAR, A. P.; MALTA, D. C.; MORAIS NETO, O. L. de. Reductions in firearm-related mortality and hospitalizations in Brazil after gun control. Health Affairs, Millwood, v. 26, n. 2, p. 575-584, 2007.

ZIMRING, F. Firearms and federal law: the Gun Control Act of 1968. Journal of Legal Studies, Chicago, v. 4, n. 2, p. 133-198, 1975. 


\title{
2 AVALIAÇÃO DE IMPACTO DO ESTATUTO DO DESARMAMENTO NA CRIMINALIDADE: UMA ABORDAGEM DE SÉRIES TEMPORAIS APLICADA À CIDADE DE SÃO PAULO
}

\section{Resumo}

O objetivo deste artigo é avaliar o efeito do Estatuto do Desarmamento sobre a criminalidade letal. Para isso utilizam-se dados de séries temporais da cidade de São Paulo na aplicação de uma metodologia de análise de intervenção. A hipótese de que a política de desarmamento causou redução na taxa de crimes letais não é rejeitada.

Palavras-chave: Estatuto do Desarmamento; Crimes letais; Análise de intervenção

\begin{abstract}
This article is intended to assess the effect of the Disarmament Statute on lethal crime rates. For this purpose, were used time-series data for São Paulo city in applying an intervention analysis methodology. The hypothesis that the disarmament policy led to a decline in the lethal crime rate is not rejected.
\end{abstract}

Keywords: Disarmament Statute; Lethal crime; Intervention analysis

\subsection{Introdução}

No Brasil, assim como em muitos outros países, a criminalidade é um dos principais problemas contemporâneos. Carvalho et al. (2007) estimam que o prejuízo derivado das mortes por homicídio custou ao país, em 2001, mais de nove bilhões de reais em termos de redução no estoque de capital humano. Eis aí a sua principal consequência econômica.

Infelizmente as estatísticas criminais, em particular sobre homicídios, mostram que a criminalidade cresce por todo o território nacional. Áreas que no passado eram consideradas seguras ou pouco violentas hoje são fortemente afetadas pela criminalidade (SANTOS; SANTOS FILHO, 2011). Felizmente, embora poucas, há exceções a essa tendência.

Dados recentemente divulgados revelam que, entre 1909 e 2009, a trajetória da taxa de homicídios na cidade de São Paulo (doravante apenas São Paulo) apresentou quatro períodos distintos. De 1909 a 1945, a taxa por cem mil habitantes passou de 15,43 para 3,98; cresceu modestamente ao longo dos anos, atingindo 8,3 em 1975; e cresceu vertiginosamente após esse ano, atingindo 64,2 em 1999, o ano mais violento do século. Surpreendentemente, e contrari- 
ando as expectativas pessimistas, a partir desse ano as taxas caíram de forma brusca e ininterruptamente, atingindo 14,7 por cem mil habitantes em $2009 .{ }^{1}$

O fato de a taxa de homicídios ter alcançado níveis próximos aos vistos na segunda metade da década de 1970 tornou mundialmente notório o caso de sucesso de São Paulo, mormente porque conquista social semelhante só foi conseguida por poucas cidades no mundo, como, por exemplo, Nova York e Bogotá.

A política de desarmamento adotada pelo Estado de São Paulo, reforçada pela Lei Federal 10.826, de 22 de dezembro de 2003, conhecida por Estatuto do Desarmamento (doravante: $\mathrm{ED})^{2}$, é recorrentemente apontada como uma das possíveis causas dessa significativa redução.

O país passou a ter critérios mais rigorosos para o controle de armas de fogo em circulação. Além de disciplinar a posse e o porte de armas de fogo no território nacional e estabelecer penas para condutas ilícitas relacionadas à matéria, a lei prevê campanhas de desarmamento. Segundo informações do Ministério da Justiça, desde 2004 as campanhas nacionais foram responsáveis por retirar de circulação uma quantidade expressiva de armas de fogo, algo em torno de 570 mil. Somente na edição de 2011, foram retiradas de circulação em torno de 34 mil, das quais cerca de 29,3\% estavam no Estado de São Paulo. ${ }^{3}$

$\mathrm{Na}$ linha do pensamento econômico sobre as causas do crime, políticas de segurança pública, eficientes e efetivamente executadas afetam o comportamento racional do potencial criminoso (BECKER, 1968; EHRLICH, 1973). Todavia, não há consenso concernente aos supostos efeitos quando se trata de políticas de desarmamento da população. De um lado, estão os defensores da tese de que a proibição da posse e porte de armas é uma medida eficaz contra a atividade criminosa. Para esses, que são a maioria, "mais armas, mais crimes" (DUGAN, 2001, entre outros). Do outro lado, posicionam-se os que defendem o contrário, ou seja, "mais armas, menos crimes" (LOTT Jr.; MUSTARD, 1997; LOTT Jr., 1998a,b, 2000; entre outros). ${ }^{4}$ Para Dezhbakhsh e Rubin (1998), o efeito líquido de leis de controle de armas de fogo depende das características da localidade em que foram adotadas. ${ }^{5}$ No caso brasileiro, os primeiros indícios

\footnotetext{
${ }^{1}$ Dados publicados no jornal "O Estado de São Paulo", em 10 de novembro de 2010.

${ }^{2}$ Detalhes sobre a lei serão oportunamente discutidos na seção 2.6. A íntegra da lei está publicada em: http://www.planalto.gov.br/ccivil_03/Leis/2003/L10.826.htm.

${ }^{3}$ Informações divulgadas em http://portal.mj.gov.br; acesso em 13/01/2012.

${ }^{4}$ A afirmação "mais armas, menos crimes" é, sem dúvida, a mais polêmica defendida na literatura empírica sobre as causas da criminalidade. No Brasil, os opositores do controle de armas de fogo não economizaram esforços em explorar essa afirmação durante as campanhas para o referendo popular sobre a proibição da comercialização de armas de fogo e munições no território brasileiro, realizado em 23 de outubro de 2005 . Vale lembrar que a maioria dos brasileiros votantes optou pela não proibição. A consulta popular foi feita com a seguinte questão: "O comércio de armas de fogo e munição deve ser proibido no Brasil?". As opções eram "sim" ou "não", voto em branco ou voto nulo. Com $63,94 \%$ dos votos válidos, o "não" venceu e a proposta de proibição do comércio de armas de fogo e munição foi rejeitada pelo legislador. Araujo Junior et al. (2007) analisam os argumentos de cada um dos grupos de interesse (o grupo do "sim", favorável à proibição do comércio de armas de fogo, e o grupo do "não", em oposição) e apresentam evidências sobre os determinantes do resultado do referendo.

${ }^{5}$ A literatura que trata de investigar uma possível relação entre a posse de armas de fogo e criminalidade é ampla, concentrada, porém, no caso dos Estados Unidos. McDowall (2005) se encarregou de reunir os principais pontos debatidos em torno dessa questão. Cerqueira (2010) também reúne e brevemente discute os principais estudos nessa temática.
} 
são de que o ED reduziu a taxa de homicídios. Dados apresentados por Peres et al. (2011) mostram que a taxa de homicídios cometidos com armas de fogo na capital paulistana diminuiu em torno de 74,1\% entre 2001 e 2008. Cerqueira (2010) deduz, a partir de resultados empíricos, que a política de desarmamento adotada pelo Estado de São Paulo entre 2001 e 2007 foi um dos determinantes da significativa redução da taxa de homicídios dolosos. ${ }^{6}$ De acordo com Kahn e Zanetic (2005), em São Paulo essa taxa apresentou quebra estrutural significativa no mês de novembro de 2003. Eles associaram essa quebra ao ED, mesmo que esse estatuto tenha sido sancionado somente no mês seguinte. Esse é, ao nosso conhecimento, o único indício sobre um possível efeito positivo da lei, em se tratando de São Paulo.

$\mathrm{O}$ fato de ser uma lei federal traz uma vantagem e uma desvantagem para uma avaliação empírica do seu efeito. A vantagem é que a lei pode ser considerada exógena, visto que foi implementada no mesmo momento em todo o território brasileiro independentemente dos índices de criminalidade em cada região. A desvantagem é que nos limita ao uso de séries temporais relativamente longas, inexistentes para um estudo de cobertura nacional.

A única alternativa é avaliar o efeito da lei sobre a criminalidade ocorrida em localidades nas quais há disponíveis séries temporais relativamente longas, tais como São Paulo. A Secretaria de Segurança Pública do Estado de São Paulo publica trimestralmente, no Diário Oficial do Estado, indicadores de criminalidade. Logo, o objetivo principal deste estudo é avaliar o efeito do ED na criminalidade, em particular na taxa de crimes letais, lançando mão aos dados referentes a São Paulo.

A avaliação é feita aplicando metodologia de análise de intervenção para séries temporais, nos moldes da análise feita por Zimring (1975) na avaliação do impacto da lei de controle de armas sobre a criminalidade nos Estados Unidos e por Enders et al. (1990) para avaliar os efeitos de políticas anti-terroristas. ${ }^{7}$

Registre-se que não se pretende explicar a surpreendente queda na taxa de crimes letais ocorrida na capital paulista simplesmente pelo maior controle de armas de fogo, mesmo porque a queda acentuada teve início muito antes da sanção e posterior regulamentação do ED. No entanto, não é possível refutar sem testes empíricos a hipótese de que tal queda tenha sido acentuada com o desarmamento da população. Hipótese plausível, e, portanto, testada empiricamente neste estudo. Ressalte-se, ainda, que a metodologia estatística que será aplicada neste estudo permite concluir se a série temporal sofreu algum impacto decorrente da medida de intervenção, cuja data de ocorrência do evento é conhecida. Uma vez que, no período em análise, não ocorreram outras medidas de intervenção que possam ter afetado o processo estocástico gerador da taxa de crimes letais, o Estatuto do Desarmamento será o único evento considerado na especificação do modelo linear de intervenção.

$\mathrm{O}$ artigo tem a seguinte estrutura: as seções 2.2, 2.3 e 2.4 tratam, respectivamente, da fonte

\footnotetext{
${ }^{6}$ Embora o autor não tenha tratado especificamente da análise dos efeitos do ED, considera-o para definição do instrumento principal na especificação dos modelos empíricos estimados.

${ }^{7}$ Uma lista extensa de estudos que empregaram essa metodologia é descrita por Vandaele (1983), Morettin e Toloi (2006) e Enders (2010).
} 
de dados e amostra utilizada, do indicador escolhido para refletir a ocorrência de crimes e da metodologia de avaliação aplicada; a etapa de identificação do modelo empírico é apresentada na seção 2.5; os resultados são apresentados e discutidos na seção 2.6; por fim, a seção 2.7 conclui o artigo.

\subsection{Dados e Amostra}

Embora também estejam disponíveis dados relativos ao Estado de São Paulo, optou-se por analisar o comportamento da criminalidade ocorrida apenas na cidade de São Paulo. O intuito é evitar viés de erros de medida decorrentes de diferenças entre os municípios nos procedimentos de coleta e na qualidade dos dados. Limitando as análises a São Paulo espera-se reduzir substancialmente a possibilidade de vieses nos resultados das estimações, pois, mesmo utilizando o melhor indicador de criminalidade, como será oportunamente discutido na próxima seção, é necessário assumir que o erro de medida é invariante no tempo. Hipótese demasiadamente forte se utilizássemos dados agregados para o estado.

O conjunto de dados utilizado cobre o período entre o terceiro trimestre de 1995 (1995T3) e o quatro trimestre de 2010 (2010T4). Tais dados, publicados no Diário Oficial do Estado sob responsabilidade da Secretaria de Segurança Pública do Estado de São Paulo (SSP-SP), estão disponíveis no sítio dessa secretaria. ${ }^{8}$

As estimativas anuais da população residente, publicadas pelo IBGE, foram interpoladas permitindo a construção das taxas trimestrais de crimes por cem mil habitantes.

\subsection{Escolha do Indicador de Criminalidade}

Sem dúvida o passo mais difícil do estudo foi a escolha de um "bom" indicador de criminalidade. Ressalte-se que a qualidade do indicador influi diretamente na robustez das estimações. Devido ao mérito da questão, cabe discutir os principais elementos que nortearam a nossa escolha.

Por se tratar de estatísticas derivadas de registros policiais, os dados oficiais revelam apenas a parte da criminalidade que é efetivamente comunicada às autoridades competentes, com o devido registro. Ou seja, subestimam o verdadeiro nível de ocorrências criminais. O subregistro de crimes ${ }^{9}$ ocorre com maior ou menor intensidade dependendo das características da localidade, sendo, em geral, maior nos casos de crimes de roubo, furto, extorsão, agressão física, extorsão mediante sequestro e estupro.

A Figura 2.1 expõe a trajetória temporal do número absoluto de registros de seis tipos de crimes: homicídios dolosos, latrocínios ${ }^{10}$, roubos de veículos, furto de veículos, roubos (exclusive veículos) e furto (exclusive veículos) do terceiro trimestre de 1995 ao quarto trimestre de

\footnotetext{
${ }^{8}$ Os detalhes sobre processo de coleta e interpretação dos dados estão em CAP/SSP-SP (2005).

${ }^{9}$ Uma discussão detalhada sobre esse fenômeno, o sub-registro, é feita em Santos e Kassouf (2008).

${ }^{10}$ Refere-se à morte da vítima para a subtração de bens patrimoniais.
} 
2010. A essas trajetórias foi adicionada uma linha de suavização Lowess (CLEVELAND, 1979, 1981) com o intuito de auxiliar na visualização de tendências.

Crimes de roubo e furto de veículos são candidatos naturais como indicadores de criminalidade, pois, devido ao valor relativamente alto do bem subtraído e pela quase geral existência de seguros, a maioria dessas vitimizações resultam em boletim de ocorrência. ${ }^{11}$ No entanto, o ideal é que sejam medidos em relação à quantidade de veículos em circulação na localidade em análise e não em relação à população residente, como, por exemplo, medido por Cerqueira (2010). Ao fazer isso, assume-se a hipótese de que ambos (frota de veículos em circulação e população residente) apresentam igual taxa de crescimento no período analisado. Hipótese forte demais, visto que a dinâmica da frota de veículos em circulação é visivelmente distinta da dinâmica populacional. A simples comparação das estatísticas anuais da frota de veículos em circulação no Estado de São Paulo com as estimativas da população residente nos levou à definitiva rejeição das taxas de roubos ou furtos de veículos por habitantes como indicadores de criminalidade acurados. Infelizmente, porém, não estão disponíveis estatísticas sobre a frota de veículos em circulação em São Paulo no período em análise. Então, optamos por não utilizar tais tipos de crimes como indicadores de criminalidade.

Passando a analisar as séries de crimes de roubo e de furtos (exclusive veículos), notouse que o número de ocorrências registradas de crimes dessa natureza apresentam comportamento totalmente distinto do observado para os demais tipos de crimes, para os quais o subregistro é menor. Nesses crimes, a taxa apresenta tendência descendente acentuada, sobretudo aproximadamente a partir do vigésimo trimestre da amostra (2000T2). Tal fato conduz a outra questão pertinente: a invariância temporal da taxa de sub-registro. Se o sub-registro de crimes fosse estável no tempo, não haveria qualquer prejuízo à robustez das estimações por meio da aplicação da metodologia apresentada na próxima seção. Mas, a análise conjunta da trajetória temporal do número de ocorrências registradas dos seis tipos de crimes, expostas na Figura 2.1, indica que a hipótese de que a taxa de sub-registro é tempo-invariante talvez só seja plausível em se tratando de crimes letais, reconhecidamente menos sujeitos ao sub-registro.

Políticas de segurança pública eficazes causam efeitos não só na redução da criminalidade real, mas também na criminalidade não registrada, sobretudo porque a população vitimizada passa a confiar mais nas autoridades de polícia e justiça. Por um lado, haverá uma redução no número de crimes registrados, porque a criminalidade ocorrida estará decrescendo e, por outro, haverá um aumento no número de crimes efetivamente registrados, devido à redução nas taxas de sub-registro. Portanto, queda nas estatísticas oficiais de criminalidade somente é observada após alguns períodos, quando o primeiro efeito predominar (SANTOS; KASSOUF, 2008). Hipótese plausível, em particular mediante a mudança de tendência no número de registros de outros roubos em torno do trigésimo trimestre da amostra.

\footnotetext{
${ }^{11}$ Conforme indicam os resultados de duas pesquisas de vitimização realizadas em São Paulo nos anos de 2003 e 2008 (CPP-INSPER, 2009), esses tipos de crimes também estão sujeitos ao sub-registro de ocorrências. Em 2003, por exemplo, $8,3 \%$ do total de roubo e furtos de carros e motocicletas ocorridos na capital paulista não foram registrados.
} 

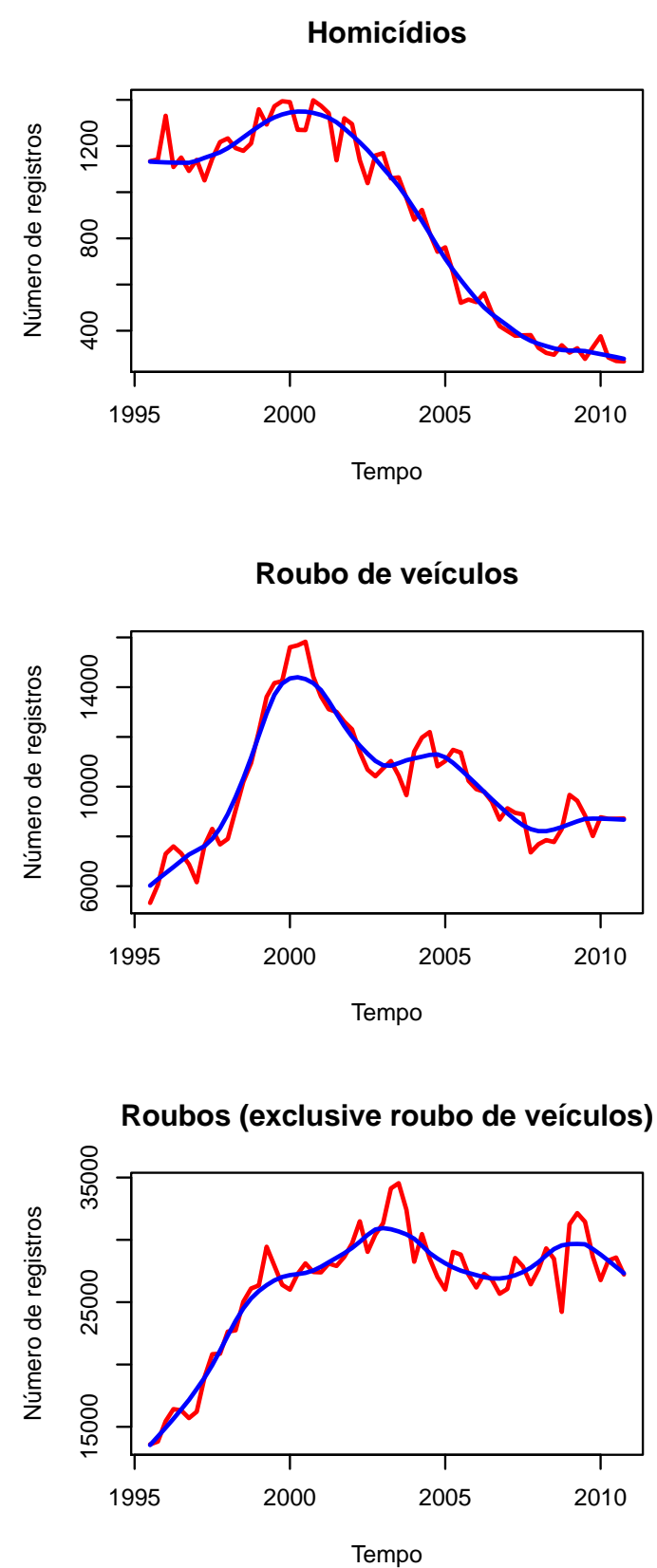
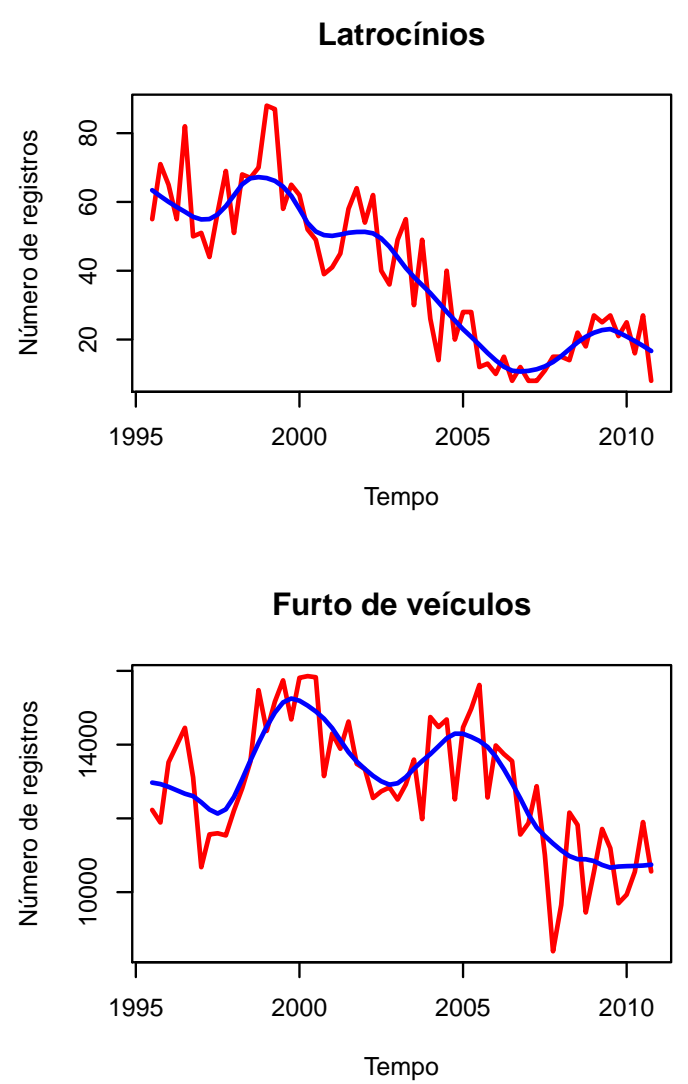

Furtos (exclusive furto de veículos)

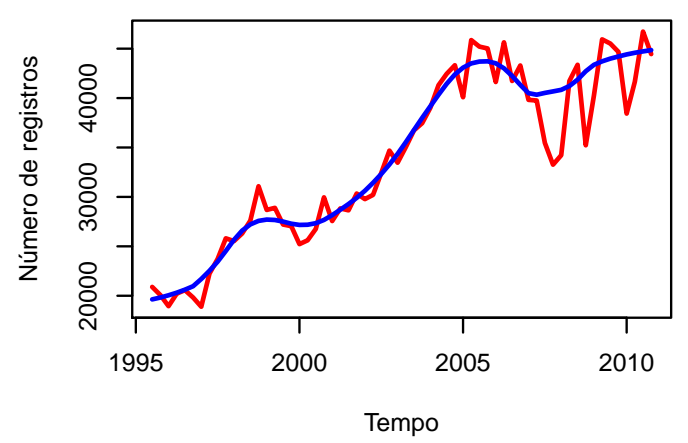

Figura 2.1 - Número de crimes registrados, por tipo de crime, 1995T3-2010T4 Fonte: Elaborada pelo autor com os dados da SSP-SP 
Por fim, concluiu-se que, para evitar vieses nos resultados resultantes de erros de medida, deveríamos utilizar os registros de homicídios e latrocínios como indicadores de criminalidade, pois são apenas minimamente sujeitos ao sub-registro pelo fato de haver morte da vítima. Mas, uma vez que não estamos interessados na classificação jurídica do crime ou na sua motivação, optamos por agregá-los em uma única categoria denominada: crimes letais. Assim, daqui em diante todas as análises e discussões são relativas à taxa de crimes letais por cem mil habitantes (doravante: taxa de crimes letais).

Ressalte-se ser consenso na literatura que a tendência da taxa de crimes letais é um bom indicador das tendências gerais da criminalidade ocorrida na localidade.

O comportamento da taxa trimestral de crimes, entre o terceiro trimestre de 1995 e o quarto trimestre de 2010, é mostrado na Figura 2.2.

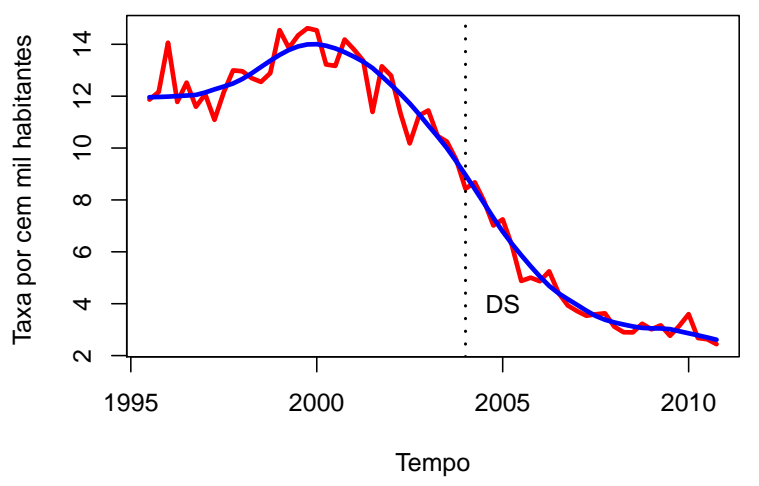

Figura 2.2 - Taxa de crimes letais por cem mil habitantes, $1995 T 3$ - $2010 T 4$

Fonte: Elaborada pelo autor com os dados das fontes citadas

A linha vertical tracejada marca o trimestre em que o ED foi sancionado no país. A média da taxa de crimes no período é 8,85 por cem mil habitantes, com desvio padrão igual a 4,35.

Conforme foi dito na seção 2.1, a taxa de crimes letais em São Paulo já apresentava forte tendência de queda muito antes do sancionamento do ED. No entanto, o processo estocástico da série é considerado dentro da metodologia que será aplicada para avaliar o efeito do ED.

\subsection{Metodologia Empírica}

O impacto de um evento sobre o comportamento de uma série temporal, cuja data de ocorrência é conhecida, pode ser avaliado por meio de uma análise de intervenção, conforme propuseram Box e Tiao (1975).

A análise de intervenção permite testar formalmente se a média de uma série temporal mudou após um evento (ENDERS, 2010). Portanto, é adequada para testar a hipótese de que o ED causou redução na taxa de crimes letais em São Paulo. ${ }^{12}$

\footnotetext{
${ }^{12}$ Observe-se que quando o objetivo é testar formalmente se uma série temporal foi impactada por um evento
} 
Essa medida de segurança pública é especificada dentro de um modelo de intervenção descrito por um modelo autorregressivo de médias móveis, $\operatorname{ARMA}(p, q)$ :

$$
\text { crime }_{t}=a_{0}+A(L) \text { crime }_{t-1}+c_{0} z_{j t}+B(L) \varepsilon_{t}
$$

em que $a_{0}$ é o termo de intercepto, crime $_{t}$ é a taxa de crimes letais (por cem mil habitantes) no trimestre $t, z$ é a variável de intervenção ED na forma $j$ (abrupta e permanente ou gradual e permanente), $A(L)$ e $B(L)$ são polinômios no operador de defasagem $L$ e $\varepsilon_{t}$ é o ruído branco.

A especificação da função de intervenção foi fundamentada na avaliação que se fez da intervenção com relação a dois aspectos: o início do impacto sobre a série (imediato ou gradual) e a sua duração (temporário ou permanente).

Uma vez que o ED continua vigente na íntegra até o presente momento, a intervenção é considerada permanente. No que diz respeito ao início do seu impacto há duas possibilidades plausíveis: a data de sanção da lei (22 de dezembro de 2003) e a data da sua regulamentação (1ํㅡ de julho de 2004) $)^{13}$. A princípio apenas a primeira data faz sentido. Entretanto, segundo a maioria dos juristas, não obstante a regulamentação esteja nela prevista, uma lei não regulamentada é ineficaz. No caso específico da lei que trata do desarmamento no Brasil, sua regulamentação foi imprescindível para a aplicabilidade dos seus principais artigos, em particular os referentes ao teste psicotécnico para aquisição e porte de armas de fogo, marcação de munição e indenização para quem entregar voluntariamente sua arma. Assim, testamos duas formas de mensuração para a função de intervenção: abrupta, a partir do momento do sancionamento da lei, em que $z=0$ para $t<2004 T 1$ e $z=1$ para $t \geq 2004 T 1$ (modelo $A$ ); gradual, a partir da data de sanção até a data de regulamentação, em que $z=0$ para $t<2004 T 1$ e $z=1 / 3$ em 2004T1, $z=2 / 3$ em $2004 T 2$ e $z=1$ para $t \geq 2004 T 3$ (modelo $B$ ).

A significância estatística do coeficiente referente ao $\mathrm{ED}, c_{0}$, pode ser testada por meio do teste- $t$ padrão. Pode-se concluir que o ED reduziu a taxa de crimes letais somente se $c_{0}$ for negativo e estatisticamente diferente de zero.

Outros detalhes metodológicos, como, por exemplo, sobre os testes de hipóteses aplicados, serão oportunamente relatados junto aos seus resultados.

\subsection{Identificação do Modelo Empírico}

Há três maneiras de identificar um modelo de intervenção (Vandaele, 1983). Seguimos os passos que, segundo Enders (2010), foram típicos da maioria dos pesquisadores que aplicaram análises de intervenção.

Utilizando o conjunto de dados pré-intervenção, o primeiro passo da avaliação é identificar um modelo para descrever o processo estocástico da taxa de crimes letais, de tal modo que

com data de ocorrência conhecida, a análise de intervenção é mais apropriada do que os métodos de checagem automática de quebra estrutural.

${ }^{13}$ Decreto $n \underline{\mathrm{O}} \mathbf{5 . 1 2 3}$, de $1 \underline{\mathrm{O}}$ de julho de 2004. 
seja possível testar o impacto do ED sobre ela. Antes, porém, foi necessário verificar as suas propriedades estocásticas, em particular a imprescindível estacionariedade. Ressalte-se que as evidências prévias indicam que, no caso de indicadores de criminalidade, é pouco provável que a propriedade de estacionariedade do processo estocástico seja verificada (ver, por exemplo, PYLE; DEADMAN, 1994; HALE, 1998; SARIDAKIS, 2011). Inclusive, é possível que haja mais de uma raiz unitária, como observaram Pyle e Deadman (1994), para séries temporais de crimes contra a propriedade. Na presença de $d$ raízes unitárias, o modelo de intervenção descrito na eq. (2.1) é estimado utilizando a $d$-ésima diferença da série (isto é, $\Delta^{d}$ crime $_{t}$ ).

A presença de tendência estocástica pode estar associada ao comportamento da variância dos dados. Se esse for o caso, antes de testar a presença de raiz unitária a variância deve ser estabilizada por meio de alguma transformação nos dados. Tal necessidade foi avaliada por meio de análises Box-Cox (BOX; COX, 1964).

Esse procedimento consistiu na estimativa, pelo método da máxima verossimilhança, do parâmetro de transformação $\lambda$ na família de transformações, crime $e_{t}^{*}=\frac{c r i m e^{\lambda}-1}{\lambda}$ se $\lambda \neq 0$ e crime $_{t}^{*}=\log \left(\right.$ crime $\left._{t}\right)$ se $\lambda=0, t=1, \cdots, n$.

Assumindo que os dados não são i.i.d, as análises indicaram que não havia necessidade de transformar os dados, visto que o valor um está contido no intervalo de confiança a 95\% para a estimativa de máxima verossimilhança do parâmetro de transformação $\hat{\lambda}=1,17$. Então, aplicaram-se testes de estacionariedade utilizando os dados originais, isto é, sem qualquer transformação.

Primeiramente, foi aplicado o teste DP (DICKEY; PANTULA, 1987) para testar a hipótese da presença de duas raízes unitárias $(d=2)$. Na primeira etapa, testou-se a hipótese nula $H_{0}: d=2$ contra a hipótese alternativa $H_{A}: d=1$ avaliando a significância estatística do coeficiente estimado $\hat{\beta}_{1}=-1,5902$, no modelo $\Delta^{2}$ crime $_{t}=\alpha+\beta_{1} \Delta y_{t-1}+\varepsilon_{t}$. Os resíduos do modelo estimado foram ruído branco com $p=1$ termos de aumento. Adotando-se os níveis de significância convencionais, a hipótese de duas raízes unitárias é rejeitada. Na segunda etapa, testou-se a hipótese $H_{0}: d=1$ contra a hipótese $H_{A}: d=0$ estimando o modelo $\Delta^{2}$ crime $_{t}=\alpha+\beta_{1} \Delta$ crime $_{t-1}+\beta_{2}$ crime $_{t-1}+\varepsilon_{t}$ e avaliando a significância estatística tanto do coeficiente $\hat{\beta}_{1}=-1,222$, que respeitou o resultado da primeira etapa, quanto do coeficiente $\hat{\beta}_{2}=-0,1547$. A hipótese de que a série tem uma raiz unitária não é rejeitada.

Descartada a hipótese da presença de duas raízes unitárias na série, a presença de uma única raiz unitária foi avaliada por dois testes específicos: ADF-GLS (ELLIOT et al., 1996) e KPSS (KWIATKOWSKI et al., 1992), ambos com a inclusão de constante e tendência na especificação do modelo, e com $p=8$ e $p=3$, respectivamente. No primeiro, testou-se a hipótese nula $H_{0}: d=1$ contra a hipótese alternativa $H_{A}: d=0$, com valores críticos a $5 \%$ e $1 \%$, respectivamente, iguais a $-3,19$ e $-3,77$. Inversamente, o segundo testou a hipótese $H_{0}: d=0$ contra a hipótese $H_{A}: d=1$, com valores críticos para os mesmos níveis de significância iguais a 0,146 e 0,216 , respectivamente.

Comparando os valores críticos com os valores obtidos pelos testes, respectivamente, $-1,861$ 
e 0,22, constatou-se que o teste KPSS corrobora o teste ADF-GLS. Vale lembrar que, ao inverter a hipótese nula, o primeiro teste reduz o problema de baixa potência do segundo, sobretudo quanto mais próximo de um for o coeficiente autorregressivo. Como conclusão final, assume-se que a série é integrada de ordem um - I(1). Portanto, na presença de uma raiz unitária, a eq. (2.1) é estimada utilizando a primeira diferença da série, $\Delta$ crime $_{t}$.

Um conjunto plausível de candidatos a modelo foi identificado por meio da função de autocorrelação estendida (TSAY; TIAO, 1984). Além dos modelos indicados, outros correspondentes a vários pares $p$ e $q$ de menor ordem foram estimados por máxima verossimilhança. Considerando que a série é I(1), o modelo que melhor se ajustou ao conjunto de dados préintervenção foi um $\operatorname{ARIMA}(3,1,1)$. Os resultados de sua estimação estão na Tabela 2.1.

O termo de intercepto, $a_{0}$, foi removido do modelo, pois, segundo a literatura (ver ENDERS, 2010), em um modelo de intervenção bem estimado, todos os coeficientes devem ser de "alta qualidade", ou seja, todos os coeficientes devem ser estatisticamente significativos aos níveis convencionais. Como em toda a modelagem ARIMA, prefere-se utilizar um modelo parcimonioso. Observou-se que os outros coeficientes foram invariantes a essa exclusão, indicando a estabilidade do modelo.

\subsection{Resultados e Discussões}

O modelo identificado na seção anterior foi estimado com o conjunto completo de dados e incluindo, sucessivamente, a variável de intervenção $(z)$ nas formas abrupta (modelo $A$ ) e gradual (modelo $B$ ), conforme definidas na seção 2.4. Os resultados estão na Tabela 2.2.

Os testes de diagnósticos aplicados nos resíduos dos modelos indicam que ambos, na forma abrupta e gradual, são satisfatórios.

A hipótese de resíduos ruído branco é sustentada pelas estatísticas $Q($.$) do teste Ljung-$ Box $^{14}$ (LJUNG; BOX, 1978); o teste ARCH-LM (ENGLE, 1982) rejeita a possibilidade de resíduos com heterocedasticidade condicional; por fim, o teste Shapiro-Wilk (ver ROYSTON, 1982, 1995) sustenta a hipótese de de resíduos com distribuição normal. ${ }^{15}$

No tocante à qualidade de ajustamento, pelos critérios de informação de Akaike - AIC (AKAIKE, 1973, 1974) e de Schwarz (ou Bayesiano) - SBC (SCHWARZ, 1978), a forma abrupta é apenas ligeiramente preferível para modelar a função de intervenção. ${ }^{16}$

Foi necessário, conforme discutido na seção 2.5 , estimar o modelo com a primeira diferença

\footnotetext{
${ }^{14}$ Estatística com redução de quatro graus de liberdade decorrente da ordem $p+q$ do modelo.

${ }^{15} \mathrm{O}$ primeiro e o segundo teste confirmam os indícios vistos no comportamento das funções de autocorrelação e autocorrelação parcial; o segundo ainda confirma as conclusões feitas utilizando o teste proposto por McLeod e Li (1983) para a mesma finalidade; e o último confirma os indícios encontrados pela comparação dos quantis (empíricos) dos dados com os quantis da distribuição normal padrão utilizando um gráfico $q \times q$.

${ }^{16}$ Simulações mostram que o AIC é o mais robusto quando a amostra de dados é pequena. Ressalte-se que independentemente do critério de informação utilizado para a identificação do modelo, o mais importante é que os resíduos sejam ruído branco. Nesse sentido, os dois critérios de informação clássicos utilizados neste estudo desde a etapa de identificação foram apenas o ponto de partida para a escolha de um modelo bem ajustado à série da taxa de crimes letais.
} 
da série. Ao fazer isso, perdeu-se a possibilidade de avaliar o efeito pontual do ED sobre a média da série original. De qualquer maneira, frente às limitações que cercam qualquer tipo de inferência pontual, ainda vale poder concluir se o efeito foi estatisticamente positivo, negativo ou nulo.

Com o coeficiente estimado da variável de intervenção, $z_{j}$, e com o seu erro-padrão calculamse as estatísticas do teste- $t$ para a hipótese nula $H_{0}: c_{0}=0$. Para a forma abrupta da função de intervenção, a estatística do teste é $t=-2,37$; para a forma gradual é $t=-2,26$. Sendo o valor crítico do teste unilateral a 5\% de significância, com 57 graus de liberdade, igual a $t=-1,67$, conclui-se que o ED reduziu a taxa de crimes letais. Em outras palavras, há evidências de que o efeito da intervenção foi negativo no sentido de que reduziu a taxa de crimes letais em São Paulo. Isso significa que menos pessoas morreram precocemente, o que, por sua vez, significa que capital humano disponível ao crescimento econômico do país foi preservado.

Com o intuito de validar a qualidade de ajuste do modelo ao conjunto de dados, utilizamos o modelo $A$ na previsão das taxas de crimes letais dos três primeiros trimestres de 2011, para os quais os dados sobre a quantidade de crimes foram recentemente publicados pela fonte citada na seção 2.2 .

Tabela 2.1 - Resultados do modelo identificado com o conjunto de dados pré-intervenção $(1995 T 3-2003 T 4)$

\begin{tabular}{lcc}
\hline Coeficiente & Estimativa & Erro-padrão \\
\hline \multicolumn{1}{c}{$a_{1}$} & $-0,713$ & 0,2694 \\
$a_{2}$ & $-0,4099$ & 0,2058 \\
$a_{3}$ & $-0,4368$ & 0,172 \\
$\quad b_{1}$ & 0,3391 & 0,2686 \\
\hline AIC & 93,25 & \\
SBC & 100,73 & \\
\hline & Estatística & Valor- $p$ \\
Ljung-Box & & \\
$K=6$ & 2,838 & 0,242 \\
$K=8$ & 4,607 & 0,330 \\
$K=10$ & 8,674 & 0,193 \\
ARCH-LM & & \\
$K=4$ & 4,206 & 0,379 \\
$K=6$ & 5,368 & 0,497 \\
$K=8$ & 7,137 & 0,522 \\
$K=10$ & 6,757 & 0,748 \\
Shapiro-Wilk & & \\
& 0,987 & 0,956 \\
\hline
\end{tabular}

As previsões com os seus respectivos intervalos de confiança são relatadas, junto aos valores efetivamente realizados, na Tabela 2.3. Concluímos que o modelo tem um "bom" poder preditivo.

Estatisticamente, rejeita-se a hipótese de nulidade de efeito do ED em favor da hipótese de que essa medida causou um efeito negativo na taxa de crimes letais. É remanescente, porém, a explicação de como uma medida meramente jurídica dessa natureza é capaz de influir no 
Tabela 2.2 - Resultados das estimações, $1995 T 3$ - $2010 T 4$

\begin{tabular}{|c|c|c|}
\hline Coeficiente & Modelo $A$ & Modelo $B$ \\
\hline$a_{1}$ & $\begin{array}{c}-0,6898 \\
(0,2474)\end{array}$ & $\begin{array}{l}-0,7351 \\
(0,303)\end{array}$ \\
\hline$a_{2}$ & $\begin{array}{l}-0,2833 \\
(0,1586)\end{array}$ & $\begin{array}{l}-0,3094 \\
(0,1666)\end{array}$ \\
\hline$a_{3}$ & $\begin{array}{c}-0,3199 \\
(0,1391)\end{array}$ & $\begin{array}{l}-0,3005 \\
(0,1374)\end{array}$ \\
\hline$b_{1}$ & $\begin{array}{l}0,4403 \\
(0,239)\end{array}$ & $\begin{array}{c}0,4692 \\
(0,3013)\end{array}$ \\
\hline$c_{0}$ & $\begin{array}{l}-1,7814 \\
(0,7525) \\
\end{array}$ & $\begin{array}{l}-2,3415 \\
(1,0376) \\
\end{array}$ \\
\hline $\begin{array}{l}\text { AIC } \\
\text { SBC }\end{array}$ & $\begin{array}{l}150,84 \\
163,50\end{array}$ & $\begin{array}{l}151,49 \\
164,15\end{array}$ \\
\hline Ljung-Box & & \\
\hline$K=6$ & $\begin{array}{c}4,579 \\
(0,101)\end{array}$ & $\begin{array}{c}2,044 \\
(0,365)\end{array}$ \\
\hline$K=8$ & $\begin{array}{c}6,441 \\
(0,168)\end{array}$ & $\begin{array}{c}4,316 \\
(0,365)\end{array}$ \\
\hline$K=10$ & $\begin{array}{l}12,846 \\
(0,046)\end{array}$ & $\begin{array}{c}6,452 \\
(0,374)\end{array}$ \\
\hline ARCH-LM & & \\
\hline$K=4$ & $\begin{array}{c}2,820 \\
(0,588)\end{array}$ & $\begin{array}{c}2,001 \\
(0,735)\end{array}$ \\
\hline$K=6$ & $\begin{array}{c}3,432 \\
(0,753)\end{array}$ & $\begin{array}{c}2,845 \\
(0,828)\end{array}$ \\
\hline$K=8$ & $\begin{array}{c}6,005 \\
(0,647)\end{array}$ & $\begin{array}{c}6,043 \\
(0,642)\end{array}$ \\
\hline$K=10$ & $\begin{array}{c}6,352 \\
(0,785)\end{array}$ & $\begin{array}{c}6,109 \\
(0,806)\end{array}$ \\
\hline Shapiro-Wilk & $\begin{array}{c}0,977 \\
(0,288) \\
\end{array}$ & $\begin{array}{c}0,981 \\
(0,460) \\
\end{array}$ \\
\hline
\end{tabular}

Notas: Número de observações $=62$; os valores entre parênteses abaixo dos coeficientes e dos testes são, respectivamente, os erros-padrão e valores- $p$.

Tabela 2.3 - Previsões do modelo A para a taxa de crimes letais, $2011 T 1-2011 T 3$

\begin{tabular}{cccc}
\hline Trimestre & Previsão & Intervalo de confiança (90\%) & Observado \\
\hline $2011 T 1$ & 2,74 & $1,48-4,00$ & 2,14 \\
$2011 T 2$ & 2,60 & $1,03-4,18$ & 2,40 \\
$2011 T 3$ & 2,67 & $0,91-4,44$ & 2,47 \\
\hline
\end{tabular}


comportamento criminoso.

Na busca de uma explicação plausível usamos como "pano de fundo" a teoria econômica da escolha racional do criminoso (BECKER, 1968; EHRLICH, 1973), em particular no tocante ao efeito dissuasão.

Analisando o teor da lei 10.286, de 22 de dezembro de 2003, conclui-se que ela tornou mais difícil que armas de fogo e munição sejam legalmente adquiridos. Para adquirir uma arma de fogo, de uso permitido, além de declarar a efetiva necessidade, é preciso comprovar idoneidade, ocupação lícita, residência certa e capacidade técnica e de aptidão psicológica para o manuseio de arma de fogo. Com efeito, esse trâmite aumentou o custo final de aquisição legal de armas de fogo. Isso poderia implicar aumento na compra ilegal de armas de fogo e munição se não fosse $\mathrm{o}$ fato de que a lei também tornou mais rígidas as penalidades para a posse e porte ilegal de armas de fogo. Desde a regulamentação da lei, o porte ilegal de armas de fogo, acessório ou munição de uso permitido, mas em desacordo com a lei, implica pena de detenção de um a três anos e multa. Na linha do pensamento econômico sobre as causas do comportamento criminoso, o aumento de formalidades legais para aquisição e porte de armas de fogo após a lei do desarmamento pode ter causado um efeito dissuasivo sobre a conduta ilícita.

Após a regulamentação da lei em epígrafe, foram realizadas campanhas de abrangência nacional para desarmar a população brasileira. Além do apelo à sociedade para cessar um dos canais que hipoteticamente causam crimes, fundamentalmente as campanhas foram baseadas em fortes incentivos à entrega de armas de fogo, inclusive mediante indenização monetária. Embora não haja estatísticas confiáveis sobre o número de armas de fogo em circulação no território brasileiro, os dados sobre quantidade entregue voluntariamente pela população desde a primeira edição das campanhas de desarmamento, mostrados na seção 2.1, mostram que muitas armas de fogo foram retiradas de circulação.

A lei, ainda, mudou o enquadramento criminal de condutas de comércio ilegal e tráfico internacional de armas de fogo. Tais condutas ilícitas eram enquadradas como contrabando e descaminho, ou seja, quando punidas resultavam apenas em penas brandas. Com a sanção da lei, passaram a ser previstas em lei específica, com penas de quatro a oito anos de prisão e multa. A mudança na rigidez da penalidade pode ter causado um efeito dissuasivo sobre o comportamento criminoso e, por sua vez, reduziu a criminalidade.

Nós nos posicionamos do lado daqueles que defendem que o ED evitou que muitos conflitos cotidianos envolvendo cidadãos comuns fossem "resolvidos" com armas de fogo e reduziu uma das fontes de abastecimento da atividade criminosa - roubo e furto de armas de residências e veículos. ${ }^{17}$ Ademais, a lei tornou mais difícil que cidadãos comuns cometessem crimes letais,

\footnotetext{
${ }^{17}$ Destaquem-se as dados levantados por Borilli e Shikida (2006) no estudo de caso feito nas penitenciárias Central, Estadual e Feminina de Piraquara (Paraná). Nesse estudo foi constatado que 55,73\% de 262 réus julgados e condenados por crimes contra a propriedade possuíam arma de fogo na época do crime, e que desses, 48,09\% utilizaram arma de fogo na execução do crime. A questão é: qual foi a fonte de fornecimento dessas armas de fogo? Embora não seja possível afirmar, provavelmente algumas dessas armas foram em algum momento do tempo furtadas/roubadas de cidadãos que as portavam ilegalmente ou mesmo legalmente. Um exemplo disso é a arma de fogo que havia sido roubada há dezoito anos e que foi utilizada para cometer o crime cruel contra várias
} 
sobretudo emocionalmente motivados. Por outro lado, porém, concordamos que ela reduziu a capacidade de autoproteção dos cidadãos em relação a vitimizações criminais. Mas, inegavelmente também reduziu o número de reações armadas a vitimizações, comportamento que, na maioria das vezes, resulta em morte.

Por tudo isso defende-se a tese de que o legislador brasileiro agiu corretamente ao regulamentar o ED. Vidas humanas foram poupadas. E, em termos econômicos, menos capital humano disponível para o crescimento econômico do país foi precocemente perdido devido a crimes letais.

\subsection{Considerações Finais}

Neste estudo avaliou-se o impacto, em São Paulo, do maior controle de armas após o Estatuto do Desarmamento sobre o comportamento da taxa de crimes letais.

É preciso considerar que as armas voluntariamente entregues nas campanhas do desarmamento pertenciam (ilegalmente ou legalmente) a cidadãos comuns, ou seja, não foram entregues por criminosos atuantes. Então, provavelmente o principal efeito do ED foi evitar que muitos conflitos cotidianos envolvendo cidadãos comuns acabassem resultando em crimes letais. Nesse sentido, o ideal para a análise feita é que fosse possível separar os crimes letais cometidos por indivíduos que nunca haviam matado ninguém dos crimes letais cometidos por indivíduos já atuantes na atividade criminosa. Infelizmente, a distinção por tipo de criminoso não foi possível com os dados agregados utilizados neste estudo.

Novamente, ressalta-se que a metodologia estatística aplicada nesta investigação empírica tem por objetivo avaliar o impacto de um evento exógeno, cuja data de ocorrência é conhecida, no comportamento de uma série temporal. Portanto, por meio dela foi possível concluir sobre o impacto do Estatuto do Desarmamento na taxa de crimes letais. No entanto, assim como é para qualquer metodologia, tal metodologia é sujeita a limitações. Contudo, por meio dela encontrou-se evidência empírica em favor da tese defendida por muitos especialistas em segurança pública: o desarmamento da população é uma medida eficaz contra o crime. Especificamente, observou-se evidência estatística em favor da não rejeição da hipótese de que o Estatuto do Desarmamento causou uma redução na taxa de crimes letais. Tal evidência, de certo modo, vai ao encontro da tese "menos armas menos crimes" defendida por Cerqueira (2010) ao investigar a hipotética relação causal entre armas de fogo e crime com dados de cidades paulistas.

Ressalte-se, ainda, que dados apresentados em Kahn e Zanetic (2005) indicam que muito antes da sanção do ED no Brasil, o Estado de São Paulo já havia adotado uma forte política de restrição de concessão de porte de armas de fogo, e já se esforçava para retirá-las de circulação. Tal conduta pode ser uma das explicações da notória queda da taxa de crimes letais desde meados de 2001, como dito, entre outros, por Cerqueira (2010). 
Questões de natureza econômica, tais como o aquecimento no mercado de trabalho, não devem ser desconsiderados na busca de uma explicação para a mudança tão rápida e acelerada na trajetória temporal das taxas de crimes, sobretudo homicídios, em São Paulo. Conforme consta na seção 2.1, não buscávamos essa explicação neste estudo. Nesse contexto, o próximo estudo dentro dessa temática foi a aplicação de uma modelagem multivariada que permite considerar, além do Estatuto do Desarmamento, outros supostos determinantes do caso de sucesso de São Paulo no tocante à redução da criminalidade: menor desemprego, maiores salários reais e o aumento no desempenho da Polícia. Essa análise será apresentada no próximo capítulo.

\section{Detalhes computacionais}

Todos os procedimentos empíricos foram feitos no pacote estatístico R (R DEVELOPMENT CORE TEAM, 2010). A suavização Lowess das séries, as funções de autocorrelação e autocorrelação parcial, a estimação dos modelos ARIMA, o gráfico $q \times q$ e o teste ShapiroWilk foram todos feitos no pacote stats (R DEVELOPMENT CORE TEAM, 2010); o pacote TSA (CHAN, 2010) foi utilizado para obter a função de autocorrelação estendida; as análises Box-Cox foram feitas com o pacote FitAR (MCLEOD; ZHANG, 2008); as equações do teste DP foram escritadas e estimadas utilizando o pacote dynlm (ZEILEIS, 2010); ambos os testes ADF-GLS e KPSS foram feitos no pacote UnitrootUrcaInterface (WUERTZ et al., 2009); os testes ARCH-LM e McLeod-Li foram realizados nos pacotes ArchTest (GRAVES, 2009) e TSA (CHAN, 2010), respectivamente; por fim, as previsões foram feitas no pacote forecast (ROB, 2011).

\section{Referências}

AKAIKE, H. Maximum likelihood identification of Gaussian autoregressive moving average models. Biometrika, Oxford, v. 60, n.2, p. 255-265, 1973.

AKAIKE, H. A new look at the statistical model identification. IEEE Transactions on Automatic Control, Piscataway, AC-19, p. 716-723, 1974.

ARAUJO JUNIOR, A. F. de; GOMES, F. A. R.; SALVATO, M. A.; SHIKIDA, C. D. Dê-me segurança ou lhe dou um não: em busca do eleitor mediano no referendo das armas. Revista Brasileira de Economia, Rio de Janeiro, v. 61, n. 4, p. 429-447, 2007.

BECKER, G. S. Crime and punishment: an economic approach. The Journal of Political Economy, Chicago, v. 76, n. 2, p. 169-217, 1968. 
BORILLI, S. P.; SHIKIDA. P. F. A . Crime econômico no Paraná: um estudo de caso. Revista Análise Econômica, Porto Alegre, ano 24, n. 46, p. 123-144, 2006.

BOX, G. E. P.; COX , D. R. An analysis of transformations. Journal of the Royal Statistical Society, London, v. 26, n.2, p. 211-252, 1964.

BOX, G. E. P.; TIAO G. C. Intervention analysis with applications to economic and environmental problems. Journal of the American Statistical Association, Alexandria, v. 70, n. 349, p. 70-79, 1975.

CAP/SSP-SP. Estatísticas de criminalidade: manual de interpretação. São Paulo: Secretaria de Segurança Pública do Estado de São Paulo, 2005, 29 p.

CARVALHO, A. X.; CERQUEIRA, D. R. C.; RODRIGUES, R. I.; LOBÃO, W. J. A. Custos das mortes por causas externas no Brasil. Texto de Discussão - IPEA, Brasília, n. 1268, 2007.

CERQUEIRA, D. R. C. Causas e consequências do crime no Brasil. 2010, 168 p. Tese (Doutorado em Economia) - Pontifícia Universidade Católica do Rio de Janeiro, Rio de Janeiro, 2010.

CHAN, K. TSA: Time series analysis. R package version 0.98, 2010.

CLEVELAND, W. S. Robust locally weighted regression and smoothing scatterplots. Journal of the American Statistical Association, Alexandria, v. 74, n. 378, p. 829-836, 1979.

CLEVELAND, W. S. LOWESS: A program for smoothing scatterplots by robust locally weighted regression. The American Statistician, Washington, v. 35, n. 1, p. 54, 1981.

CPP-INSPER. Relatório da pesquisa de vitimização em São Paulo. São Paulo: Centro de Políticas Públicas do Instituto de Ensino e Pesquisa Insper, 2009, 18 p.

DEZHBAKHSH, H.; RUBIN, H. P. Lives saved or lives lost? the effects of concealed-handgun laws on crime. The American Economic Review, Chicago, v. 88, n. 2, p. 448-474, 1998.

DICKEY, D. A.; PANTULA, S. G. Determining the order of differencing in autoregressive process. Journal of Business and Economic Statistics, Washington, v. 15, n.4, p. 445-461, 1987.

DUGAN, M. More guns, more crime. The Journal of Political Economy, Chicago, v. 109, n. 
5, p. 1086-1114, 2001.

EHRLICH, I. Participation in illegitimate activities: a theoretical and empirical investigation. Journal of Political Economy, Chicago, v. 81, n. 3, p. 526-536, 1973.

ELLIOT, G.; ROTHENBERG, T. J.; STOCK, J. H. Efficient tests for an autoregressive unit root. Econometrica, Oxford, v. 64, n. 4, p. 813-836, 1996.

ENDERS, W. Applied econometric time series, 3rd ed. Hoboken: Wiley, 2010.

ENDERS, W.; SANDLER, T.; CAULEY, J. Assessing the impact of terrorist-thwarting policies: an intervention time series approach. Defense Economics, United Kingdom, v. 2, n.1, p. $1-18,1990$.

ENGLE, R. F. Autoregressive conditional heteroscedasticity with estimates of the variance of United Kingdon inflation. Econometrica, Oxford, v. 50, n. 4, p. 987-1008, 1982.

GRAVES, S. FinTS: Companion to Tsay (2005) analysis of financial time series. R package version 0.4-4, 2009.

HALE, C. Crime and the business cycle in post-war Britain revisited. British Journal of Criminology, Oxford, v. 38, n.4, p. 681-698, 1998.

KAHN, T; ZANETIC, A. Estudos criminológicos 4 - o papel dos municípios na segurança pública, 2005. Disponível em: http:

www.ssp.sp.gov.br/estatistica/downloads/manual_estudos_criminologicos_4.pdf. Acesso em: 25 de out. de 2011.

KWIATKOWSKI, D. et al. Testing the null hypothesis of stationarity against the alternative of unit root: how sure are we that economic time series have a unit root?. Journal of Econometrics, Amsterdam, v. 54, n. 1-3, p. 159-178, 1992.

LJUNG, G. M.; BOX, G. E. P. On a measure of lack of fit in time series models. Biometrika, Oxford, v. 65, n.2, p. 297-303, 1978.

LOTT Jr., J. R. The concealed handgun debate. Journal of Legal Studies, Chicago, v. 27, n. 1, p. 221-243, 1998a.

LOTT Jr., J. R. More guns, less crime: understanding crime and gun control laws. 
University of Chicago Press, 1998b.

LOTT Jr., J. R. More guns, less crime: understanding crime and gun control laws. 2nd ed. University of Chicago Press, 2000.

LOTT Jr., J. R; MUSTARD, D. B. Crime, deterrence, and right-to-carry concealed handguns. Journal of Legal Studies, Chicago, v. 26, n. 1, p. 1-68, 1997.

MacDONALD, Z. (2000). The impact of under-reporting on the relationship between unemployment and property crime. Applied Economics Letters, Lausanne, v. 7, n. 10, p. 659-663, 2000.

McDOWALL, D. Jonh R. Lott, Jr.'s defensive gun brandishing estimates. Public Opinion Quarterly, Oxford, v. 69, n. 2, p. 246-263, 2005.

McLEOD, A. I.; LI, W. K. Diagnostic checking ARMA time series models using squared residual autocorrelations. Journal of Time Series Analysis, Malden , v. 4, n.4, p. 269-273, 1983.

McLEOD, A. I.; ZHANG, Y. Improved subset autoregression: with R package. Journal of Statistical Software, Los Angeles, v. 28, n. 2, 2008.

McLEOD, G. Box-Jenkins in Pratice. Lancaster: Gwilym Jenkins and Partners Ltd., 1983.

MORETTIN, P. A.; TOLOI, C. M. Análise de séries temporais. 2.ed. São Paulo: Edgar Blucher, 2006.

PERES, M. F. T.; VICENTIN, D.; NERY, M. B.; LIMA, R. S.; SOUZA, E. R.; CERDA, M.; CARDIA, N.; ADORNO, S.. Queda dos homicídios em São Paulo, Brasil: uma análise descritiva. Rev Panam Salud Publica, Washington, v. 29, n. 1, p. 17-26, 2011.

PYLE, D.; DEADMAN, D. Crime and business cycle in post war Britain. British Journal of Criminology, Oxford, v. 34, n. 10, p. 339-357, 1994.

R DEVELOPMENT CORE TEAM. A language and environment for statistical computing. Vienna, Austria: Foundation for Statistical Computing, 2010.

ROB, J. H. Forecast: forecasting functions for time series. R package version 3.10, 2011. 
ROYSTON, P. Algorithm AS 181: The W test for normality. Journal of the Royal Statistical Society. Series C (Applied Statistics), New York, v. 31, n.2, p. 176-180, 1982.

ROYSTON, P. Remark AS R94: A remark on Algorithm AS 181: The W test for normality. Journal of the Royal Statistical Society. Series C (Applied Statistics), New York, v. 44, n. 4, p. 547-551, 1995.

SANTOS, M. J. dos; KASSOUF, A. L. Existe explicação econômica para o sub-registro de crimes contra a propriedade? Economia Aplicada, Ribeirão Preto, v. 12, n. 1, p. 5-27, 2008.

SANTOS, M. J. dos; SANTOS FILHO, J. I. dos. Convergências nas taxas de crimes no território brasileiro. Economia, Brasília, v. 12, n. 1, p. 131-147, 2011.

SARIDAKIS, G. Violent crime in the United States of America: a time-series analysis between 1960-2000. European Journal of Law and Economics, New York, v. 18, n. 2, p. 203-221, 2004.

SARIDAKIS, G. Violent crime and incentives in the long-run: evidence from England and Wales. Journal of Applied Statistics, Oxon, v. 38, n. 4, p. 647-660, 2011.

SCHWARZ, G. Estimating the dimension of a model. Annals of Statistics, Cleveland, v. 6, p. 461-464, 1978.

TSAY, R. S.; TIAO, G. C. Consistent estimates of autoregressive parameters and extended sample autocorrelation function for stationary and nonstationary ARMA models. Journal of the American Statistical Association, Alexandria, v. 79, n. 385, p. 84-96, 1984.

VANDAELE, W. Applied time series and Box-Jenkins models. New York: Academic Press, 1983.

WUERTZ, D. et. al. fUnitRoots: Trends and unit roots. R package version 2100.76, 2009.

ZEILEIS, A. dynlm: Dynamic linear regression. R package version 0.3-0, 2010.

ZIMRING, F. Firearms and federal law: the Gun Control Act of 1968. Journal of Legal Studies, Chicago, v. 4, n. 2, p. 133-198, 1975. 


\title{
3 RELAÇÕES DE LONGO PRAZO ENTRE ATIVIDADE ECONÔMICA, DISSUASÃO E CRIME: EVIDÊNCIAS PARA A CIDADE DE SÃO PAULO
}

\section{Resumo}

O principal objetivo deste artigo é investigar possíveis causas da significativa redução da criminalidade na cidade de São Paulo. Por meio de uma análise de cointegração evidenciaram-se relações de longo prazo entre crime, atividade econômica e desempenho da Polícia. Os resultados indicam que a taxa de crimes letais é positivamente relacionada ao desemprego, negativamente relacionada ao salário real e negativamente relacionada aos resultados das atividades de polícia, especificamente prisões e apreensão de armas de fogo. Ademais, não é rejeitada a hipótese de que o Estatuto do Desarmamento causou uma redução na taxa de crimes letais, reforçando a conclusão feita no primeiro artigo desta tese.

Palavras-chave: Crimes letais; Criminalidade; Séries temporais; Cointegração

\begin{abstract}
The main objective of this paper is to investigate possible causes for the significant reduction observed in crime rates in São Paulo city. By applying a cointegration analysis, we observed long-run relationships between crime, economic activity and police performance. The results indicate that the lethal crime rate is positively related to unemployment and negatively related to real wages and to the results of law-enforcement activities, specifically arrests and seizure of firearms. Moreover, the hypothesis that the Disarmament Statute led to a reduction in the lethal crime rate is not rejected, reinforcing the conclusion arrived at in the first article of this thesis.
\end{abstract}

Keywords: Lethal crime; Criminality; Time series; Cointegration

\subsection{Introdução}

Conforme foi destacado no primeiro artigo desta tese (capítulo 2), a cidade de São Paulo (doravante apenas São Paulo) conseguiu interromper e reverter uma forte tendência de crescimento na criminalidade, máxime nos crimes letais. Conquista notória, colocando São Paulo no seleto grupo de cidades com sucesso semelhante, em particular Nova York e Bogotá.

Nesse contexto, uma questão se impôs desafiadoramente. Qual ou quais as causas da redução do crime em São Paulo? Ainda não há uma resposta apoiada em evidências observadas empiricamente. Alguns especialistas acreditam que resultou da política de desarmamento exe- 
cutada no estado desde 2001 e ampliada pelo Estatuto do Desarmamento, outros alegam que a Polícia se tornou mais ativa e eficiente e, ainda, há aqueles que creem que é fruto da melhoria nas condições econômicas, como a significativa redução do desemprego. No entanto, as únicas evidências são aquelas vistas por Cerqueira (2010) e que foram vistas no primeiro artigo desta tese. Tais estudos, embora não tenham buscado responder a questão em epígrafe, lançaram as primeiras luzes sobre o assunto. ${ }^{1}$

Vale lembrar que no primeiro artigo desta tese o objetivo foi avaliar o efeito do Estatuto do Desarmamento $^{2}$ na taxa de crimes letais em São Paulo. A hipótese de que a política de desarmamento causou uma redução nesse indicador de criminalidade não foi rejeitada. Conclusão que, embora plausível, foi feita a partir dos resultados obtidos por meio de uma metodologia estatística (análise de intervenção) em que toda a fonte de informações para a modelagem empírica foi extraída da própria taxa de crimes. Não obstante, corrobora a conclusão de Cerqueira (2010) sobre a relação causal entre armas de fogo e crime nos municípios de São Paulo. Nesse estudo, inevitavelmente foi utilizada uma variável proxy para a quantidade de armas de fogo em circulação, variáveis instrumentais para contornar a endogeneidade dessa variável, e assumiuse que sub-registro em todos os tipos de crimes analisados foi invariante no período analisado. No capítulo 2 desta tese foram apresentados alguns argumentos contrários a essa hipótese para alguns tipos de crimes, em particular crimes contra a propriedade. Retomaremos essa discussão na seção 3.3 .

Nesse contexto, o principal intuito deste estudo é avançar na identificação das causas da significativa redução nas taxas de crimes em São Paulo. Partindo do que foi evidenciado no primeiro artigo, aplica-se uma metodologia estatística que permite a inclusão de outros supostos determinantes da redução do crime na especificação do modelo empírico. Especificamente, buscam-se evidências a respeito das hipóteses apresentadas no segundo parágrafo desta seção.

Ressalte-se que a maioria dos estudos econômicos sobre as causas do crime, sobretudo para o Brasil, são feitos com dados agregados em painel. Aqui, aborda-se o problema analisando dados de uma única unidade espacial por meio de uma metodologia de econometria de séries temporais. Decorrentemente, evita-se viés devido à dependência espacial que existe entre municípios ou mesmo entre estados; a possibilidade de viés devido a erros de medida resultantes de diferenças nos procedimentos de coleta e na qualidade dos dados entre localidades é reduzida. Considere-se, ainda, que a metodologia aplicada não requer que se pressuponha exogeneidade para nenhuma das variáveis e, portanto, não foi preciso utilizar variáveis instrumentais para as variáveis potencialmente endógenas. A última distinção é que foi possível utilizar indicadores de resultados das atividades de polícia ao invés dos gastos com segurança pública, variável comumente utilizada para refletir esses resultados.

\footnotetext{
${ }^{1}$ Também Souza et al. (2007), Goertzel e Kahn (2009) e Peres et al. (2011) discutem de forma qualitativa, mas com muita propriedade, a redução do crime em São Paulo.

${ }^{2}$ A Lei Federal 10.826, de dezembro de 2003, conhecida por Estatuto do Desarmamento, regulamentada em julho de 2004, disciplinou a posse e o porte de armas de fogo no território nacional, tornou mais rígidas as penalidades para a posse e porte ilegal de armas de fogo e permitiu a realização de campanhas de desarmamento.
} 
Observe-se, ainda, que, mesmo na literatura internacional, há poucos estudos analisando as causas do crime utilizando os recentes avanços na econometria de séries temporais. Cabe destacar os estudos feitos por Corman e Mocan (2000), Saridakis (2004) e, recentemente, por Saridakis (2011). O primeiro deles foi feito com dados mensais de Nova York, o segundo com dados anuais dos Estados Unidos e o último com dados anuais da Inglaterra e País de Gales. Portanto, enriquecemos essa literatura apresentando evidências específicas para São Paulo, onde o problema pôde ser analisado sob uma perspectiva distinta: redução da criminalidade.

Após essa introdução apresenta-se, na seção 3.2, a estrutura do modelo estatístico; os detalhes sobre a amostra, variáveis e dados estão na seção 3.3; as etapas de identificação do modelo empírico são apresentadas na seção 3.4; nas seções 3.5 e 3.6, respectivamente, discutem-se os resultados e conclui-se o artigo.

\subsection{Estrutura do Modelo}

O ponto de partida da modelagem empírica é a forma básica de um modelo vetorial autorregressivo - VAR (SIMS, 1980), que consiste de um conjunto de $K$ variáveis endógenas $\mathbf{y}_{t}=\left(y_{1 t}, \ldots, y_{k t}, \ldots, y_{K t}\right)$ para $k=1, \ldots, K$. O processo $\operatorname{VAR}(p)$ é definido por:

$$
\mathbf{y}_{t}=\mathbf{A}_{1} \mathbf{y}_{t-1}+\ldots+\mathbf{A}_{p} \mathbf{y}_{t-p}+\mathbf{u}_{t}
$$

em que $\mathbf{A}_{1}$ são os $(K \times K)$ coeficientes matriciais para $i=1, \ldots, p$ e $\mathbf{u}_{t}$ é um processo $K$-dimensional com $E\left(\mathbf{u}_{t}\right)=0$ e com matriz de covariância definida positiva e invariante no tempo, $E\left(\mathbf{u}_{t}, \mathbf{u}_{t}^{\prime}\right)=\Sigma_{u}$ (ruído branco).

Além das variáveis dentro do vetor autorregresivo, apoiando-se no diagnóstico feito no primeiro artigo desta tese, a eq. (3.1) é ampliada para conter uma variável dummy para a intervenção do Estatuto do Desarmamento. Também acrescentam-se dummies sazonais centradas. Então, a especificação inicial do modelo é:

$$
\mathbf{y}_{t}=\mathbf{A}_{1} \mathbf{y}_{t-1}+\ldots+\mathbf{A}_{p} \mathbf{y}_{t-p}+\Phi \mathbf{D}_{t}+\mathbf{u}_{t}
$$

em que $\mathbf{D}_{t}$ é a matriz composta pelas dummies sazonais centradas $(D S)$ e pela dummy de intervenção $D_{e d}$, em que $D_{e d}=0$ para $t<2004 T 1$ e $D_{e d}=1$ para $t \geq 2004 T 1$. $^{3}$

Outros detalhes pontuais sobre a metodologia e testes de hipóteses aplicados serão oportunamente informados junto aos resultados. ${ }^{4}$

\footnotetext{
${ }^{3} 2004 T 1$ denota primeiro trimestre de 2004 .

${ }^{4}$ A exposição completa da metodologia econométrica aplicada encontra-se nos livros-textos escritos por Hamilton (1994), Johansen (1995) e Enders (2010), entre outros.
} 


\subsection{Amostra, Variáveis e Dados}

A amostra utilizada nas estimações é formada por cinquenta e seis observações referentes a São Paulo entre o primeiro trimestre de 1997 e o quarto trimestre de 2010.

A especificação do modelo expresso pela eq. (3.2) é composta por três tipos de indicadores: criminalidade, atividade econômica e desempenho da Polícia. Especificamente, analisam-se os efeitos dos dois últimos indicadores sobre o crime. Trata-se de uma variante da curva de oferta de crimes proposta nos trabalhos de Becker (1968) e Ehrlich (1973), entre outros.

O nível de atividade econômica é proxy tanto para custos de oportunidade como para o retorno esperado do crime. O efeito líquido de seu efeito pode ser negativo ou positivo, e, portanto, é uma questão que somente pode ser respondida empiricamente. Espera-se, porém, que o crime seja negativamente relacionado ao salário e positivamente relacionado ao desemprego; espera-se, especificamente, que melhores condições no mercado de trabalho causem redução dos níveis de criminalidade.

O último indicador é proxy para as variáveis que, teoricamente, causam efeitos de dissuasão sobre o comportamento criminoso. Espera-se que os seus efeitos sobre o crime sejam negativos.

Com relação ao indicador de criminalidade cabe um comentário sobre a sua qualidade. Uma vez que se investiga, entre outras possíveis relações, se há relação entre o nível de atividade econômica e crimes, a primeira impressão é que isso deveria ser feito somente para crimes contra a propriedade, isto é, para crimes com motivação estritamente econômica. Embora esse tipo de análise seja comum nos estudos empíricos, em particular os realizados com dados dos Estados Unidos, a robustez das estimações é questionável. Segundo MacDonald (2000), as discussões sobre a relação entre ciclos econômicos e criminalidade têm se limitado às metodologias econométricas utilizadas, sem fazer qualquer menção à qualidade dos indicadores de criminalidade analisados. O autor evidencia empiricamente que a taxa de sub-registro de crimes contra a propriedade é sensível às condições econômicas, mas na direção oposta à da sensibilidade da própria criminalidade. Em outras palavras, a taxa de sub-registro de crimes aumenta durante períodos de recessão econômica e diminui em períodos de crescimento econômico. Se isso for verdade, a taxa de sub-registro de crimes contra a propriedade diminuiu em São Paulo no período que se estuda aqui, pois o crescimento no nível de emprego deixa evidente que houve elevado crescimento econômico no período. Por esse motivo, e pelas demais razões que foram expostas previamente no primeiro artigo desta tese, optamos pela taxa de crimes letais homicídios e latrocínios - por cem mil habitantes (cri) como indicador do nível de criminalidade. A taxa trimestral de crimes letais por cem mil habitantes (doravante apenas crimes) foi calculada interpolando os dados das estimativas anuais da população residente, publicadas pelo Instituto Brasileiro de Geografia e Estatística.

O desempenho da Polícia na prevenção e combate ao crime é mensurado por meio de duas medidas, construídas a partir de indicadores de resultados diretos (armas de fogo apreendidas, crimes registrados de tráfico de entorpecentes e total de prisões efetuadas), que variam de acordo 
com a criminalidade, e indicadores de atividade indireta (revistas pessoais e identificação), que refletem o que a Polícia faz (CAP/SSP-SP, 2005). Trata-se de indicadores de desempenho policial, e, como já foi dito, são utilizadas para construção de proxies para as variáveis que causam efeitos de dissuasão sobre o comportamento criminoso mediante aumento da probabilidade de fracasso no crime.

A escolha de "bons" indicadores de desempenho da Polícia é uma tarefa árdua. E, como no caso do indicador de criminalidade, os resultados dependem da qualidade desses indicadores. Apresentam-se, sucintamente, os argumentos que justificam a escolha feita.

A quantidade de armas de fogo apreendidas pela Polícia é um indicador que pode ser interpretado tanto como proxy da quantidade de armas em circulação quanto como um indicador de resultados da atividade policial (KAHN; ZANETIC, 2005). Sob a primeira interpretação assume-se que menos armas de fogo são apreendidas porque há menos armas nas ruas, e, na segunda, que se apreendem mais armas porque a Polícia está realizando mais operações para retirá-las de circulação. No entanto, é preciso reconhecer que a maioria das armas são apreendidas durante operações que visam combater outros tipos de crimes, como, por exemplo, tráfico de drogas. Portanto, variam com a quantidade de crimes. ${ }^{5}$ Ressalte-se que, em se tratando de análises da série histórica, só faz sentido afirmar que a medida absoluta de armas apreendidas reflete a quantidade de armas em circulação se (e somente se) a produtividade da Polícia for constante ao longo do tempo. Hipótese forte demais, visto que houve mudanças na "tecnologia" policial utilizada no Estado de São Paulo, e, por sua vez, na cidade de São Paulo, no período considerado neste estudo. Tais avanços na tecnologia utilizada pela Polícia podem ter afetado o desempenho policial.

É evidente, ainda, que a fiscalização e aplicação da lei e as campanhas de desarmamento promovidas após a regulamentação do Estatuto do Desarmamento tiveram resultado inquestionável: reduziram a quantidade de armas de fogo em circulação. Segundo dados de uma pesquisa de vitimização realizada em São Paulo nos anos de 2003 e 2008 (CPP-INSPER, 2009), o número de pessoas que possuem algum tipo de arma de fogo em casa diminuiu 11,5\% nesse período; revelam, ainda, que a utilização de armas de fogo em roubos a residência e roubo a pessoa diminuíram, respectivamente, $69 \%$ e 14,2\%. Ora, se há menos armas em circulação, menos armas são passíveis de apreensão. De fato, os dados da SSP-SP revelam que nesse mesmo período a quantidade de armas de fogo apreendidas em São Paulo diminuiu 51,2\%.

Nesse contexto, para que essa variável seja entendida como indicador de desempenho da Polícia, é preciso medi-la em relação ao que essa instituição faz. Para isso se utiliza a variável definida pela razão entre o número de armas de fogo apreendidas e o número de revistas pessoais e identificação feitas por policiais $(\mathrm{arm})$. Portanto, a variável construída pela razão entre essas duas medidas reflete um número relativo de armas de fogo apreendidas.

\footnotetext{
${ }^{5}$ De fato a taxa de crimes letais e o número de armas de fogo apreendidas por cem mil habitantes tiveram trajetórias de longo prazo muito semelhantes no período amostral analisado. O coeficiente de correlação de pearson estimado entre elas é $0,96(t=24,42)$.
} 
Observe-se que a quantidade relativa de revistas cresceu significativamente. A taxa de revistas por cem pessoas passou de 1,98 para 5,83 no período em análise. Embora seja possível que mais operações dessa natureza tenham sido feitas com o mesmo número de policiais e equipamentos, é mais provável que seja reflexo direto do aumento no efetivo policial e em equipamentos, como veículos e armas. Portanto, assume-se que aumentos nessa variável refletem diretamente a maior presença de policiais nas ruas e subsequente maior probabilidade de fracasso do crime, e, por sua vez, dissuasão sobre o crime.

O segundo indicador de desempenho da Polícia é proposto para refletir o combate específico ao tráfico de drogas. Utiliza-se como medida a razão entre o número de crimes por tráfico de entorpecentes $^{6}$ e o total de prisões efetuadas (pri). Uma vez que a primeira variável mede o número de ocorrências e não a quantidade apreendida, e que a segunda mede o número de prisões e não o número de pessoas presas, presume-se que, para cada crime de tráfico de droga registrado, ocorre uma prisão. Portanto, a variável construída pela razão entre essas duas medidas é uma aproximação do percentual do total de prisões referente a traficantes de entorpecentes.

Os dados utilizados na construção das três variáveis referentes à segurança pública estão publicados no Diário Oficial do Estado, sob responsabilidade da Secretaria de Segurança Pública do Estado de São Paulo (SSP-SP). ${ }^{7}$

Para refletir o nível de atividade econômica local utilizamos duas medidas: taxa de desemprego total $(d e s)^{8}$ e salário mínimo real $(s a l)$. Ressalte-se que ambas as variáveis são medidas especificamente de São Paulo e foram obtidas, respectivamente, na Fundação Sistema Estadual de Análise de Dados (SEADE) ${ }^{9}$ e no Departamento Intersindical de Estatística e Estudos Socioeconômicos (DIEESE) ${ }^{10}$.

O sumário estatístico do conjunto de dados utilizado é reportado na Tabela 3.1. As trajetórias temporais das séries no período amostral são expostas na Figura 3.1. A essas trajetórias foi adicionada uma linha de suavização Lowess (CLEVELAND, 1979, 1981) com o intuito de auxiliar na visualização de tendências.

\footnotetext{
${ }^{6}$ Inclui inúmeras condutas relacionadas à comercialização ou distribuição de substâncias causadoras de dependência física ou psíquica.

${ }^{7}$ Dados disponíveis em http://www.ssp.sp.gov.br/estatistica/trimestrais.aspx. Infelizmente, esses dados são divulgados separadamente por trimestre. Registre-se, ainda, que os dados do número de revistas ou identificação pessoal para os períodos anteriores ao primeiro trimestre de 2005 foram cordialmente disponibilizados pelo Dr. Tulio Kahn. Para detalhes sobre processo de coleta e interpretação dos dados, ver CAP/SSP-SP (2005).

${ }^{8}$ Saridakis (2004) usa a taxa de desemprego entre os homens. Além dessa medida, avaliamos a possibilidade de utilizar o desemprego somente entre aqueles que ocupavam a posição de pessoa de referência na família (chefes de família). Mas não foi observada nenhuma diferença relevante na trajetória temporal dessas três séries.

${ }^{9}$ Dados disponíveis em http://www.seade.gov.br/produtos/ped/.

${ }^{10} \mathrm{O}$ salário mínimo é deflacionado pelo índice de custo de vida de São Paulo, calculado pelo DIEESE. Outros detalhes em http://www.dieese.org.br/esp/metodsm.xml.
} 
cri

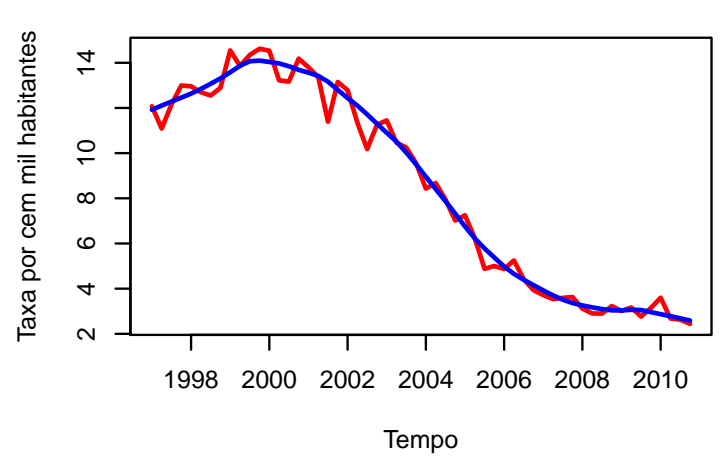

pri

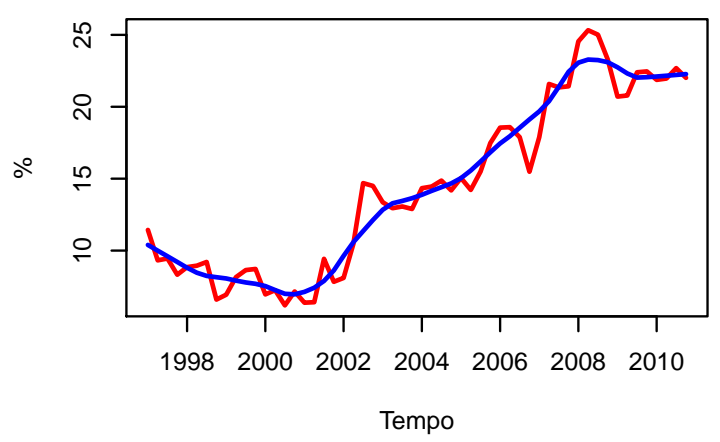

sal

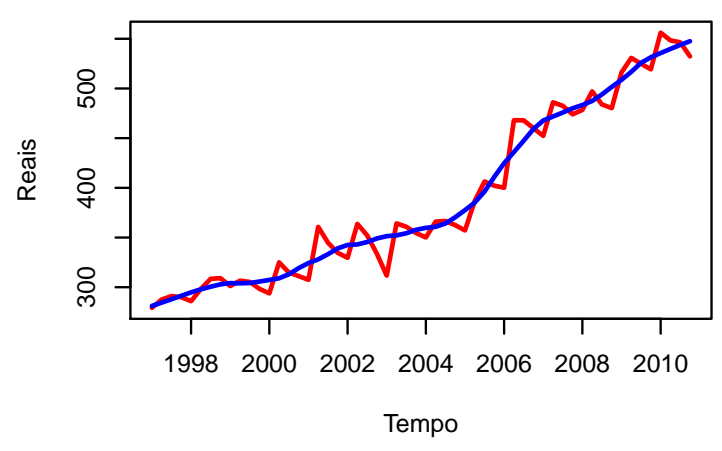

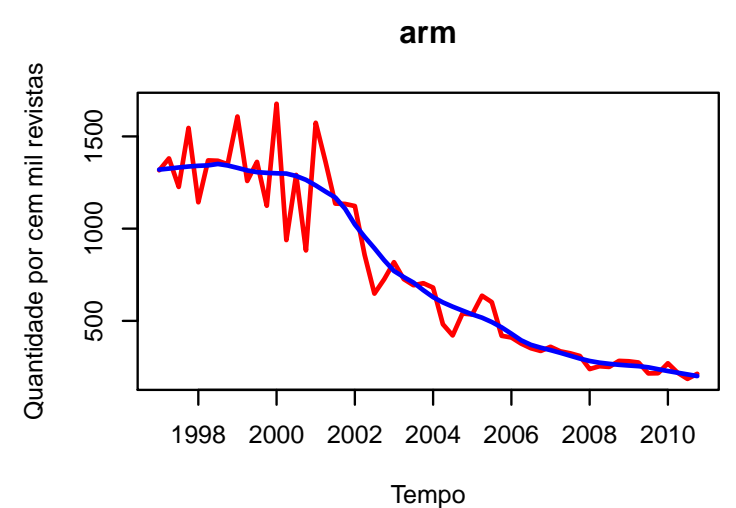

des

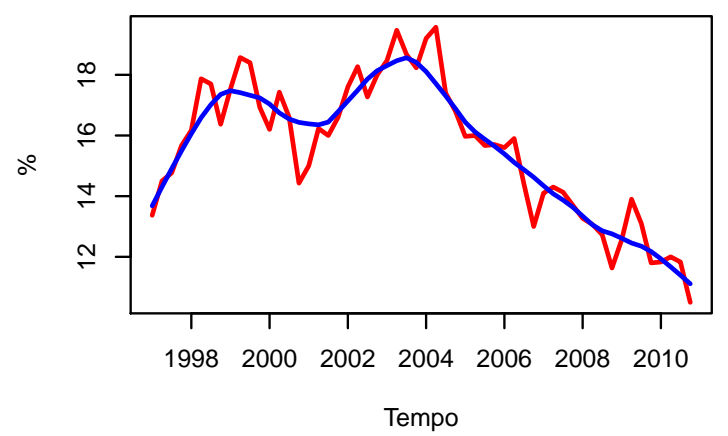

Figura 3.1 - Séries temporais, 1997T1 - 2010T4

Fonte: Elaborada pelo autor com os dados das fontes citadas

Tabela 3.1 - Sumário estatístico, 1997T1 - 2010T4

\begin{tabular}{llrrrr}
\hline Variável & \multicolumn{1}{c}{ Definição } & Média & DP & Mínimo & Máximo \\
\hline cri & Taxa de crimes por cem mil habitantes & 8,48 & 4,41 & 2,44 & 14,62 \\
pri & Percentual de prisões por tráfico & 14,43 & 5,99 & 6,19 & 25,32 \\
& de drogas & & & & \\
arm & Quantidade de armas de fogo apreendidas & 756,38 & 465,37 & 185,41 & $1.677,46$ \\
& por cem mil revistas pessoais ou identificação & & & & \\
des & Taxa de desemprego total (\%) & 15,57 & 2,31 & 10,50 & 19,57 \\
sal & Salário mínimo real (em R\$) & 389,76 & 87,02 & 279,28 & 556,15 \\
\hline
\end{tabular}

Fonte: Elaborada pelo autor com os dados das fontes citadas 


\subsection{Identificação do Modelo}

\subsubsection{Transformação nos Dados}

A estimação do modelo expresso pela eq. (3.2) requer que todas as séries sejam estacionárias. Tal propriedade será checada na próxima subseção. Sabe-se, porém, que a presença de tendência estocástica pode estar associada ao comportamento da variância dos dados. Se esse for o caso, antes da aplicação dos testes de raiz unitária é necessário estabilizar a variância das séries aplicando uma transformação apropriada aos dados.

A necessidade de transformação foi avaliada por meio de análises Box-Cox (BOX; COX, 1964). Esse procedimento consistiu em estimar por máxima verossimilhança o parâmetro de transformação $\lambda$ na família de transformações, $y_{t}^{*}=\frac{y^{\lambda}-1}{\lambda}$ se $\lambda \neq 0$ e $y_{t}^{*}=\log \left(y_{t}\right)$ se $\lambda=0$, $t=1, \cdots, n$. Assumindo que os dados não são i.i.d, concluiu-se que duas das cinco séries não necessitavam de transformação. Para uma delas, porém, a transformação logarítmica não é rejeitada a 95\% de confiança. No caso das outras três séries, que necessitam de transformação, a logarítmica também é adequada. Nesse contexto, segue-se a convenção entre os economistas de aplicar a transformação logarítmica para todas as séries. Portanto, o logaritmo de todas as variáveis foi tomado antes de aplicar os testes de raiz unitária e, sendo o caso, antes de tomar as primeiras diferenças das séries. As trajetórias temporais dos logaritmos das séries estão na Figura 3.2.

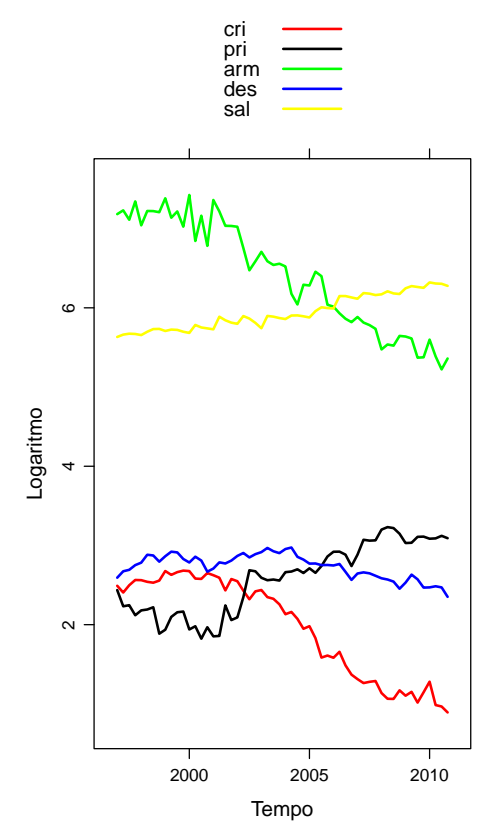

Figura 3.2 - Logaritmo das séries temporais, 1997T1 - $2010 T 4$

Fonte: Elaborada pelo autor com os dados das fontes citadas 


\subsubsection{Testes de Raiz Unitária}

É muito comum nos estudos econômicos evidenciar que séries macroeconômicas, como, por exemplo, desemprego e salário, são processos não estacionários. No tocante às séries de segurança pública, porém, muito pouco se conhece sobre as propriedades do processo estocástico gerador dos dados. Portanto, além de imprescindível à modelagem empírica que será apresentada nas próximas seções, essa seção traz novas evidências e se constitui como uma contribuição marginal deste estudo, sobretudo a futuras análises empíricas das causas do crime utilizando dados de séries temporais.

As evidências prévias sugerem que os indicadores de criminalidade são variáveis não estacionárias (ver PYLE; DEADMAN, 1994; HALE, 1998; SARIDAKIS, 2011). Inclusive, é possível que haja mais de uma raiz unitária, conforme visto por Pyle e Deadman (1994) para dados de crimes contra a propriedade. Havendo essa possibilidade, o primeiro passo foi aplicar o teste DP (DICKEY; PANTULA, 1987) para testar a hipótese da presença de duas raízes unitárias. Os resultados estão na Tabela 3.2.

Na primeira etapa do teste, testou-se a hipótese nula $H_{0}: d=2$ contra a hipótese alternativa $H_{A}: d=1$, julgando a significância estatística do coeficiente estimado, $\hat{\beta}_{1}$, no modelo $\Delta^{2} y_{t}=$ $\alpha+\beta_{1} \Delta y_{t-1}+\varepsilon_{t}$. A hipótese da existência de duas raízes unitárias é rejeitada em todas as séries. Na segunda etapa, testou-se a hipótese nula $H_{0}: d=1$ contra a hipótese alternativa $H_{A}: d=0$, estimando o modelo $\Delta^{2} y_{t}=\alpha+\beta_{1} \Delta y_{t-1}+\beta_{2} y_{t-1}+\varepsilon_{t}$, e avaliando a significância estatística de ambos os coeficientes, $\hat{\beta}_{1}$ e $\hat{\beta}_{2}$. Para todas as séries testadas, os resultados dessa etapa, com relação à significância do $\hat{\beta}_{1}$, não divergem dos resultados da primeira etapa. E, para todas as séries, a hipótese da existência de uma única raiz unitária não é rejeitada. ${ }^{11}$

Descartada a hipótese da presença de duas raízes unitárias, a existência de uma única raiz unitária no processo estocástico gerador dos dados foi avaliada pelos testes ADF-GLS (ELLIOT et al., 1996) e KPSS (KWIATKOWSKI et al., 1992). Em ambos os testes, a especificação do modelo contém constante e tendência. No primeiro, testou-se a hipótese nula $H_{0}: d=1$ contra a hipótese alternativa $H_{A}: d=0$, com valores críticos a $5 \%$ e $1 \%$, respectivamente, iguais a $-3,58$ e $-3,03$. Inversamente, o segundo testou a hipótese $H_{0}: d=0$ contra a hipótese $H_{A}: d=1$, com valores críticos para os mesmos níveis de significância iguais a 0,146 e 0,216 , respectivamente. ${ }^{12}$ Os resultados estão na Tabela 3.3 .

Confrontando os valores críticos com as estatísticas dos testes, conclui-se que, para todas as séries, os resultados do segundo teste corroboram os resultados do primeiro teste de que todas

\footnotetext{
${ }^{11}$ Ainda, com o intuito de averiguar a indicação dos testes de raiz unitária aplicados, utilizou-se o critério estatístico sugerido por McLeod (1983), monitorando o comportamento da variância de sucessivas diferenças das séries para avaliar o número de diferenças necessárias para tornar as séries estacionárias. Simulações feitas por esse autor apontam que um número excessivo de diferenças resulta em um valor negativo da autocorrelação de ordem 1 da série diferenciada que tende a -0,5; quando, porém, a série é corretamente diferenciada, a variância da série transformada diminui; por outro lado, excesso de diferenças aumenta a variância.

${ }^{12} \mathrm{O}$ uso concomitante dos dois testes é justificado pelo fato de que, ao inverter a hipótese nula, o primeiro teste reduz o problema de baixa potência do segundo, máxime quanto mais próximo de um for o coeficiente autorregressivo.
} 
Tabela 3.2 - Teste Dickey-Pantula*

\begin{tabular}{ccllc}
\hline Série & $p$ & \multicolumn{1}{c}{$\hat{\beta}_{1}$ e $\hat{\beta}_{2}$} & \multicolumn{1}{c}{ Valor- $p$} & Conclusão \\
\hline cri & 1 & $-1,317$ & 0,000 & \\
& 1 & $-1,136$ e 0,016 & 0,000 e 0,992 & $\mathrm{I}(1)$ \\
arm & 1 & $-1,595$ & 0,000 & \\
& 0 & $-1,504$ e $-0,00562$ & 0,000 e 0,938 & $\mathrm{I}(1)$ \\
pri & 1 & $-1,213$ & 0,000 & \\
& 0 & $-1,029$ e $-0,0301$ & 0,000 e 0,820 & $\mathrm{I}(1)$ \\
des & 1 & $-1,297$ & 0,000 & \\
& 1 & $-1,322$ e 0,0196 & 0,000 e 0,978 & $\mathrm{I}(1)$ \\
\multirow{2}{*}{ sal } & 3 & $-1,247$ & 0,041 & \\
& 3 & $-1,2303$ e $-0,002875$ & 0,074 e 0,942 & $\mathrm{I}(1)$ \\
\hline
\end{tabular}

Notas: *A primeira e a segunda linha reportam, respectivamente, os resultados da primeira e da segunda etapa do teste; reporta-se o valor- $p$ de Mackinnon; as definições das variáveis estão na página 47.

Tabela 3.3 - Testes ADF-GLS e KPSS*

\begin{tabular}{|c|c|c|c|}
\hline Série & $p$ & Valor & Conclusão \\
\hline \multirow[t]{2}{*}{ cri } & 5 & $-1,366$ & \\
\hline & 2 & 0,358 & $\mathrm{I}(1)$ \\
\hline \multirow[t]{2}{*}{ arm } & 4 & $-1,764$ & \\
\hline & 2 & 0,207 & $\mathrm{I}(1)$ \\
\hline \multirow[t]{2}{*}{ pri } & 1 & $-1,920$ & \\
\hline & 2 & 0,173 & $\mathrm{I}(1)$ \\
\hline \multirow[t]{2}{*}{ des } & 2 & -0.765 & \\
\hline & 2 & 0,384 & $\mathrm{I}(1)$ \\
\hline \multirow[t]{2}{*}{ sal } & 4 & $-2,110$ & \\
\hline & 2 & 0,305 & $\mathrm{I}(1)$ \\
\hline \multicolumn{4}{|c|}{$\begin{array}{l}\text { Nota: * A primeira e a segunda li- } \\
\text { nha reportam os resultados dos tes- } \\
\text { tes ADF-GLS e KPSS, respectiva- } \\
\text { mente; as definições das variáveis } \\
\text { estão na página } 47 .\end{array}$} \\
\hline
\end{tabular}


as séries têm uma raiz unitária.

Ressalte-se, porém, que no primeiro artigo desta tese não foi rejeitada a hipótese de que Estatuto do Desarmamento causou uma redução na taxa de crimes letais, isto é, na série cri. Na presença de quebra estrutural, os testes convencionais são enviesados no sentido da não rejeição da hipótese de raiz unitária. Então, para checar a conclusão feita a partir dos três testes prévios foi aplicado o teste com quebra estrutural exógena proposto por Perron (1989). Esse teste foi feito a partir da estimação do seguinte modelo, com constante e tendência:

$$
c r i_{t}=a_{0}+\mu_{1} D_{P}+\mu_{2} D_{L}+a_{2} t+a_{1} c r i_{t-1}+\sum_{i=1}^{k} \beta_{i} \Delta c r i_{t-i}+\varepsilon_{t}
$$

em que $D_{P}$ é uma variável dummy de pulso definida por $D_{P}=1$ se $t=2004 T 1$ e 0 caso contrário, $D_{L}$ é uma variável dummy de nível definida por $D_{L}=1$ se $t \geq 2004 T 1$ e 0 caso contrário, $\varepsilon_{t}$ é ruído branco. O tamanho da defasagem (isto é, os valores de $k$ ) foi determinado empregando o mesmo critério adotado por Perron (1989). Selecionamos $k=2$, pois a estatística- $t$ sobre $\beta_{2}$ foi maior do que 1,6 em valor absoluto e a estatística- $t$ sobre $\beta_{3}$ foi menor do que esse valor. Para $a_{0}, \mu_{1}, \mu_{2}$ e $a_{2}$, a hipótese nula é que o coeficiente é igual a zero; para $a_{1}$, a hipótese nula é $a_{1}=1$.

$\mathrm{O}$ coeficiente $\hat{\mu_{1}}=0,144$ não é estatisticamente significativo $(t=-1,58)$. No entanto, $\hat{\mu_{2}}=-0,137$ é estatisticamente significativo $(t=-2,49)$. Resultado que corrobora o tipo de mudança estrutural que foi diagnosticada no primeiro artigo desta tese. A hipótese nula de que $a_{1}=1$ é avaliada utilizando o valor crítico a $5 \%$ simulado por Perron (1989) para $\lambda=29 / 56 \approx 0,5$, em que $\lambda$ é a proporção de observações antes da quebra estrutural. Como o valor da estatística do teste é $t=\frac{0,7503-1}{0,06838}=-3,65$ e o valor crítico é igual a $-3,76$, não se rejeita a hipótese de mudança no nível de um processo estocástico com raiz unitária.

Finalmente, conclui-se, com elevado nível de confiança, que todas as séries especificadas no modelo empírico têm uma raiz unitária, ou seja, são integradas de ordem um - I(1). Diante disso, o modelo expresso na eq. (3.2) deve ser estimado com a primeira diferença das séries, $\Delta y_{t}$. Mas, ao aplicar uma diferença para torná-las diferenças-estacionárias perde-se a possibilidade de análise das relações de longo prazo entre elas. Todavia, se existir pelo menos uma relação estacionária entre elas (ou seja, se forem cointegradas) é possível recuperar tais relações (ver PHILLIPS, 1986, 1987; ENGLE; GRANGER, 1987; JOHANSEN, 1988, 1991).

\subsubsection{Análises de Cointegração}

Este estudo não é único na tentativa de identificar uma relação de cointegração em sistemas compostos, entre outras variáveis, por indicadores de crime. Na literatura brasileira, porém, trata-se de uma aplicação inédita da análise de cointegração de Johansen (JOHANSEN, 1988, 
1991, 1992a, 1995) na identificação dos efeitos de longo prazo dos determinantes do crime ${ }^{13}$

A presença de uma única relação de cointegração, $r$, é condição suficiente para assegurar a existência de um elo linear entre as tendências estocásticas das séries em análise. Então, se $r \geq 1$, o modelo VAR, expresso na equação (3.2), pode ser reescrita na forma de um modelo vetorial autorregressivo com correção de erro (doravante: VEC):

$$
\Delta \mathbf{y}_{t}=\alpha \beta^{\prime} \mathbf{y}_{t-1}+\Gamma_{1} \Delta \mathbf{y}_{t-1}+\ldots+\boldsymbol{\Gamma}_{p-1} \Delta \mathbf{y}_{t-p-1}+\Phi \mathbf{D}_{t}+\mathbf{u}_{t}
$$

$\operatorname{com} \boldsymbol{\Gamma}_{i}=-\left(\mathbf{A}_{i+1}+\ldots+\mathbf{A}_{p}\right)$ para $i=1, \ldots, p-1$ e $\boldsymbol{\Pi}=\alpha \beta^{\prime}=-\left(\mathbf{I}-\mathbf{A}_{1}-\ldots-\mathbf{A}_{p}\right)$. Em $\alpha$ estão os coeficientes de ajustamento, e em $\beta$ os vetores de cointegração. Ambos com dimensão $K \times r$, em que $r$ é o rank de cointegração.

O número ótimo de defasagens $(p)$ para o VAR irrestrito com constante e tendência, para um máximo de $p=4$, foi determinado pela análise conjunta dos critérios de informação de Akaike - AIC (AKAIKE, 1973, 1974), Hannan-Quinn - HQ (HANNAN; QUINN, 1979), Erro de Previsão Final - FPE (AKAIKE, 1969, 1970), e Schwarz (ou Bayesiano) - SBC (SCHWARZ, 1978). A especificação do modelo inclui constante e tendência. Os resultados estão na Tabela 3.4 .

Todos os quatro critérios indicaram $p=1$. No entanto, além de ser restritiva em relação às análises de cointegração, essa ordem não gerou resíduos ruído branco. Então, optou-se por estimar e submeter a testes de diagnóstico dos resíduos o conjunto de modelos com $p \in\{2,3,4\}$. Mantiveram-se os modelos com $p=2$ e $p=3$ como candidatos à análise de cointegração.

Com relação ao modelo de cointegração a ser testado, três possíveis especificações serão avaliadas: constante fora do vetor de cointegração (especificação $A$ ); constante dentro do vetor de cointegração (especificação $B$ ); tendência dentro do vetor de cointegração e constante fora do vetor (especificação $C$ ). ${ }^{14}$ Mais à frente, porém, aplicam-se testes específicos para avaliar a significância estatística dos regressores determinísticos no vetor de cointegração.

Os resultados do teste do traço estão na Tabela 3.5. ${ }^{15}$ Independentemente da especificação do modelo, tanto com relação à ordem como pela inclusão de regressores determinísticos, a $1 \%$ de significância não se rejeita a existência de pelo menos um vetor de cointegração. Portanto, há fortes evidências de cointegração nas séries. Sabe-se, porém, que a inclusão de variáveis dummies torna os valores críticos simulados por Osterwald-Lenum (1992) não apropriados para os testes (JOHANSEN et al., 2000). ${ }^{16}$ No entanto, a distância observada entre os valores da es-

\footnotetext{
${ }^{13}$ Ao nosso conhecimento apenas Pereira e Carrera-Fernandez (2000) haviam se empenhado nesse sentido utilizando, porém, a metodologia proposta por Engle e Granger (1987). Os autores concluíram que crime (total e furto ou roubo de veículo) e desigualdade de renda cointegram. Ressalte-se que, devido às suas limitações, o teste aplicado pelos autores só é adequado no caso de modelos bivariados e quando há certeza sobre qual das duas variáveis é endógena e qual é exógena. Limitações superadas pela análise de cointegração de Johansen.

${ }^{14}$ Para detalhes sobre as possíveis especificações ver Johansen (1992b), Johansen (1995) e Harris (1995), entre outros.

${ }^{15}$ A conclusão desse teste não diverge da conclusão do teste do máximo autovalor.

${ }^{16}$ Nas simulações feitas por (JOHANSEN et al., 2000), os valores obtidos pela superfície de resposta estimada
} 
tatística do teste e seus valores críticos, em particular a $1 \%$ de significância estatística, assegura que a conclusão do teste não mudaria caso fossem simulados os valores críticos ajustados.

Tabela 3.4 - Determinação da ordem $(p)$ do VAR

\begin{tabular}{lcccc}
\hline \multirow{2}{*}{ Critério } & \multicolumn{4}{c}{$p$} \\
\cline { 2 - 5 } & 1 & 2 & 3 & 4 \\
\hline AIC & $-2,62^{*}$ & $-2,60$ & $-2,59$ & $-2,55$ \\
HQ & $-2,54^{*}$ & $-2,48$ & $-2,44$ & $-2,37$ \\
SBC & $-2,41^{*}$ & $-2,30$ & $-2,20$ & $-2,07$ \\
FPE & $4,37 \mathrm{e}-12^{*}$ & $5,70 \mathrm{e}-12$ & $7,14 \mathrm{e}-12$ & $1,31 \mathrm{e}-11$ \\
\hline \multicolumn{4}{l}{ Nota: * Ordem sugerida pelo critério. }
\end{tabular}

Tabela 3.5 - Testes de cointegração de Johansen (traço)

\begin{tabular}{|c|c|c|c|c|c|}
\hline \multicolumn{2}{|c|}{ Hipótese } & \multicolumn{2}{|c|}{ Estatística do teste } & \multicolumn{2}{|c|}{ Valor crítico } \\
\hline Nula & Alternativa & $p=2$ & $p=3$ & $95 \%$ & $99 \%$ \\
\hline \multicolumn{6}{|c|}{ Especificação $A$} \\
\hline$r=0$ & $r>0$ & 88,84 & 90,25 & 68,56 & 76,07 \\
\hline$r \leq 1$ & $r>1$ & 45,10 & 43,73 & 47,21 & 54,46 \\
\hline \multicolumn{6}{|c|}{ Especificação $B$} \\
\hline$r=0$ & $r>0$ & 96,80 & 97,71 & 76,07 & 84,45 \\
\hline$r \leq 1$ & $r>1$ & 52,34 & 50,56 & 53,12 & 60,12 \\
\hline \multicolumn{6}{|c|}{ Especificação $C$} \\
\hline$r=0$ & $r>0$ & 102,59 & 115,34 & 87,31 & 96,58 \\
\hline$r \leq 1$ & $r>1$ & 58,82 & 67,82 & 62,99 & 70,05 \\
\hline
\end{tabular}

Vale dizer que este estudo não foi o único a identificar cointegração num sistema composto, entre outras variáveis, por indicadores de criminalidade. Cointegração foi encontrada também por Corman e Mocan (2000) e Saridakis (2011), entre outros. Mas foi rejeitada nas análises feitas por Scorcu e Celline (1998), Hale (1998) e Saridakis (2004).

Para seguir com as análises das relações de longo prazo entre crime e as demais variáveis do sistema é preciso escolher um dos seis modelos estimados. Especificamente, é preciso checar o comportamento dos resíduos e a significância estatística dos regressores determinísticos dentro do vetor de cointegração.

O modelo VEC(1) foi descartado por não gerar resíduos ruído branco. Mas os testes de diagnóstico aplicados nos resíduos do modelo $\mathrm{VEC}(2)$ indicam que ele é robusto. Os resultados dos testes aplicados nesse modelo, com a especificação $B$, estão na Tabela $3.6{ }^{17}$

são sempre maiores do que os valores críticos conhecidos. Assim, utilizar os valores críticos sem considerar a quebra estrutural causa um viés no teste na direção da rejeição da hipótese nula; em outras palavras, o teste poderia indicar $r=1$ quando na verdade $r=0, r=2$ quando na verdade $r=1$, e assim por diante.

${ }^{17}$ Registre-se que nas outras duas especificações, $A$ e $C$, os resultados dos testes não divergem dos resultados obtidos para o modelo estimado com a especificação $B$. 
Avaliando cada uma das cinco equações, a hipótese de resíduos ruído branco é sustentada pelas estatísticas- $Q$ de Ljung-Box (LJUNG; BOX, 1978), o teste ARCH-LM (ver ENGLE, 1982; HAMILTON, 1994) sustenta a hipótese de que não há heterocedasticidade condicional, e o teste Jarque-Bera (BERA; JARQUE, 1980, 1981; JARQUE; BERA, 1987) sustenta a hipótese de resíduos com distribuição normal. Hipóteses que também são sustentadas pelos testes em suas versões multivariadas. ${ }^{18}$

Tabela 3.6 - Testes de diagnóstico nos resíduos do modelo identificado

\begin{tabular}{|c|c|c|}
\hline Variáveis & Estatísticas univariadas & \\
\hline & Ljung-Box $(K=14, \mathrm{gl}=12) \quad$ ARCH-LM $(K=4, \mathrm{gl}=4)$ & Jarque-Bera $(\mathrm{gl}=2)$ \\
\hline$c r i$ & $Q=12,79[0,38]$ & $\chi^{2}=1,86[0,39]$ \\
\hline pri & $Q=19,38[0,08]$ & $\chi^{2}=2,83[0,24]$ \\
\hline arm & $Q=13,01[0,37]$ & $\chi^{2}=0,80[0,67]$ \\
\hline des & $Q=12,29[0,43]$ & $\chi^{2}=1,06[0,59]$ \\
\hline sal & $Q=11,26[0,51]$ & $\chi^{2}=1,13[0,56]$ \\
\hline \multicolumn{3}{|c|}{ Estatísticas multivariadas } \\
\hline \multicolumn{3}{|l|}{ Portmanteau** } \\
\hline$K=14(\mathrm{gl}=280)$ & $Q=303,22[0,16]$ & \\
\hline \multicolumn{3}{|l|}{ Edgerton-Shukur*** } \\
\hline$K=1(\mathrm{gl}=25,90)$ & $F=0,80[0,73]$ & \\
\hline$K=2(\mathrm{gl}=50,90)$ & $F=1,09[0,35]$ & \\
\hline$K=3(\mathrm{gl}=75,71)$ & $F=0,86[0,74]$ & \\
\hline$K=4(\mathrm{gl}=100,48)$ & $F=1,14[0,32]$ & \\
\hline$K=5(\mathrm{gl}=125,24)$ & $F=0,90[0,66]$ & \\
\hline \multicolumn{3}{|l|}{ ARCH-LM } \\
\hline$K=1(\mathrm{gl}=225)$ & $\chi^{2}=225,39[0,48]$ & \\
\hline$K=2(\mathrm{gl}=450)$ & $\chi^{2}=435,53[0,68]$ & \\
\hline$K=3(\mathrm{gl}=675)$ & $\chi^{2}=677,80[0,46]$ & \\
\hline$K=4(\mathrm{gl}=900)$ & $\chi^{2}=735,00[1,00]$ & \\
\hline \multicolumn{3}{|l|}{ Jarque-Bera } \\
\hline Assimetria $(\mathrm{gl}=5)$ & $2,69[0,75]$ & \\
\hline Curtose $(\mathrm{gl}=5)$ & $2,85[0,72]$ & \\
\hline Ambos $(\mathrm{gl}=10)$ & $5,54[0,85]$ & \\
\hline
\end{tabular}

As relações de longo prazo e os respectivos coeficientes de ajustamento estimados nos três modelos de cointegração estão na Tabela 3.7. Observe-se que o vetor de cointegração foi normalizado para a variável $\mathrm{cri}$.

Para avaliar a significância estatística dos termos determinísticos no vetor de cointegração, os modelos $B$ e $C$ foram reestimados com restrição na matriz $\beta .{ }^{19}$

No modelo $C$, a estatística do teste para a hipótese nula $H_{0}: \beta_{\text {tend }}=0$, com um grau de

\footnotetext{
${ }^{18} \mathrm{Na}$ versão multivariada do teste Jarque-Bera, a estatística é computada com os resíduos padronizados utilizando a decomposição de Choleski da matriz de variância-covariância dos resíduos centrados. Nesse caso, o resultado do teste depende da ordenação das variáveis dentro do vetor autorregressivo. Para checagem do resultado, o teste foi refeito considerando diferentes horizontes de ordenação das variáveis do modelo. Não há divergências entre os resultados dos testes com relação à conclusão.

${ }^{19}$ Para detalhes dos testes de restrição sobre $\alpha$ e $\beta$, consulte Johansen e Juselius (1990) e Johansen (1995), entre outros.
} 
liberdade, é $\chi^{2}=0,99$ (valor- $p=0,32$ ). Portanto, não se rejeita a hipótese de que não há tendência linear dentro do vetor de cointegração. Mas, no modelo $B$ a estatística do teste para a hipótese nula $H_{0}: \beta_{\text {cons }}=0$, com um grau de liberdade, é $\chi^{2}=14,41$. Sendo a constante dentro do vetor de cointegração estatisticamente significativa a menos de $1 \%$, optou-se pela especificação $B$. Portanto, as análises daqui para frente referem-se aos resultados da estimação do modelo $\operatorname{VEC}(2)$ com constante no espaço de cointegração.

O passo seguinte foi aplicar testes de razão de verossimilhança sucessivamente para testar a significância de cada um dos coeficientes estimados. As estatísticas do teste, com um grau de liberdade, são: $\chi_{p r i}^{2}=21,86, \chi_{\text {arm }}^{2}=17,91, \chi_{\text {des }}^{2}=14,2, \chi_{\text {sal }}^{2}=12,57$. Portanto, conclui-se que, na relação de longo prazo, todas as variáveis são altamente significativas.

É importante observar que os mesmos sinais das relações de longo prazo identificadas na estimação do modelo com a especificação $B$ foram evidenciados nas duas outras especificações avaliadas. E, como sugerem os baixos erros-padrão das respectivas estimativas dos coeficientes, tais relações também se revelaram estatisticamente significativas nos testes de razão de verossimilhança. Portanto, independentemente da especificação do modelo de cointegração em que as relações de longo prazo foram testadas, as relações identificadas são estatisticamente significativas. A estabilidade de resultados indica que as estimações são robustas.

Aparentemente apenas as variáveis cri e des cointegram, pois os coeficientes de ajustamento relativos às demais variáveis apresentam elevado erro-padrão. Nesse contexto, convém impor e testar restrições sobre o vetor de coeficientes de ajustamento. Primeiramente, testou-se a

Tabela 3.7 - Vetor de cointegração e coeficientes de ajustamento do modelo VEC(2)

\begin{tabular}{|c|c|c|c|c|c|c|c|}
\hline \multirow[t]{2}{*}{ Vetor } & \multicolumn{5}{|c|}{ Variáveis } & \multicolumn{2}{|c|}{ Termos determinísticos } \\
\hline & cri & pri & arm & des & sal & constante & tendência \\
\hline \multicolumn{8}{|c|}{ Especificação $A$} \\
\hline$\hat{\beta}^{\prime}$ & 1,0 & $\begin{array}{c}1,3502 \\
(0,1275)\end{array}$ & $\begin{array}{c}1,0784 \\
(0,1602)\end{array}$ & $\begin{array}{l}-1,2854 \\
(0,1466)\end{array}$ & $\begin{array}{c}2,2548 \\
(0,3069)\end{array}$ & & \\
\hline$\hat{\alpha}^{\prime}$ & $\begin{array}{c}-0,279 \\
(0,1161)\end{array}$ & $\begin{array}{c}-0,1475 \\
(0,1622)\end{array}$ & $\begin{array}{c}-0,3936 \\
(0,2058)\end{array}$ & $\begin{array}{c}0,2044 \\
(0,05981)\end{array}$ & $\begin{array}{c}-0,04003 \\
(0,04638)\end{array}$ & & \\
\hline \multicolumn{8}{|c|}{ Especificação $B$} \\
\hline$\hat{\beta}^{\prime}$ & 1,0 & $\begin{array}{c}1,3509 \\
(0,1275)\end{array}$ & $\begin{array}{c}1,0689 \\
(0,1603)\end{array}$ & $\begin{array}{l}-1,3034 \\
(0,1467)\end{array}$ & $\begin{array}{c}2,211 \\
(0,307)\end{array}$ & $\begin{array}{c}-22,003 \\
(3,0683)\end{array}$ & \\
\hline$\hat{\alpha}^{\prime}$ & $\begin{array}{c}-0,286 \\
(0,1155)\end{array}$ & $\begin{array}{l}-0,1584 \\
(0,1604)\end{array}$ & $\begin{array}{c}-0,3538 \\
(0,2055)\end{array}$ & $\begin{array}{c}0,2144 \\
(0,05948)\end{array}$ & $\begin{array}{l}-0,02249 \\
(0,04821)\end{array}$ & & \\
\hline \multicolumn{8}{|c|}{ Especificação $C$} \\
\hline$\hat{\beta}^{\prime}$ & 1,0 & $\begin{array}{c}1,593 \\
(0,1557)\end{array}$ & $\begin{array}{c}1,4756 \\
(0,2102)\end{array}$ & $\begin{array}{l}-1,5262 \\
(0,2093)\end{array}$ & $\begin{array}{c}2,0451 \\
(0,4627)\end{array}$ & & $\begin{array}{c}0,01046 \\
(0,005924)\end{array}$ \\
\hline$\hat{\alpha}^{\prime}$ & $\begin{array}{c}-0,2228 \\
(0,09826)\end{array}$ & $\begin{array}{l}-0,1086 \\
(0,1367)\end{array}$ & $\begin{array}{l}-0,3917 \\
(0,1708)\end{array}$ & $\begin{array}{c}0,1765 \\
(0,05003)\end{array}$ & $\begin{array}{c}-0,001278 \\
(0,0393)\end{array}$ & & \\
\hline
\end{tabular}

Notas: Erros-padrão entre parênteses; as definições das variáveis estão na página 47. 
hipótese nula conjunta de que todos os coeficientes de ajustamento $(\alpha)$ são iguais a zero. Sob a hipótese nula, com quatro graus de liberdade, a estatística do teste é $\chi^{2}=21,97$. Um segundo conjunto de testes foi aplicado para testar hipóteses individuais. As estatísticas do teste, com um grau de liberdade, são: $\chi_{c r i}^{2}=4,1, \chi_{\text {pri }}^{2}=0,67, \chi_{\text {arm }}^{2}=1,77, \chi_{\text {des }}^{2}=8,49$ e $\chi_{\text {sal }}^{2}=0,18$. Conclui-se que, de fato, somente as variáveis cri e des cointegram. Considere-se, porém, que o coeficiente de ajustamento da variável arm é significativo a $18 \%$.

\subsection{Resultados e Discussões}

A Tabela 3.8 reporta as estimativas obtidas para a equação $\Delta c r i_{t}$ pelo modelo identificado na seção anterior, isto é, pelo $\operatorname{VEC(2)~com~constante~dentro~do~vetor~de~cointegração.~}$

Tabela 3.8 - Resultados das estimativas

\begin{tabular}{|c|c|c|}
\hline Coeficiente & Estimativa & Erro-padrão \\
\hline$\alpha$ & $-0,286^{* *}$ & 0,1155 \\
\hline$D_{e d}$ & $-0,1286^{*}$ & 0,0415 \\
\hline$D S_{1}$ & 0,00306 & 0,05457 \\
\hline$D S_{2}$ & $-0,06438$ & 0,0607 \\
\hline$D S_{3}$ & $-0,1014 * * *$ & 0,0553 \\
\hline$\Delta c r i_{t-1}$ & $-0,08359$ & 0,1713 \\
\hline$\Delta c r i_{t-2}$ & 0,02545 & 0,1658 \\
\hline$\Delta s a l_{t-1}$ & 0,005803 & 0,437 \\
\hline$\Delta s a l_{t-2}$ & 0,1376 & 0,3849 \\
\hline$\Delta d e s_{t-1}$ & 0,3269 & 0,2871 \\
\hline$\Delta d e s_{t-2}$ & 0,13066 & 0,3192 \\
\hline$\Delta a r m_{t-1}$ & 0,1168 & 0,1337 \\
\hline$\Delta \operatorname{arm}_{t-2}$ & 0,05866 & 0,1016 \\
\hline$\Delta p r i_{t-1}$ & 0,2110 & 0,1644 \\
\hline$\Delta p r i_{t-2}$ & 0,2054 & 0,141 \\
\hline$R^{2}$ & 0,4527 & \\
\hline Núm. de obs. $(n)$ & 53 & \\
\hline \multicolumn{3}{|c|}{$\begin{array}{l}\text { Notas: } * * * \text { e } * * * \text { denotam, respectivamente } \\
\text { significância estatística a } 1 \%, 5 \% \text { e } 10 \% \text { no } \\
\text { teste } t \text {; o erro-padrão do } \hat{\alpha} \text { foi ajustado para } \\
\text { graus de liberdade. }\end{array}$} \\
\hline
\end{tabular}

Em primeiro lugar, merece destaque a estimativa do coeficiente da variável dummy de intervenção do Estatuto do Desarmamento, negativo $(-0,1286)$ e estatisticamente significativo a $1 \%(t=-3,096)$, indicando que o desarmamento da população causou redução da taxa de crimes letais. A significância estatística dessa variável dummy corrobora a evidência vista no primeiro artigo desta tese (capítulo 2) de que o desarmamento dos cidadãos causou redução da taxa de crimes letais. Se tal relação tivesse sido significativa também nas demais equações do sistema (isto é, para as outras variáveis do sistema) haveria indícios de espuriedade na relação evidenciada naquele estudo, sobretudo se fosse significante para as variáveis econômicas, com as quais a política de desarmamento não deveria ter qualquer relação. Mas, aos níveis convencionais, além de significativa na equação da taxa de crimes, essa relação foi significante 
somente na equação da série arm, o que é plausível. Com a regulamentação da lei que trata do tema, menos armas de fogo ficaram passíveis de apreensão, seja porque menos pessoas circulam armadas nas ruas ou armas de fogo, em número significativo, foram voluntariamente devolvidas pelos cidadãos durante as campanhas do desarmamento. ${ }^{20}$ Portanto, mesmo considerando na estimação do modelo outros supostos causadores da redução do crime em São Paulo, não se rejeita a hipótese de que o Estatuto do Desarmamento colaborou para esse fato.

No tocante às relações de curto prazo, as evidências são de que não há efeitos estatisticamente significativos das condições econômicas e do desempenho da Polícia sobre a taxa de crimes letais. Em se tratando das variáveis testadas neste estudo, considera-se que a ausência de efeitos de curto prazo é plausível. É possível que seja necessário um intervalo de tempo razoável para que mudanças nas condições econômicas influam na decisão de novos indivíduos atuarem ou não atuarem na criminalidade.

Cantor e Land (1985) discutem essa questão, afirmando que é pouco provável que mudanças nas condições econômicas causem efeitos contemporâneos no crime, especialmente porque muitas vezes a queda no nível de atividade econômica é compensada por ações do governo. No Brasil, por exemplo, um indivíduo que fica desempregado no mercado formal recebe um seguro desemprego por vários meses, tempo considerado suficiente para que ele consiga um novo emprego. Além disso, muitas vezes a ajuda financeira é dada pela própria família, amigos ou organizações de caridade. Portanto, para Cantor e Land (1985), não é possível afirmar que as recessões econômicas imediatamente motivem as pessoas a cometer infrações penais. Contudo, segundo eles, é possível que um desempregado se torne mais propenso ao crime do que um indivíduo empregado quando os benefícios governamentais e outras fontes de apoio financeiro e psicológico se esgotarem. Nesse contexto, é plausível que as condições econômicas não causem efeitos de curto prazo na criminalidade, mas causem efeitos no longo prazo. Da mesma maneira, é possível que melhores condições econômicas exijam um intervalo de tempo razoável para efetivamente influir no custo de oportunidade do crime. Esse custo, segundo Becker (1968), é avaliado pelo indivíduo no momento em que decide se cometerá ou se não cometerá crimes.

Relações entre condições econômicas e criminalidade não significativas do ponto de vista estatístico já foram evidenciadas e discutidas em estudos anteriores. Scorcu e Cellini (1998), por exemplo, observaram que as taxas de crescimento das variáveis econômicas não afetam significativamente a dinâmica de curto prazo dos índices de criminalidade. Segundo esses autores, o maior efeito das condições econômicas sobre a criminalidade surgiu do processo de ajustamento que conduz o nível corrente dos índices de criminalidade para o seu nível de equilíbrio de longo prazo. Em termos gerais, os autores concluíram que a taxa de crimes não é correlacionada com as variáveis econômicas consideradas no estudo. A partir dessas evidências eles sugeriram que a atenção dada na maioria dos estudos para a relação de curto prazo entre a

\footnotetext{
${ }^{20}$ Vale lembrar que no primeiro artigo desta tese foram apresentados alguns dados sobre o número de armas devolvidas.
} 
atividade econômica e criminalidade é, talvez, excessiva e que mais atenção deveria ser dada às relações de longo prazo. Saridakis (2011) também abordou a questão sobre os efeitos de curto prazo das condições econômicas no crime. Utilizando dados da Inglaterra e do País de Gales, o autor concluiu que, das variáveis econômicas analisadas, apenas a taxa de desemprego revelou ter um efeito de curto prazo estatisticamente significativo sobre a taxa de crimes violentos. Contudo, conforme ressaltado pelo próprio autor, o efeito é numericamente muito pequeno, sugerindo que a criminalidade violenta não se ajusta no curto prazo às condições econômicas. Ainda, conforme sugerido por Field (1990), os determinantes de curto prazo da criminalidade podem diferir dos seus determinantes de longo prazo, o que torna a identificação das causas da criminalidade ainda mais complexa.

Uma vez que as relações de curto prazo são não significativas do ponto de vista estatístico, volta-se ao foco deste estudo: os determinantes de longo prazo da criminalidade.

Para analisar as relações de longo prazo entre crime e as demais variáveis do modelo, o vetor $\hat{\beta}^{\prime}$ do modelo escolhido na seção anterior foi reescrito na forma de uma relação de determinação da taxa de crimes:

$$
\hat{c r i}_{t}=22,003+1,3034 d_{e s}-2,211 \text { sal }_{t}-1,3509 \text { pri }_{t}-1,0689 \text { arm }_{t}
$$

Devido às diferenças metodológicas deste estudo, seus resultados não são diretamente comparáveis aos demais estudos feitos para investigar as causas da criminalidade no Brasil. Não obstante, busca-se discuti-los na medida do possível à luz da teoria econômica que pioneiramente tratou do tema (BECKER, 1968; EHRLICH, 1973) e das evidências empíricas prévias no âmbito nacional e internacional.

Primeiramente vale dizer que os sinais de todos os coeficientes da eq. (3.5) correspondem às relações previstas nessas abordagens econômicas do comportamento criminoso, embora não se trate em essência da original equação de oferta de crimes proposta no trabalho de Becker (1973) e extendida no trabalho de Ehrlich (1973).

Evidencia-se que a taxa de crimes é positivamente relacionada ao desemprego, e negativamente relacionada ao salário. É válido lembrar que ambas são variáveis proxies tanto para o custo de oportunidade do crime quanto para o retorno esperado no crime. No tocante às variáveis proxies do desempenho da Polícia evidencia-se que aumentos no número relativo de prisões de traficantes e no número relativo de armas de fogo apreendidas causam redução no crime.

Os níveis de desemprego e de salários são frequentemente apontados, sobretudo pelos economistas, como importantes determinantes do comportamento criminoso. Nesse contexto, hipoteticamente, a melhoria nas condições do mercado de trabalho na capital paulista explica ao menos parcialmente a redução do crime em São Paulo.

Os efeitos das condições do mercado de trabalho nos níveis de criminalidade têm motivado estudos econômicos empíricos mesmo antes da publicação do clássico estudo teórico de Becker 
(1968). Precedendo esse autor, Fleisher (1963) apresenta as primeiras evidências empíricas sobre a relação entre condições do mercado de trabalho e crime.

$\mathrm{Na}$ literatura nacional, ao nosso conhecimento, inexistem análises empíricas específicas da relação supracitada. Tem sido comum, porém, utilizar alguma mensuração das condições de mercado como controle para o custo de oportunidade do crime na estimativa de equações de "oferta" de crimes (ver ANDRADE; LISBOA, 2000; FAJNZYLBER; ARAUJO JUNIOR, 2001; MENDONÇA et al., 2002; GUTIERREZ et al., 2004; SANTOS; KASSOUF, 2007; e outros).

Na linha do pensamento econômico sobre as causas do crime, melhores condições no mercado de trabalho aumentam os custos de oportunidade do crime. Por sua vez, isso reduz a probabilidade de um indivíduo cometer crimes. Em São Paulo, conforme visto na Figura 3.1, os níveis da taxa de desemprego têm tendência descendente desde aproximadamente o vigésimo oitavo trimestre do período amostral. Como se vê nessa mesma figura, tal queda ocorreu concomitantemente à tendência ascendente do salário real, a qual se tornou mais acentuada em torno do trigésimo trimestre.

A evidência de que uma taxa de desemprego mais baixa reduz os níveis de criminalidade vai ao encontro da maioria dos estudos prévios que analisaram essa relação (SCORCU; CELLINE, 1998; SARIDAKIS, 2011; e outros), mas diverge daqueles que não encontraram relação significante (LEVITT, 1996; HALE, 1998; MOCAN; REES, 2005).

No tocante ao salário real, o resultado vai ao encontro do evidenciado por Gould et al. (2002) ao analisar os efeitos das oportunidades no mercado de trabalho sobre a taxa de crimes nos Estados Unidos. Também vai ao encontro dos resultados obtidos em Santos e Kassouf (2007), embora nesse estudo tenha sido utilizada uma mensuração distinta para refletir as condições do mercado de trabalho. Utilizando uma medida para rotatividade do emprego, concluiu-se que o aquecimento do mercado de trabalho causa redução dos níveis de criminalidade.

É relevante destacar a possibilidade de que os efeitos das variáveis econômicas analisadas sejam importantes na decisão dos indivíduos que potencialmente podem se tornar criminosos no futuro e para aqueles que cumprem suas penas e deverão decidir no ato da soltura se buscarão um trabalho ou se reincidirão no crime. Mas, muito provavelmente as condições do mercado de trabalho não são consideradas na decisão de cometer um crime pelos indivíduos que são criminosos contumazes. Em outras palavras, melhores condições no mercado de trabalho são provavelmente mais efetivas para evitar que novos indivíduos atuem nas atividades criminosas do que para induzir os criminosos atuantes a encerrar a sua "carreira" criminosa. Para aqueles que já optaram pelo crime, os efeitos dissuasivos causados pela política de segurança pública são mais efetivos para redução da quantidade de crimes cometidos.

Uma hipótese defendida, sobretudo pelos gestores da política de segurança pública é que o maior desempenho da Polícia é a principal causa da queda ocorrida na criminalidade em São Paulo.

De acordo com a clássica teoria econômica do crime (BECKER, 1968), o objetivo da so- 
ciedade é minimizar os prejuízos da criminalidade induzindo os indivíduos a cometerem um nível "ótimo" de crimes. Ela faz isso por meio de seus representantes legais, os quais, por sua vez, podem escolher o montante e a forma de alocação de recursos em segurança pública. Tal decisão afeta diretamente a probabilidade de fracasso do ato criminoso. Cabe, também, ao legislador definir as formas e a severidade das penalidades aos criminosos condenados. Nesse contexto, é plausível assumirmos que ambas as variáveis pri e arm refletem indiretamente essas escolhas, pois foram construídas a partir de indicadores de resultados de atividades de polícia.

Nesse contexto, a evidência de que há relações de longo prazo entre o número relativo de prisões por tráfico de drogas e a taxa de crimes é plausível. Voltando à Figura 3.1, nota-se que essa série, que tinha uma tendência descendente até aproximadamente o décimo quinto trimestre da amostra, teve sua trajetória visivelmente revertida para uma forte tendência ascendente, ao passo que o nível da taxa de crimes começava a cair. Intui-se que o efetivo combate ao narcotráfico causa queda também em outros tipos de crimes, em particular letais. Vale lembrar que a inclusão dessa variável na especificação do modelo empírico teve duas motivações: de um lado, ela reflete os resultados das atividades de polícia, sobretudo no combate ao crime organizado; por outro lado, ela é proxy para a presença de atividades ilícitas lucrativas, em geral geridas e mantidas por meio de violência e corrupção.

Mediante os resultados das estimações, não se refuta a hipótese de que o efetivo combate ao tráfico de drogas é co-responsável pela significativa queda na taxa de crimes em São Paulo.

Considere-se, porém, que há intensa discussão sobre o papel do encarceramento de criminosos de baixa periculosidade sobre a dinâmica do crime. Mas, em se tratando de traficantes, é consenso que a reclusão é a única penalidade eficaz visando redução dos níveis de criminalidade. Além disso, desarmar, sobretudo os criminosos, é imprescindível para redução do crime.

A série pri reflete a quantidade relativa de prisões por tráfico de drogas. Em se tratando do mercado de drogas, geralmente apreensões de traficantes, em particular dos chefes do tráfico, implicam prisões de outros elementos atuantes nas organizações criminosas. Portanto, considerase plausível que choques nessa variável causem efeitos de longo prazo negativos na taxa de crimes. Também é preciso considerar que quando um criminoso é preso haverá menos atuantes na criminalidade, e, portanto, exceto se novos indivíduos ingressarem na atividade criminosa, espera-se que menos crimes ocorram nos períodos subsequentes à prisão ocorrida.

Ainda é preciso ponderar que, assim como há nas atividades lícitas, nas atividades ilícitas também há especialização ao longo do tempo. O aprendizado no crime reduz os custos de planejamento e execução de novos crimes, bem como reduz a probabilidade de fracasso de cada crime cometido no futuro (probabilidade de denúncia, prisão, julgamento, condenação e efetiva punição). Consequentemente, o aprendizado eleva os retornos esperados na atividade criminosa. Além disso, quanto mais tempo de sua vida um indivíduo atua nas atividades ilícitas, menores serão, relativamente os rendimentos esperados nas atividades lícitas, e, portanto, menor será o seu custo de oportunidade do crime. Também, é preciso considerar que, no Brasil, a 
probabilidade de fracasso nas atividades criminosas é inegavelmente baixa. A forte sensação de impunidade eleva ainda mais o retorno esperado do crime. Todos esses fatores somados aumentam a probabilidade de um indivíduo se tornar um criminoso contumaz. Portanto, o aumento na taxa de apreensão de criminosos causa um importante efeito dissuasivo na decisão de novos indivíduos entrarem na atividade criminosa.

Com relação à segunda medida utilizada na tentativa de captar o efeito do desempenho da Polícia, arm, considera-se que a estimativa de que o aumento no número relativo de armas de fogo apreendidas causa efeitos negativos na taxa de crimes, de certo modo, vai ao encontro da maioria dos estudos que se esforçaram em investigar a suposta relação entre a disponibilidade de armas de fogo e a taxa de crimes. Nessa literatura, a maioria dos autores defendem a tese "menos armas, menos crimes" (DUGAN, 2001, e outros). Tese, porém, refutada por Lott Jr. e Mustard (1997) e Lott Jr. (1998a,b, 2000). ${ }^{21}$ Ressalte-se, ainda, que o evidenciado neste estudo corrobora as conclusões feitas por Cerqueira (2010).

É preciso ponderar que a série arm reflete dois tipos de resultados. Por um lado, quanto mais armas de fogo são apreendidas em um determinado momento, menos armas ilegais ficarão sujeitas a apreensões em momentos futuros. Por outro lado, como a quantidade de armas de fogo foi vista com relação à quantidade de revistas pessoais ou identificação realizadas pela Polícia, ela reflete efeitos do desempenho policial no que diz respeito ao desarmamento da população que mantinha ilegalmente em seu poder armas de fogo e o desarmamento da atividade criminosa. Portanto, a constatação de que essa variável causa efeito negativo na taxa de crimes é sinal de que o desarmamento é imprescindível para a redução da criminalidade em outras localidades, assim como se defende que foi para o caso de São Paulo.

\subsection{Considerações Finais}

Este estudo traz evidências sobre os efeitos de longo prazo dos determinantes da criminalidade. Em particular, foi evidenciado o importante papel do desemprego na explicação dos níveis de criminalidade. A sua principal contribuição, porém, foi lançar luz sobre as possíveis causas da abrupta queda do crime em São Paulo. Acredita-se que foi dado um passo importante nessa investigação. Novas investigações são imprescindíveis, sobretudo para validação dos resultados encontrados aqui. Uma outra contribuição do estudo à literatura empírica é ter gerado mais conhecimento sobre as propriedades de estacionariedade e cointegração da taxa de crimes. Os resultados do estudo foram apresentados e discutidos na seção anterior. Vale, porém, sumarizar os mais relevantes.

O primeiro deles é que o efeito negativo do Estatuto do Desarmamento permaneceu significante, mesmo após terem sido considerados os outros supostos causadores da redução do crime em São Paulo. Fato que reforça a conclusão que fizemos no primeiro artigo desta tese.

Não foram observados efeitos de curto prazo estatisticamente significativos sobre as taxas de

\footnotetext{
${ }^{21}$ McDowall (2005) reúne e discute os principais pontos dessa polêmica discussão.
} 
crimes letais, da taxa de desemprego, dos salários reais e das variáveis proxy para o desempenho da Polícia. Mas, há evidências estatísticas de que essas variáveis causam efeitos de longo prazo na criminalidade. As relações de longo prazo identificadas entre as condições econômicas e a criminalidade indicam que a redução do desemprego e o crescimento do salário real foram determinantes na redução do crime em São Paulo. Não menos importantes do que a melhoria nas condições econômicas foram o efetivo combate ao tráfico de drogas, mediante a prisão de traficantes, e a apreensão de armas de fogo.

Ao estudar o notório caso de sucesso de São Paulo no tocante à redução da criminalidade, conclui-se que, no longo prazo, a atividade econômica guarda estreita relação com o nível da atividade criminosa. Se extrapolada para o país, tal evidência sugere que, além de intensificar a dissuasão sobre o comportamento criminoso, aumentando a probabilidade de fracasso do crime, é preciso que o governo brasileiro execute políticas que melhorem as condições do mercado de trabalho brasileiro, sobretudo reduzindo ainda mais a taxa de desemprego. Isso causará elevação do custo de oportunidade do crime, e, consequentemente, desestimulará a entrada de novos indivíduos no crime e poderá reduzir a taxa de reincidência criminal.

$\mathrm{Na}$ seção anterior ressaltou-se ser pouco provável que as condições do mercado de trabalho sejam ponderadas pelos criminosos contumazes na execução de mais um crime. É pouco plausível que a redução na taxa de desemprego e o aumento dos salários pagos nas atividades lícitas sejam capazes de retirar indivíduos que atuam na criminalidade, ou seja, que já optaram pela atividade criminosa. Considere-se, ainda, que os criminosos não sofrem efeito direto das políticas de desarmamento da população. O efeito é apenas indireto, visto que menos armas estarão em circulação e, portanto, menos armas estarão passíveis de furto ou roubo. Portanto, para reduzir os elevados índices de criminalidade vistos na maior parte do território brasileiro, são imprescindíveis políticas eficazes de segurança pública. Nesse contexto, aumentar a taxa de prisão por crimes cometidos é fundamental para retirar criminosos das ruas e para dissuadir os indivíduos que estão propensos a participar de atividades criminosas. Antes, porém, é preciso rever a estrutura prisional brasileira, a severidade das penas e a qualidade das instituições de segurança pública. Caso contrário, mais prisões no presente não necessariamente causarão menos crimes no futuro.

\section{Detalhes computacionais}

Todos os procedimentos empíricos foram feitos no pacote estatístico R (R DEVELOPMENT CORE TEAM, 2010). A suavização Lowess das séries foram feitas no pacote stats (R DEVELOPMENT CORE TEAM, 2010); as análises Box-Cox foram feitas com o pacote FitAR (MCLEOD; ZHANG, 2008); as equações do teste DP e do teste de Perron foram escritas e estimadas lançando mão ao pacote dynlm (ZEILEIS, 2010); ambos os testes ADF-GLS e KPSS foram feitos no pacote UnitrootUrcaInterface (WUERTZ et al., 2009); os testes de 
razão de verossimilhança sobre restrições no sistema foram feitos no pacote urca; todos os procedimentos referentes às análises de cointegração e os testes de diagnóstico nos resíduos foram feitos utilizando as funções disponíveis no pacote vars (PFAFF, 2008).

\section{Referências}

AKAIKE, H. Fiting autoregressive models for prediction. Ann. Inst. Statist. Math., Tokio, v. 21, n.1, p. 243-247, 1969.

AKAIKE, H. Statistical predictor identification. Ann. Inst. Statist. Math., Tokio, v. 22, n.1, p. 203-217, 1970 .

AKAIKE, H. Maximum likelihood identification of Gaussian autoregressive moving average models. Biometrika, Oxford, v. 60, n.2, p. 255-265, 1973.

AKAIKE, H. A new look at the statistical model identification. IEEE Transactions on Automatic Control, Piscataway, AC-19, n.6, p. 716-723, 1974.

BECKER, G. S. Crime and punishment: an economic approach. The Journal of Political Economy, Chicago, v. 76, n. 2, p. 169-217, 1968.

BERA, A. K; JARQUE, C. M. Eficient test for normality, homoscedasticity and serial independence of regression residuals. Economics letters, Lausanne, v. 6, n. 3, p. 255-259, 1980.

BERA, A. K.; JARQUE, C. M. Efficient test for normality, homoscedasticity and serial independence of regression residuals: Monte Carlo evidence. Economics letters, Lausanne, v. 7, n. 4, p. 313-318, 1981.

BOX, G. E. P.; COX , D. R. An analysis of transformations. Journal of the Royal Statistical Society, London, v. 26, n.2, p. 211-252, 1964.

CANTOR, D.; LAND, K. C. Unemployment and crime rates in the post-world war II United States: a theoretical and empirical analysis . American Sociological Review, Menasha, v. 50, n. 3, p. 317-332, 1985.

CAP/SSP-SP. Estatísticas de criminalidade: manual de interpretação. São Paulo: Secretaria de Segurança Pública do Estado de São Paulo, 2005, 29 p. 
CERQUEIRA, D. R. C. Causas e consequências do crime no Brasil. 2010, 168 p. Tese (Doutorado em Economia) - Pontifícia Universidade Católica do Rio de Janeiro, Rio de Janeiro, 2010.

CLEVELAND, W. S. Robust locally weighted regression and smoothing scatterplots. Journal of the American Statistical Association, Alexandria, v. 74, n. 378, p. 829-836, 1979.

CLEVELAND, W. S. LOWESS: A program for smoothing scatterplots by robust locally weighted regression. The American Statistician, Washington, v. 35, n. 1, p. 54, 1981.

CORMAN, H; MOCAN, H. N. A time-series analysis of crime, deterrence and drug abuse in New York City. The American Economic Review, Nashville, v. 90, n. 3, p. 584-604, 2000.

CPP-INSPER. Relatório da pesquisa de vitimização em São Paulo. São Paulo: Centro de Políticas Públicas do Instituto de Ensino e Pesquisa Insper, 2009, 18 p.

DICKEY, D. A.; PANTULA, S. G. Determining the order of differencing in autoregressive process. Journal of Business and Economic Statistics, Washington, v. 15, n.4, p. 445-461, 1987.

DUGAN, M. More guns, more crime. The Journal of Political Economy, Chicago, v. 109, n. 5, p. 1086-1114, 2001.

EDGERTON, D.; SHUKUR, G. Testing autocorrelation in a system perspective testing autocorrelation. Econometrics Reviews, Philadelphia, v. 18, n. 4, p. 343-386, 1999.

EHRLICH, I. Participation in illegitimate activities: a theoretical and empirical investigation. Journal of Political Economy, Chicago, v. 81, n. 3, p. 526-536, 1973.

ELLIOT, G.; ROTHENBERG, T. J.; STOCK, J. H. Efficient tests for an autoregressive unit root. Econometrica, Oxford, v. 64, n. 4, p. 813-836, 1996.

ENDERS, W. Applied econometric time series, 3rd ed. Hoboken: Wiley, 2010.

ENGLE, R. F. Autoregressive conditional heteroscedasticity with estimates of the variance of United Kingdon inflation. Econometrica, Oxford, v. 50, n. 4, p. 987-1008, 1982.

ENGLE, R. F.; GRANGER, C. W. J. Cointegration and error correction: representation, estimation, and testing. Econometrica, Oxford, v. 55, n. 2, p. 251-276, 1987. 
FAJNZYLBER, P.; ARAÚJO JÚNIOR, A. Violência e criminalidade. In: LISBOA, M.B; MENEZES FILHO, N.A. (Org.). Microeconomia e sociedade no Brasil. Rio de Janeiro: Contra Capa; FGV; EPGE, 2001. p. 333-394.

FIELD, S. Trends in crime and their interpretation: a study of recorded crime in post-war England and Wales. Home Office Research Study, v. 19, London, 1990, p. 1-91.

FLEISHER, B. M. The effect of unemployment on juvenile delinquency. The American Economic Review, Nashville, v. 71, n. 6, p. 543-555, 1963.

GOERTZEL, T.; KAHN, T. The Great São Paulo homicide drop. Homicide Studies, Thousand Oaks, v. 13, n. 4, p. 398-410, 2009.

GOULD, E. D.; WEINBERG, B. A.; MUSTARD, D. Crime rates and labor market opportunities in the United States:1979-1995. Review of Economics and Statistics, Amsterdam, v. 84, n. 1, p. 45-61, 2002.

HALE, C. Crime and the business cycle in post-war Britain revisited. British Journal of Criminology, Oxford, v. 38, n.4, p. 681-698, 1998.

HAMILTON, J. D. Time Series Analysis. Princeton University Press, 1974.

HANNAN, E. J.; QUINN, B. G. The determination of the order of an autorregression. Journal of the Royal Statistical Society, London, v. 41, Series B, p. 190-195, 1979.

HARRIS, R. Using Cointegration Analysis in Econometric Modelling. Prentice Hall/Harvester Wheatsheaf, 1995.

JARQUE, C. M.; BERA, A. K. A test for normality of observations and regression residuals. International Statistical Review, Malden, v. 55, p. 163-172, 1987.

JOHANSEN, S. Statistical analysis of cointegration vectors. Journal of Economic Dynamics and Control, North-Holland, v. 12, n. 2-3, p. 231-254, 1988.

JOHANSEN, S. Estimation and hypothesis testing of cointegration vectors in Gaussian vector autorregressive models. Econometrica, Oxford, v. 59, p. 1551-1580, 1991.

JOHANSEN, S. Cointegration and partial systems and the efficiency of single-equation analysis. Journal of Econometrics, Amsterdam, v. 52, n. 3, p. 389-402, 1992a. 
JOHANSEN, S. Determination of cointegration rank in the presence of a linear trend. Oxford Bulletin of Economics and Statistics, Malden, v. 54, p. 383-397, 1992b.

JOHANSEN, S. Likelihood-Based inference in cointegrated vector autoregressive models. Oxford: Oxford University Press, 1995.

JOHANSEN, S.; JUSELIUS, K. Maximum likelihood estimation and inference on cointegration - with applications to the demand for money. Oxford Bulletin of Economics and Statistics, Malden, v. 52, n. 2, p. 169-210, 1990.

JOHANSEN, S.; MOSCONI, R; NIELSEN, B. Cointegration analysis in the presence of structural breaks in the deterministic trend. Econometrics Journal, Oxford, v. 3, n. 2, p. 216-249, 2000.

KAHN, T; ZANETIC, A. Estudos criminológicos 4 - o papel dos municípios na segurança pública, 2005. Disponível em: http:

www.ssp.sp.gov.br/estatistica/downloads/manual_estudos_criminologicos_4.pdf. Acesso em: 25 de out. de 2011.

KUME, L. Uma estimativa dos determinantes da taxa de criminalidade brasileira: uma aplicação em painel dinâmico. In ENCONTRO NACIONAL DE ECONOMIA, XXXII, 2004, João Pessoa. Disponível em: http://www.anpec.org.br/encontro2004/artigos/A04A148.pdf. Acesso em: 30 dez. 2004.

KWIATKOWSKI, D. et al. Testing the null hypothesis of stationarity against the alternative of unit root: how sure are we that economic time series have a unit root?. Journal of Econometrics, Amsterdam, v. 54, n. 1-3, p. 159-178, 1992.

LEVITT, S. D. The effect of prison population size on crime rates: evidence from prison overcrowding litigation. The Quarterly Journal of Economics, Cambridge, v. 111, n. 2, p. 319-351, 1996.

LJUNG, G. M.; BOX, G. E. P. On a measure of lack of fit in time series models. Biometrika, Oxford, v. 65, n.2, p. 297-303, 1978.

LOTT Jr., J. R. The concealed handgun debate. Journal of Legal Studies, Chicago, v. 27, n. 1, p. 221-243, 1998a.

LOTT Jr., J. R. More guns, less crime: understanding crime and gun control laws. 
University of Chicago Press, 1998b.

LOTT Jr., J. R. More guns, less crime: understanding crime and gun control laws. 2nd ed. University of Chicago Press, 2000.

LOTT Jr., J. R; MUSTARD, D. B. Crime, deterrence, and right-to-carry concealed handguns. Journal of Legal Studies, Chicago, v. 26, n. 1, p. 1-68, 1997.

MacDONALD, Z. (2000). The impact of under-reporting on the relationship between unemployment and property crime. Applied Economics Letters, CIDADE, v. 7, n. 10, p. 659-663, 2000.

McDOWALL, D. Jonh R. Lott, Jr's defensive gun brandishing estimates. Public Opinion Quarterly, Oxford, v. 69, n. 2, p. 246-263, 2005.

McLEOD, A. I.; ZHANG, Y. Improved subset autoregression: with R package. Journal of Statistical Software, Los Angeles, v. 28, n. 2, 2008.

McLEOD, G. Box-Jenkins in Pratice. Lancaster: Gwilym Jenkins and Partners Ltd., 1983.

MENDONÇA, M. J. C. et al. A. Uma análise empírica a partir dos dados do Presídio da Papuda. Estudos Econômicos, São Paulo, v. 32, n. 4, p. 621-641, 2002.

MOCAN, H. N; REES, D. I. Economic conditions, deterrence and juvenile crime: Evidence from micro data. American Law and Economics Review, Cary, v. 7, n. 2, p. 319-349, 2005.

OSTERWALD-LENUM, M. A note with quantiles of the asymptotic distribuition of the maximum likelihood cointegration rank test statistics. Oxford Bulletin of Economics and Statistics, Malden, v. 55, n. 3, p. 461-472, 1992.

PEREIRA, R; CARRERA-FERNANDEZ, J. A criminalidade na região policial da Grande São Paulo sob a ótica da economia do crime. Revista Econômica do Nordeste, Fortaleza, v. 31, n. Especial, p. 898-918, 2000.

PERES, M. F. T.; VICENTIN, D.; NERY, M. B.; LIMA, R. S.; SOUZA, E. R.; CERDA, M.; CARDIA, N.; ADORNO, S.. Queda dos homicídios em São Paulo, Brasil: uma análise descritiva. Rev Panam Salud Publica, Washington, v. 29, n. 1, p. 17-26, 2011.

PERRON, P. The great crash, the oil price shoks, and the unit root hypothesis. Econometrica, 
Oxford, v. 57, n.6, p. 1361-1401, 1989.

PFAFF, B. VAR, SVAR and SVEC Models: Implementation Within R Package vars. Journal of Statistical Software, v. 27, n. 4, p. 1-32, 2008.

PHILLIPS, P. C. B. Understanding spurious regressions in econometrics. Journal of Econometrics, Amsterdam, v. 33, n. 3, p. 311-340, 1986.

PHILLIPS, P. C. B. Time series regression with a unit root. Econometrica, Oxford, v. 55, n. 2, p. 277-301, 1987.

PYLE, D.; DEADMAN, D. Crime and business cycle in post war Britain. British Journal of Criminology, Oxford, v. 34, n. 10, p. 339-357, 1994.

R DEVELOPMENT CORE TEAM. A language and environment for statistical computing. Vienna, Austria: Foundation for Statistical Computing, 2010.

SANTOS, M. J. dos; KASSOUF, A. L. Uma investigação econômica da influência do mercado de drogas ilícitas sobre a criminalidade brasileira. Economia, Brasília, v. 8, n. 2, p. 187-210, 2008.

SARIDAKIS, G. Violent crime in the United States of America: a time-series analysis between 1960-2000. European Journal of Law and Economics, New York, v. 18, n. 2, p. 203-221, 2004.

SARIDAKIS, G. Violent crime and incentives in the long-run: evidence from England and Wales. Journal of Applied Statistics, Oxon, v. 38, n. 4, p. 647-660, 2011.

SCHWARZ, G. Estimating the dimension of a model. Annals of Statistics, Cleveland, v. 6, p. 461-464, 1978.

SCORCU, A.; CELLINE, R. Economic activity and crime in the long run: An empirical investigation on aggregate data from Italy, 1951-1994. International Review of Law and Economics, New York, v. 18, n. 3, p. 279-292, 1998.

SIMS, C. A. Macroeconomics and reality. Econometrica, Chicago, v. 48, n. 1, p. 1-47, 1980.

SOUZA, M. F. M.; MACINKO, J.; ALENCAR, A. P.; MALTA, D. C.; MORAIS NETO, O. L. Reductions in firearm-related mortality and hospitalizations in Brazil after gun control. Health 
Affairs, Bethesda, v. 26, n. 2, p. 575-584, 2007.

WUERTZ, D. et. al. fUnitRoots: Trends and unit roots. R package version 2100.76, 2009.

ZEILEIS, A. dynlm: Dynamic linear regression. R package version 0.3-0, 2010. 


\title{
4 EFEITOS DA RIQUEZA NO RISCO DE VITIMIZAÇÃO CRIMINAL: EVIDÊNCIAS PARA A CIDADE DE SÃO PAULO
}

\section{Resumo}

O objetivo deste estudo é investigar os efeitos da riqueza dos indivíduos no risco de serem vítimas de crimes contra a propriedade, em particular crimes de furto/roubo a residência e furto/roubo a pessoa. Em termos específicos, o intuito é investigar se a relação entre riqueza e risco de vitimização pode ser descrita por uma parábola com concavidade voltada para baixo. São utilizados os dados de duas pesquisas domiciliares de vitimização realizadas na cidade de São Paulo na estimação de modelos probit. Os resultados das estimações indicaram que a riqueza dos indivíduos é um dos determinantes do risco de vitimização criminal à propriedade. Ademais, evidenciou-se que o risco de vitimização cresce com a riqueza, mas atinge um ponto de máximo, a partir do qual se reduz para níveis de riqueza mais elevados.

Palavras-chave: Crime; Vitimização; Riqueza

\begin{abstract}
This study is intended to investigate the effects of the Individuals' wealth on the risk of becoming victims of property crimes, particularly crimes of theft/robbery of residence and theft/robbery of a person. Specifically, we investigate whether the relationship between wealth and victimization risk can be described by a concave down parabola. Data from two household surveys on victimization held in São Paulo were used to estimate probit models. It became evident that the wealth of individuals is one of the determinants of victimization risk. It was also found that criminal victimization risk increases with wealth, but that it reaches a maximum point from which it decreases as wealth levels increase.
\end{abstract}

Keywords: Crime; Victimization; Wealth

\subsection{Introdução}

A primeira dificuldade na investigação das causas da criminalidade é que há pouca (ou quase nenhuma) disponibilidade de informações fidedignas. Os dados oficiais existentes, especialmente os extraídos dos registros policiais, são apenas estimativas subestimadas dos crimes ocorridos. A subestimação da quantidade de ocorrências criminais ocorre porque muitas das vitimizações criminais não são efetivamente registradas na Polícia por meio de um boletim de 
ocorrência. ${ }^{1}$

A elevada quantidade de crimes não registrados pelas vítimas (sub-registro de crimes), principalmente no caso de alguns tipos de crimes como, por exemplo, roubos, furtos, sequestros e estupros, implica erro de medida nos indicadores de criminalidade. Fato que pode enviesar os resultados de estudos empíricos caso o analista não utilize alguma estratégia para contornar o problema.

O fato é que, como apontam todas as pesquisas de vitimização realizadas no exterior e no Brasil $^{2}$, há claras evidências de que a verdadeira taxa de crimes é significativamente superior à reportada pelos dados oficiais. Em outras palavras, os dados oficiais subestimam a dimensão da criminalidade, que tanto influi negativamente na vida dos cidadãos. Então, embora úteis para orientar ações de segurança pública, os dados extraídos de registros policiais não permitem conhecer o verdadeiro nível de criminalidade ao qual a sociedade está exposta. Para isso surgiram, nos Estados Unidos, na década de 1960, as pesquisas de vitimização. Tais pesquisas são realizadas com uma amostra aleatória de determinada população, à qual se pergunta sobre ocorrências de determinados tipos de crimes em determinado período de tempo. Além de permitir uma melhor medição da verdadeira taxa de crime, entre outras vantagens, esse tipo de pesquisa permite o conhecimento das características das vítimas. Informações importantes para estudos empíricos das causas da vitimização criminal.

Uma vez que o crime reduz o bem-estar social, economistas foram envolvidos por mais essa questão ${ }^{3}$. Entre as várias teorias que buscam explicar as causas da criminalidade está a teoria da escolha racional do criminoso, originada no trabalho seminal de Becker (1968), ampliada por Ehrlich (1973). Embora alguns estudos econômicos das causas do crime já tivessem sido feitos antes mesmo dessas publicações (por exemplo, FLEISHER, 1963, 1966; SMIGELLEIBOWISTZ, 1965; EHRLICH, 1967) ${ }^{4}$, foi a partir dos trabalhos de Becker (1968) e Ehrlich (1973) que os estudos empíricos puderam ser fundamentados numa teoria. Desde então, o envolvimento dos economistas nessa linha de pesquisa cresceu ininterruptamente. Não obstante, quase sempre o foco das análises tem sido o lado da oferta da atividade criminosa, ou seja, o lado composto pelos criminosos. Em síntese, nesses estudos busca-se a identificação das principais causas do comportamento criminoso. As evidências empíricas geralmente têm sustentado os postulados pela teoria econômica sobre os efeitos de dissuasão, retorno esperado e custo de

\footnotetext{
${ }^{1}$ A elaboração de um boletim de ocorrência pela Polícia envolve avaliações e decisões de diversos indivíduos envolvidos em um evento que foi interpretado como um "caso de polícia". Em Santos e Kassouf (2008b) apresentase um esquema do padrão de encaminhamento dos eventos considerados a priori como "eventos criminais", e discutem-se os principais fatores que influem na decisão de efetivamente registrar uma vitimização à Polícia.

${ }^{2}$ No exterior, as duas principais pesquisas de vitimização são a British Crime Survey, atualmente chamada de Crime Survey for England, e a National Crime Victimization Survey. Madalozzo e Furtado (2011) listaram as pesquisas de vitimização feitas no Brasil, finalizadas e divulgadas até agosto de 2009. A essa lista inclui-se o Suplemento Especial sobre Segurança Alimentar, Vitimização e Justiça conduzido e divulgado junto à Pesquisa Nacional por Amostra de Domicílios de 2009, do IBGE.

${ }^{3}$ Em Santos e Kassouf (2008b) apresenta-se sucintamente o envolvimento dos economistas, em particular no Brasil, na área de pesquisa conhecida por Economia do Crime. Especificamente, nesse estudo há uma seção que trata da importância do economista e da Economia na investigação das causas da criminalidade.

${ }^{4}$ Os dois últimos estudos foram citados por Ehrlich (1973).
} 
oportunidade do crime. Mas, pouco se conhece sobre quais fatores influem na probabilidade de um indivíduo ser vitimizado, ou seja, no seu risco de vitimização. Isso porque a maioria dos estudos têm sido feitos utilizando dados agregados por países, estados ou municípios. Com dados de pesquisas de vitimização, porém, é possível estudar os determinantes da vitimização criminal utilizando uma amostra de dados individuais. Esse tipo de dado torna possível controlar as principais características dos indivíduos que influem no risco de vitimização, como, por exemplo, idade e gênero.

Entre os estudos anteriores que investigaram os determinantes do risco de vitimização cabe destacar, no exterior, os estudos feitos por Witte (1980), Sparks (1981), Meier e Miethe (1993), Miethe e McDowall (1993) e Levitt (1999). No Brasil, destacam-se as análises empíricas dos determinantes do risco de vitimização feitas por Carneiro (2000), Beato et al. (2004), Gomes e Paz (2008) e Madalozzo e Furtado (2011). Além desses estudos, na literatura nacional, cabe destacar mais três pesquisas sobre as causas da vitimização. Gomes (2011) investigou a importância da dimensão espacial no risco de vitimização de roubo ou furto a residência na cidade de São Paulo; Peixoto et al. (2011) analisaram os determinantes da vitimização por meio de uma perspectiva sistêmica da dinâmica criminal, com a expectativa de compreender as causas das mudanças no padrão de vitimização entre 2003 e 2008 na cidade de São Paulo; Scorzafave et al. (2011) analisaram, de uma forma geral, os determinantes do risco de vitimização de crimes contra a propriedade e contra a pessoa. Nesse estudo, ainda, foram investigadas as possíveis causas do sub-registro de crimes, na mesma linha dos estudos anteriormente feitos por Santos e Kassouf (2008b) e Madalozzo e Furtado (2011).

O processo de vitimização é complexo e, consequentemente, de difícil modelagem empírica. Não há uma teoria que possa ser considerada bem estruturada para guiar as análises empíricas. ${ }^{5}$ Em geral, os estudos têm sido fundamentados em duas abordagens que consideram as vítimas como objeto de estudo, enaltecendo a importância do papel do "estilo de vida" das vítimas e das "oportunidades" dadas aos criminosos para a execução de seus crimes. As análises empíricas têm sido fundamentadas principalmente no arcabouço teórico proposto por Cohen et al. (1981). Fundamentando-se em alguns estudos anteriores ${ }^{6}$, tais autores ampliaram e formalizaram uma teoria sociológica (denominada por eles "opportunity model of predatory victmization"), para explicar o risco de vitimização. Nessa abordagem há cinco fatores de risco: a exposição, a capacidade de proteção, a proximidade aos criminosos, a atratividade da vítima e a natureza dos crimes.

Não parece haver na literatura empírica rejeição à abordagem proposta por esses autores. A principal questão em aberto é sobre quais variáveis influem nos quatro primeiros fatores. O que

\footnotetext{
${ }^{5}$ Cerqueira (2004), resumindo as principais abordagens teóricas sobre as causas do crime, afirma que a teoria do estilo de vida (desenvolvida principalmente no trabalho de Hindelang et al. (1978)), não constitui stricto sensu uma teoria de causação do crime.

${ }^{6}$ Os estudos prévios citados são: Land e Felson (1976), Hindelang et al. (1978), Cohen e Felson (1979) Cohen et al. (1980) e Cohen e Cantor (1980). As referências completas desses estudos estão em Cohen et al. (1981, p. 523-534).
} 
dizer, por exemplo, sobre os efeitos da riqueza no risco de vitimização de crimes de natureza econômica, como, furtos e roubos?

Hipoteticamente, a riqueza influi no risco de vitimização por meio de dois canais que, segundo Cohen et al. (1981), determinam o risco de vitimização. Por um lado, indivíduos mais ricos são economicamente mais atrativos ao crime. Nessa direção, maior riqueza implica maior risco de vitimização. Por outro lado, porém, indivíduos mais ricos têm razões mais fortes e mais dinheiro para gastar com sua própria segurança. ${ }^{7}$ Logo, o efeito da riqueza no risco de vitimização é ambíguo, de tal modo que o efeito líquido somente pode ser observado empiricamente.

Considerando os gastos das potenciais vítimas com proteção particular e criminosos com habilidades heterogêneas, Gomes e Paz (2008) concluem que é possível que exista uma relação crescente mas não monotônica entre a renda de um cidadão e o seu risco de vitimização criminal à propriedade. Esses autores analisaram empiricamente o efeito das características individuais e do tamanho das cidades no risco de vitimização utilizando dados de 104 cidades do estado de São Paulo. Os resultados apontaram que o risco de vitimização é não monotonicamente crescente em relação à renda das vítimas. Três possíveis explicações para esse tipo de relação são apresentadas pelos autores, sendo os gastos particulares em proteção a mais plausível delas. Nesse estudo, a renda domiciliar per capita foi controlada por meio de cinco variáveis binárias de classes sociais definidas por faixas de renda. Utilizando a faixa de renda mais baixa (pobres) como controle, os coeficientes das demais variáveis referentes às classes sociais mais altas (classe média baixa, classe média, classe média alta e ricos) apresentaram coeficientes estatisticamente significativos e positivos. Os efeitos marginais sobre o risco de vitimização foram aumentando até a classe média alta, mas o efeito marginal para os ricos foi menor do que o estimado para a classe média alta. Evidências de que o risco de vitimização não cresce monotonicamente com a renda. Madalozzo e Furtado (2011), controlando o efeito da renda por meio de variáveis binárias definidas por classes de renda, também observaram que o efeito marginal da renda no risco de vitimização, embora positivo, depende da classe social considerada.

Neste estudo o foco da análise será no efeito da riqueza no risco de vitimização criminal à propriedade. Um questão não aprofundada nas análises empíricas anteriores, sobretudo nas análises feitas com dados de pesquisas de vitimização realizadas no Brasil. A hipótese norteadora do desenvolvimento do estudo é que o risco de vitimização de crimes contra a propriedade aumenta com o nível de riqueza devido à maior atratividade econômica, mas tal aumento ocorre a taxas decrescentes devido à maior capacidade de gastar recursos próprios com segurança particular, de tal modo que a partir de um dado nível de riqueza o risco é decrescente em relação à riqueza. Em outras palavras, o risco de vitimização criminal aumenta com

\footnotetext{
${ }^{7}$ Segundo dados do suplemento especial da Pesquisa Nacional por Amostras de Domicílio 2009, a sensação de insegurança, no Brasil, cresce significativamente com maior renda domiciliar per capita. Por exemplo, na região metropolitana de São Paulo 42,9\% das pessoas com renda domiciliar per capita abaixo de um quarto do salário mínimo se sentiam seguras. Esse percentual decresce à medida que a faixa de renda é maior, chegando a ser 12,7 pontos percentuais menor para a faixa de renda de dois ou mais salários mínimos.
} 
a riqueza, mas atinge um ponto de máximo, a partir do qual se reduz com maiores níveis de riqueza. Investigar essa hipótese é o principal objetivo deste estudo.

Após esta breve introdução, o artigo tem a seguinte estrutura: na seção 4.2 apresenta-se sucintamente um referencial teórico para auxiliar nas discussões sobre o efeito da riqueza no risco de vitimização criminal; na seção 4.3 são dados detalhes específicos sobre a modelagem empírica; na seção 4.4 é feita uma análise descritiva dos dados; os resultados empíricos são reportados e discutidos na seção 4.5 ; a seção 4.6 conclui o artigo.

\subsection{Riqueza e Risco de Vitimização}

Na seção 4.1 apresentaram-se os fatores que, segundo Cohen et al. (1981), determinam o risco de vitimização. A questão remanescente é saber quais variáveis influem nesses fatores. Conforme foi enunciado naquela seção, a ênfase neste estudo recai sobre o papel da riqueza na determinação do risco de um indivíduo ser vítima de crimes contra a propriedade, reconhecidamente vistos como crimes com motivação econômica. Para analisar o suposto efeito da riqueza sobre o risco de vitimização, este estudo apoiou-se especificamente no trabalho de Gaviria e Pagés (2002). Os autores propuseram um modelo simples de vitimização, mas bastante útil para a discussão feita neste estudo.

A estrutura do modelo é formada por dois atores (cidadãos e criminosos) e dois estágios. No primeiro estágio, os cidadãos (que diferem apenas em função de suas riquezas) decidem quanto gastarão em proteção particular. No segundo estágio, os cidadãos são expostos aos criminosos que, por sua vez, decidem se executam ou não executam um crime observando a riqueza $(w)$ de suas potenciais vítimas e os seus gastos em proteção particular $(e)$. Pressupondo que os criminosos decidem baseados em fatores meramente pecuniários, deduz-se que um criminoso pondera dois fatores na tomada de decisão: se tiver sucesso na execução do crime será recompensado por uma parcela da riqueza da vítima dada por $\alpha$ vezes $w(\alpha \leq 1)$, e se fracassar ${ }^{8}-0$ que ocorre com probabilidade $p$ - pagará uma penalidade equivalente a $F$.

Três hipóteses adicionais são feitas: a probabilidade de apreensão cresce monotonicamente com os gastos particulares em proteção (isto é, $p=\mathbf{p}(e)$, em que $\mathbf{p}^{\prime}>0$ ); as vítimas e os criminosos são considerados risco-neutros; os criminosos têm informações completas sobre a riqueza de suas potenciais vítimas e são capazes de inferir corretamente os riscos de fracasso na execução do crime

Nesse contexto, um criminoso tentará vitimizar um cidadão $i$ que possui uma riqueza de $w_{i}$ e que gastou $e_{i}$ em sua proteção particular, se e somente se

$$
\left[1-\mathbf{p}\left(e_{i}\right)\right] \alpha w_{i}-\mathbf{p}\left(e_{i}\right) F>0
$$

Uma vez que todos os cidadãos são potenciais vítimas para os criminosos, um dado cidadão

\footnotetext{
${ }^{8}$ Os autores não destacam, mas é preciso considerar que o fracasso significa que o criminoso foi denunciado, preso, condenado e punido com a pena prevista em lei.
} 
$i$ poderá evitar ser vítima se gastar pelo menos $h_{i}$ em proteção particular, em que $h_{i}$ corresponde aos gastos com proteção que tornariam o criminoso indiferente entre tentar vitimizar o cidadão $i$ ou não vitimizá-lo porque o risco envolvido é muito elevado. Em suma,

$$
h_{i}=\mathbf{p}^{(-1)}\left[\frac{\alpha w_{i}}{\alpha w_{i}+F}\right]
$$

em que $\mathbf{p}^{(-1)}$ é o inverso da função $\mathbf{p}$ que liga os gastos em proteção particular às probabilidades de punição do criminoso.

A eq. (4.2) indica, para cada nível de riqueza, o gasto mínimo com proteção particular necessário para dissuadir totalmente os criminosos: qualquer valor abaixo de $h_{i}$ é insuficiente e qualquer valor acima é desperdício. Portanto, os cidadãos precisam decidir se gastarão $h_{i}$ na sua própria proteção ou se não gastarão nada para evitar a vitimização criminal. Eles gastarão $h_{i}$ somente se esse valor não exceder as possíveis perdas se vitimizados. Isto é, se

$$
h_{i} \leq \alpha w_{i}
$$

Cidadãos mais ricos terão que, ceteris paribus, gastar mais em proteção particular para evitar a vitimização. Conclusão feita a partir da primeira derivada da eq. (4.2) com respeito a $w$,

$$
\frac{\mathrm{d} h_{i}}{\mathrm{~d} w_{i}}=\frac{\alpha F}{\left(F-\alpha w_{i}\right)^{2} \mathbf{p}^{\prime}[h]}>0
$$

Mas será que os indivíduos mais ricos estão dispostos a gastar mais recursos próprios em proteção para evitar a vitimização? Ou será que eles preferem, ao invés disso, tolerar algum risco de serem vitimizados? A resposta depende do sinal da segunda derivada de $h$ com relação a $w$.

A Figura 4.1 mostra os dois tipos de soluções relevantes do modelo teórico proposto por Gaviria e Pagés (2002). No primeiro caso, a eq. (4.2) é côncava, $h$ é inferior a $\alpha w$ para valores mais elevados de $w$. Isso significa que os cidadãos mais ricos gastarão em proteção particular, e os cidadãos com menor riqueza serão as vítimas de crimes. No segundo caso, a eq. (4.2) é convexa, significando que os cidadãos com menor riqueza são os que gastam em proteção particular e os mais ricos serão os vitimizados. Em resumo, o resultado depende crucialmente da concavidade da a eq. (4.2).

Mas o que determina a concavidade da eq. (4.2)? A resposta é obtida por meio da segunda derivada de $h$ com respeito ao $w$,

$$
\frac{\mathrm{d}^{2} h_{i}}{\mathrm{~d} w_{i}^{2}}=-\frac{\alpha^{2} F\left(2\left(F+\alpha w_{i}\right) \mathbf{p}^{\prime}\left[h_{i}\right]^{2}+F \mathbf{p}^{\prime \prime}\left[h_{i}\right]\right.}{\left(F+\alpha w_{i}\right)^{4} \mathbf{p}^{\prime}[h]^{3}}
$$

Claramente, a eq. (4.5) será negativa, a menos que a segunda derivada de $\mathbf{p}$ seja tanto negativa como grande em valor absoluto. Então, os ricos, rotineiramente, gastarão em proteção particular, com o intuito de evitar a vitimização, a menos que $\mathbf{p}$ apresente retornos decrescentes 
à escala. Se os retornos marginais de um valor extra gasto em proteção particular contra o crime são muito baixos, os cidadãos mais ricos poderão achar extremamente oneroso atingir o nível de proteção necessário para evitar a vitimização e, racionalmente, decidirão tolerar algum risco. Caso contrário, eles gastarão, de sua riqueza, a parcela necessária para não serem vitimizados.

Em síntese, na abordagem de Gaviria e Pagés (2002), a riqueza dos indivíduos determina tanto a sua atratividade econômica como vítima quanto a sua capacidade de proteção em relação aos criminosos mediante seus gastos com a própria segurança.
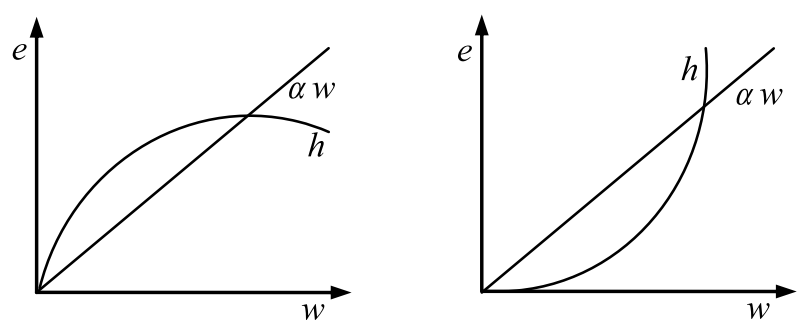

Figura 4.1 - Gastos privados em proteção versus perdas com crimes Fonte: Gaviria e Pagés (2002)

Apoiando-se em Becker (1968), Ehrlich (1973), Cohen et al. (1981) e Gaviria e Pagés (2002) espera-se que, dado o custo de oportunidade do crime, a parcela da probabilidade de fracasso determinada pelos gastos governamentais em segurança pública, as penalidades previstas na lei e os custos de planejamento e execução do crime, o criminoso escolha suas vítimas avaliando entre os cidadãos quais são economicamente mais atrativos para o ato criminal. Nessa avaliação subjetiva o criminoso considera tanto as riquezas das potenciais vítimas quanto a parcela da probabilidade de fracasso do ato criminoso determinada pelos gastos efetuados pelas potenciais vítimas com sua própria segurança. Agindo dessa maneira, o criminoso otimizará o retorno esperado do crime. Portanto, o comportamento das potenciais vítimas influi diretamente no processo de otimização implícito na escolha racional do criminoso. Isso conduz a uma ligação, mesmo que distante, entre as teorias do estilo de vida e das oportunidades e a teoria econômica da escolha racional do criminoso. Assim, se valer o princípio da racionalidade do criminoso, o risco de vitimização cresce com a riqueza. Mas, conforme apontaram Gaviria e Pagés (2002), pessoas mais ricas têm motivos mais fortes e mais dinheiro para gastar com sua própria segurança com o intuito de se proteger dos criminosos. Por outro lado, pessoas mais pobres não têm capacidade financeira de gastar com proteção para evitar uma vitimização, mas são potenciais vítimas economicamente menos atrativas do que as pessoas mais ricas para os criminosos. 


\subsection{Modelagem Empírica}

\subsubsection{Tipos de Crimes, Dados e Amostra}

A hipótese norteadora do desenvolvimento deste estudo é investigada para dois tipos de crimes com motivação estritamente econômica: furto/roubo a residência e furto/roubo a pessoa.

A amostra utilizada nas estimações é composta por dados de duas pesquisas domiciliares de vitimização realizadas na cidade de São Paulo, em 2003 e 2008, pelo Instituto Futuro Brasil ${ }^{9}$ e pela empresa Ipsos Public Affairs, responsável pelo processo de amostragem, entrevistas e pelo banco de dados.

O período de cobertura das pesquisas com relação às ocorrências de vitimização é de um ano. Para crime de furto/roubo a residência, os indivíduos responderam se tiveram algum objeto ou outra coisa roubada ou retirada da sua residência sem o consentimento dos moradores no período de cobertura da pesquisa; para crime de furto/roubo a pessoa, os indivíduos responderam se tiveram algum bem furtado/roubado fora do seu domicílio (inclusive casa de temporada) ou do seu veículo no período de cobertura da pesquisa.

Na primeira edição foram pesquisados 5.000 domicílios e, na segunda, 2.967 domicílios. Infelizmente, há observações perdidas em algumas das variáveis que compõem as especificações dos modelos. Além disso, diferentemente dos estudos anteriores feitos com a mesma base de dados utilizada neste estudo, foram mantidas na amostra utilizada nas estimações para furto/roubo somente as observações referentes aos respondentes que disseram que eles e suas respectivas famílias moravam na atual residência há pelo menos um ano, período de cobertura das questões sobre ocorrências criminais envolvendo as pessoas que residiam no domicílio. Esse filtro, embora tenha implicado exclusão de 676 observações, foi necessário para evitar um possível viés nas estimações. Restaram 5.076 e 5.581 observações às estimações, respectivamente para crimes de furto/roubo a residência e furto/roubo a pessoa.

\subsubsection{Modelo e Metodologia de Estimação}

Serão estimados modelos de vitimização para dois tipos de crimes: furto/roubo a residência $\left(\right.$ crime $\left._{1}\right)$ e furto/roubo a pessoa ( crime $_{2}$ ). A variável resposta desses modelos é resultado de um processo binário, definido pela ocorrência ou não de pelo menos uma vitimização no período considerado nas pesquisas de vitimização utilizadas neste estudo. Portanto, a variável crime $_{z}$ $(z=1,2)$ assume somente dois valores, 0 e 1 , para cada indivíduo $i$. A variável assume o valor 1 se o indivíduo foi vitimizado e o valor 0 caso contrário. Dada essa característica da variável dependente, a modelagem empírica dos determinantes da vitimização dos crimes $z$ é feita por meio de modelos probit estimados por máxima verossimilhança. ${ }^{10}$ A especificação geral dos

\footnotetext{
${ }^{9}$ A partir de fevereiro de 2009, todas as atividades desenvolvidas por esse instituto passaram a ser desenvolvidas no Centro de Políticas Públicas, que passou a ser parte integrante do Insper - Instituto de Ensino e Pesquisa.

${ }^{10}$ Para uma revisão sobre modelos para variáveis dependentes binárias, sugere-se Cameron e Trivedi (1998, 2005, 2009).
} 
modelos estatísticos que serão estimados é:

$$
\operatorname{Pr}\left(\text { crime }_{z, i}=1\right)=\Phi\left(\mathbf{x}_{j, i} \beta\right)
$$

em que $\Phi$ é a distribuição normal cumulativa, $\mathbf{x}$ é um vetor que contém as $j$ variáveis explicativas e uma constante, e $\beta$ é o vetor de coeficientes.

O conjunto de dados utilizado nas estimações desses modelos é formado pela combinação das amostras de 2003 e 2008 (pooled cross-section) das duas pesquisas de vitimização citadas na seção 4.3.1.

Na seção 4.1 destacou-se que o interesse deste estudo está na hipotética relação entre riqueza e risco de vitimização. Mas a mensuração da riqueza é uma tarefa difícil. Como variável proxy utiliza-se a despesa total domiciliar per capita mensal (doravante: despesa), medida em reais de 2003 (des). ${ }^{11}$ E, para controlar e testar uma possível não linearidade na relação entre riqueza e risco de vitimização, utiliza-se também o quadrado dessa variável $\left(\operatorname{des}^{2}\right) .^{12}$

As demais variáveis de controle, comuns aos dois tipos de crimes, são:

- os anos de idade (ida);

- uma binária para distinguir gênero, que assume valor 1 se o indivíduo é homem e valor 0 se é mulher (sex);

- uma binária para distinguir cor ou raça, que assume valor 1 se o indivíduo é branco ou amarelo e valor 0 se é negro, pardo ou indígena (cor);

Nos modelos de vitimização de furto/roubo a residência há dois controles específicos:

- uma binária para distinguir a localização da residência, que assume valor 1 se a residência é localizada numa favela, num conjunto habitacional popular ou próximo a uma favela, e valor 0 se não há favela nas proximidades $(l o c)$;

- uma binária que assume valor 1 se o domicílio é casa e valor 0 se é apartamento ou casa/apartamento em condomínio fechado (cas).

E, relativamente ao modelo de vitimização de furto/roubo a pessoa, a especificação contêm:

- uma binária para distinguir a condição de ocupação, que assume valor 1 se o indivíduo trabalha fora de casa e valor 0 caso contrário (tra);

- uma binária de interação entre idade e gênero $(i d s)$.

\footnotetext{
${ }^{11}$ Os valores de 2008 foram deflacionados utilizando Índice Nacional de Preços ao Consumidor (INPC).

${ }^{12}$ É importante dizer que se optou por uma medida de despesa ao invés de uma medida de rendimentos por três motivos. Primeiro porque as perguntas sobre os rendimentos das pessoas que moravam no domicílio foram feitas para respostas fechadas por faixas de rendimentos, tornando-as inadequadas para testar a hipótese norteadora deste estudo. Isso poderia ser contornado utilizando a medida de rendimentos (provenientes do trabalho e de outras fontes) pessoais dos respondentes. Mas, por ser relativa somente ao respondentes, a sua utilização foi considerada inadequada para o que se quer refletir, a riqueza observada pelos criminosos, sobretudo no caso de furto/roubo a residência. O segundo motivo é que as medidas de rendimentos são reconhecidamente enviesadas. O terceiro motivo, o qual consideramos o mais revelante, é que acreditamos que a despesa reflete melhor do que os rendimentos a riqueza observável pelos criminosos. Reconhece-se, porém, que a medida de despesa utilizada é apenas uma aproximação do verdadeiro valor gasto pelas pessoas do domicílio. Entretanto, uma vez que a pergunta feita ao entrevistado permitiu a não declaração do total de gastos ou simplesmente o desconhecimento do total de gastos, reduziu-se substancialmente a possibilidade de erro de mensuração nessa variável.
} 
Por fim, com o intuito de controlar efeitos de tempo em ambos os tipos de crimes, as especificações contêm uma variável binária para distinguir o ano da pesquisa de vitimização, que assume valor 1 se a observação é da pesquisa de 2008 e valor 0 se é da pesquisa de 2003 (ano).

Para o crime de furto/roubo a residência, ainda, diferentemente dos estudos anteriores feitos com a mesma base de dados utilizada neste estudo, no que diz respeito ao gênero, idade e cor, são utilizadas as informações do indivíduo responsável pelo domicílio. Scorzafave et al. (2011) mantiveram na amostra somente os respondentes que eram os próprios responsáveis pelo domicílio; Peixoto et al. (2011) utilizaram os atributos dos respondentes independentemente da posição ocupada no domicílio; Gomes (2011) não controlou nenhum desses atributos nas estimações; Madalozzo e Furtado (2011) consideraram o gênero e a cor do respondente e a média de idade no domicílio.

Definidas todas as variáveis, o modelo expresso na eq. (4.6) é reescrito para cada um dos tipos crimes analisados. As especificações dos modelos de vitimização de crimes de furto/roubo a residência e furto/roubo a pessoa são, respectivamente:

$\operatorname{Pr}\left(\right.$ crime $\left._{1, i}=1\right)=\Phi\left(\beta_{0}+\beta_{1}\right.$ des $_{i}+\beta_{2}$ des $_{i}^{2}+\beta_{3} i d a_{i}+\beta_{4}$ sex $_{i}+\beta_{5}$ cor $_{i}+\beta_{6} l_{\text {loc }}+\beta_{7}$ cas $_{i}+\beta_{8}$ ano $\left._{i}\right)$

$\mathrm{e}$

$\operatorname{Pr}\left(\right.$ crime $\left._{2, i}=1\right)=\Phi\left(\beta_{0}+\beta_{1} d e s_{i}+\beta_{2} d e s_{i}^{2}+\beta_{3} i d a_{i}+\beta_{4}\right.$ sex $_{i}+\beta_{5}$ cor $_{i}+\beta_{6}$ tra $_{i}+\beta_{7} i d s_{i}+\beta_{8}$ ano $\left._{i}\right)$

Vale lembrar que a hipótese a ser testada é: o risco de vitimização criminal aumenta com a riqueza, mas atinge um ponto de máximo, a partir do qual o risco se reduz com níveis de riqueza mais elevados. Essa hipótese não será rejeitada se os coeficientes $\hat{\beta}_{1}$ e $\hat{\beta}_{2}$ dos dois modelos acima especificados forem estatisticamente significativos, e com sinais positivo e negativo, respectivamente.

As expectativas sobre os sinais dos demais coeficientes dos modelos expressos nas eq. (4.7) e (4.8) serão confrontadas com as evidências empíricas na seção 4.5. Exceto para as variáveis referentes à riqueza, as expectativas para as demais variáveis limitam-se a padrões identificados nas análises descritivas que apresentaremos na próxima seção. Isso porque, além de não haver um modelo teórico bem estruturado que pudesse guiar as expectativas, é praticamente impossível identificar os canais pelos quais essas variáveis de controle influem no risco de vitimização, pois elas são determinantes, em maior ou menor grau, dos fatores que hipoteticamente influem no risco de vitimização criminal, descritos na seção 4.2. 


\subsection{Análises Preliminares}

As estatísticas apresentadas nesta seção foram calculadas utilizando os dados das amostras utilizadas nas estimações, ou seja, com os dados que restaram após os filtros aplicados para tornar as amostras adequadas às estimações.

Na Tabela 4.1 reportam-se as definições, médias e desvios padrão das variáveis listadas na seção anterior. Observe-se que, do total da amostra selecionada para as estimações, 6,6\% e $8,39 \%$ dos indivíduos foram vítimas pelo menos uma vez de furto/roubo a residência e furto/roubo a pessoa no período de cobertura das pesquisas, respectivamente.

No que diz respeito a furtos/roubos a residência constata-se que 5,06\% dos indivíduos foram vitimizados uma vez no intervalo de um ano considerado nas pesquisas; $1,0 \%$ foi vítima duas vezes e $0,53 \%$ foram vitimizados pelo menos três vezes. Em se tratando de crimes de furto/roubo a pessoa tais percentuais foram, respectivamente, iguais a $6,77 \%, 1,18 \%$ e $0,43 \%$ (Tabela 4.2).

Ressalte-se que a baixa frequência de indivíduos que foram vitimizados mais de uma vez no período de cobertura das pesquisas impossibilitou uma modelagem robusta dos determinantes da vitimização repetida por meio da estimação de modelos de contagem como foi feita, por exemplo, por Ybarra e Lohr (2002) e Carvalho e Lavor (2008). Não obstante, apenas com o intuito de visualizar padrões nos dados que ajudem na formação de expectativas com relação aos resultados empíricos, além de calcular algumas estatísticas condicionais à vitimização, calculamos outras condicionais ao número de vitimizações do mesmo tipo de crime sofridas no período.

Entre os indivíduos que moravam em apartamento ou condomínio fechado, 4,2\% tiveram sua residência furtada ou roubada. Mas, entre os que que moravam em casas comuns esse percentual foi 7,23\%. Portanto, morar em apartamento ou condomínio fechado aparentemente reduz o risco de vitimização. Observa-se também que o percentual de indivíduos que foram vítimas de furto/roubo a residências foi cerca de 1,7 p.p maior nas localidades em que não havia favelas nas proximidades. Fato que sugere que crimes dessa natureza são cometidos longe da periferia da cidade, onde geralmente o nível de riqueza é maior.

No tocante a furtos/roubos a pessoa, observa-se que o percentual de indivíduos vitimizados foi muito maior no grupo composto por indivíduos que trabalhavam fora de casa $(10,2 \%)$ do que no grupo composto por indivíduos que não trabalhavam fora de casa $(6,5 \%)$. Tal diferença sugere que indivíduos que exercem alguma atividade laboral fora de sua residência são sujeitos a maior risco de vitimização.

Com relação ao gênero, cor e tempo não há diferenças que possam ser julgadas relevantes ou significativas tanto para crime de furto/roubo a residência quanto para crime de furto/roubo a pessoa.

Nas Tabelas 4.3 e 4.4, respectivamente, estão reportadas as frequências percentuais de vitimizações e vitimizações repetidas condicionais às categorias das variáveis de controle qua- 
Tabela 4.1 - Definição, média e desvio padrão (d.p) das variáveis, por tipo de crime

\begin{tabular}{|c|c|c|c|c|c|}
\hline \multirow[t]{2}{*}{ Variável } & \multirow[t]{2}{*}{ Definição } & \multicolumn{2}{|c|}{$\begin{array}{l}\text { Furto/roubo } \\
\text { a residência }\end{array}$} & \multicolumn{2}{|c|}{$\begin{array}{l}\text { Furto/roubo } \\
\text { a pessoa }\end{array}$} \\
\hline & & Média & d.p & Média & d.p \\
\hline crime $_{z}$ & 1 se foi vitimizado e 0 caso contrário & 0,0660 & 0,2483 & 0,08385 & 0,2772 \\
\hline des & $\begin{array}{l}\text { Despesa total domiciliar per capita mensal, } \\
\text { em R } \$ \text { de } 2003\end{array}$ & 359,13 & 445,64 & 360,03 & 442,77 \\
\hline$i d a$ & Anos de idade & 38,56 & 15,85 & 38,03 & 15,66 \\
\hline $\operatorname{sex}$ & 1 se é homem e 0 se é mulher & 0,5228 & 0,4995 & 0,5212 & 0,4996 \\
\hline cor & 1 se é branco ou amarelo e 0 caso contrário & 0,6032 & 0,4893 & 0,5967 & 0,4906 \\
\hline ano & 1 se a observação é da pesquisa de 2008 e 0 se é de 2003 & 0,4050 & 0,4910 & 0,3931 & 0,4885 \\
\hline$l o c$ & $\begin{array}{l}1 \text { se a residência fica em uma favela, próximo a uma } \\
\text { favela ou em um conj. habitacional e } 0 \text { caso contrário }\end{array}$ & 0,4143 & 0,4926 & & \\
\hline cas & $\begin{array}{l}1 \text { se residência é do tipo casa (exclusive em } \\
\text { condomínio fechado) e } 0 \text { caso contrário }\end{array}$ & 0,7843 & 0,4114 & & \\
\hline $\operatorname{tra}$ & 1 se trabalha fora de casa e 0 caso contrário & & & 0,5078 & 0,4999 \\
\hline \multicolumn{2}{|c|}{ Tamanho da amostra $(n)$} & \multicolumn{2}{|c|}{5.076} & \multicolumn{2}{|c|}{5.581} \\
\hline
\end{tabular}

Tabela 4.2 - Frequência de vitimizações, por tipo de crime

\begin{tabular}{ccccc}
\hline Quantidade & \multicolumn{2}{c}{ Furto/roubo a residência } & \multicolumn{2}{c}{ Furto/roubo a pessoa } \\
\cline { 2 - 5 } de vitimizações & Frequência & Freq. relativa \% & Frequência & Freq. relativa \% \\
\hline 0 & 4.741 & 93,40 & 5.113 & 91,61 \\
1 & 257 & 5,06 & 378 & 6,77 \\
2 & 51 & 1,00 & 66 & 1,18 \\
$\geq 3$ & 27 & 0,53 & 24 & 0,43 \\
\hline
\end{tabular}

litativas que compõem as especificações dos modelos empíricos.

Note-se que as mesmas conclusões feitas até aqui, com mudanças apenas nos valores percentuais apresentados, também são válidas para o caso de vitimizações repetidas. A seguir apresentam-se as médias das variáveis quantitativas que compõem as especificações.

No tocante à média da idade dos indivíduos, há uma padrão claro tanto para vitimizações quanto para vitimizações repetidas (Tabelas 4.5 e 4.6). Independentemente do tipo de crime, a média de idade dos indivíduos que foram vitimizados é menor do que a média de idade dos indivíduos que não foram vitimizados. A diferença é mais acentuada no caso de furto/roubo a pessoa, crime em que a média da idade das vítimas é cerca de 5,8 anos menor do que a média da idade dos indivíduos não vitimizados. Como essa diferença é relativamente grande, suspeita-se que os indivíduos mais jovens se expõem mais ao risco de serem furtados/roubados fora de casa. Essa suspeita se tornou ainda mais forte observando-se o comportamento das médias de idade de acordo com o número de vitimizações sofridas, em que se observa que a média da idade é tão menor quanto maior o número de vezes que os indivíduos foram vitimizados.

Com relação à despesa, variável proxy para a riqueza, observa-se que a média dessa variável é maior entre os indivíduos vitimizados do que entre os indivíduos que não foram vitimizados. Observa-se que tal diferença é mais acentuada entre vítimas e não vítimas de furto/roubo a pes- 
Tabela 4.3 - Frequência percentual de vitimizações condicional às categorias das variáveis de controle qualitativas, por tipo de crime

\begin{tabular}{lccccc}
\hline \multirow{2}{*}{ Variável } & Categoria & \multicolumn{2}{c}{$\begin{array}{c}\text { Furto/roubo } \\
\text { a residência }\end{array}$} & \multicolumn{2}{c}{$\begin{array}{c}\text { Furto/roubo } \\
\text { a pessoa }\end{array}$} \\
\cline { 3 - 6 } & & 0 & 1 & 0 & 1 \\
\hline sex & 0 & 93,60 & 6,40 & 91,28 & 8,72 \\
& 1 & 93,22 & 6,78 & 91,92 & 8,08 \\
cor & 0 & 94,24 & 5.76 & 92,05 & 7,95 \\
& 1 & 92,85 & 7,15 & 91,32 & 8,68 \\
ano & 0 & 93,18 & 6,82 & 91,91 & 8,09 \\
& 1 & 93,73 & 6,27 & 91,16 & 8,84 \\
cas & 0 & 95,71 & 4,29 & & \\
& 1 & 92,77 & 7,23 & & \\
loc & 0 & 92,70 & 7,30 & & \\
& 1 & 94,39 & 5,61 & & \\
tra & 0 & \multicolumn{5}{c}{93,48} & 6,52 \\
& 1 & \multicolumn{5}{c}{89,80} & 10,20 \\
\hline \multicolumn{2}{l}{ Nota: As definições das variáveis estão na página 82.}
\end{tabular}

Tabela 4.4 - Frequência percentual de vitimizações repetidas condicional às categorias das variáveis de controle qualitativas, por tipo de crime

\begin{tabular}{|c|c|c|c|c|c|c|c|c|c|}
\hline \multirow{3}{*}{ Variável } & \multirow{3}{*}{ categoria } & \multicolumn{4}{|c|}{ Furto/roubo a residência } & \multicolumn{4}{|c|}{ Furto/roubo a pessoa } \\
\hline & & \multicolumn{8}{|c|}{ Quantidade de vitimizações } \\
\hline & & 0 & 1 & 2 & $\geq 3$ & 0 & 1 & 2 & $\geq 3$ \\
\hline \multirow[t]{2}{*}{ sex } & 0 & 93,60 & 4,62 & 1,16 & 0,62 & 91,28 & 7,00 & 1,35 & 0,37 \\
\hline & 1 & 93,22 & 5,46 & 0,87 & 0,45 & 91,92 & 6,57 & 1,03 & 0,48 \\
\hline \multirow[t]{2}{*}{ cor } & 0 & 94,24 & 4,07 & 1,09 & 0,60 & 92,05 & 6,71 & 0,93 & 0,31 \\
\hline & 1 & 92,85 & 5,72 & 0,95 & 0,49 & 91,32 & 6,82 & 1,35 & 0,51 \\
\hline \multirow[t]{2}{*}{ ano } & 0 & 93,18 & 5,33 & 0,99 & 0,50 & 91,91 & 6,52 & 1,15 & 0,41 \\
\hline & 1 & 93,73 & 4,67 & 1,02 & 0,58 & 91,16 & 7,16 & 1,23 & 0,46 \\
\hline \multirow[t]{2}{*}{ cas } & 0 & 95,71 & 3,38 & 0,64 & 0,27 & & & & \\
\hline & 1 & 92,77 & 5,53 & 1,11 & 0,60 & & & & \\
\hline \multirow[t]{2}{*}{$l o c$} & 1 & 92,70 & 5,75 & 1,14 & 0,40 & & & & \\
\hline & 0 & 94,39 & 4,09 & 0,81 & 0,71 & & & & \\
\hline \multirow[t]{2}{*}{ tra } & 0 & & & & & 93,48 & 5,39 & 0,84 & 0,29 \\
\hline & 1 & & & & & 89,80 & 8,12 & 1,52 & 0,56 \\
\hline
\end{tabular}

Nota: As definições das variáveis estão na página 82. 
Tabela 4.5 - Média das variáveis de controle quantitativas condicionais à vitimização, por tipo de crime

\begin{tabular}{lcccc}
\hline \multirow{2}{*}{ Variável } & \multicolumn{2}{c}{$\begin{array}{c}\text { Furto/roubo } \\
\text { a residência }\end{array}$} & \multicolumn{2}{c}{$\begin{array}{c}\text { Furto/roubo } \\
\text { a pessoa }\end{array}$} \\
\cline { 2 - 5 } & 0 & 1 & 0 & 1 \\
\hline ida & 38,72 & 36,17 & 38,53 & 32,69 \\
\multirow{2}{*}{ des } & & & & \\
& 356,75 & 392,72 & 352,08 & 446,83 \\
\hline
\end{tabular}

Nota: As definições das variáveis estão na página 82.

Tabela 4.6 - Média das variáveis de controle quantitativas condicionais à vitimização repetida, por tipo de crime

\begin{tabular}{lcccccccc}
\hline \multirow{2}{*}{ Variável } & \multicolumn{7}{c}{ Furto/roubo a residência } & \multicolumn{5}{c}{ Furto/roubo a pessoa } \\
\cline { 2 - 9 } & 0 & 1 & 2 & $\geq 3$ & 0 & 1 & 2 & $\geq 3$ \\
\hline$i d a$ & 38,72 & 36,53 & 36,53 & 32,11 & 38,52 & 33,06 & 30,76 & 32,17 \\
& & & & & & & & \\
des & 356,75 & 386,22 & 402,29 & 436,43 & 352,08 & 455,41 & 424,52 & 373,01 \\
\hline
\end{tabular}

Nota: As definições das variáveis estão na página 82.

soa (Tabela 4.5). Especificamente, em se tratando de vitimizações repetidas de furto/roubo a residência observa-se que a média da despesa é maior no grupo composto por indivíduos que foram vitimizados duas vezes do que no grupo composto por indivíduos que foram vitimizados uma única vez, e que é maior no grupo composto por indivíduos que foram vítimas pelo menos três vezes do que no grupo composto por indivíduos que foram vitimizados duas vezes. Entretanto, para o crime de furto/roubo a pessoa não há um padrão claro entre despesa e vitimização repetida (Tabela 4.6). As diferenças observadas na média da despesa entre os grupos de indivíduos vitimizados e não vitimizados indicam que possivelmente a riqueza, aproximada pela despesa, é um dos determinantes do risco de vitimização criminal à propriedade.

\subsection{Resultados e Discussões}

Evidenciam-se sinais estatisticamente significativos aos níveis convencionais, positivos e negativos para os coeficientes associados às variáveis des e $d e s^{2}$, respectivamente. Para o crime de furto/roubo a residência os coeficientes estimados para essas variáveis são $\hat{\beta}_{1}=0,0007279$ e $\hat{\beta}_{2}=-2,56 \mathrm{e}-07$, respectivamente. E para furto/roubo a pessoa estima-se que sejam iguais a $\hat{\beta}_{1}=0,0004771$ e $\hat{\beta}_{2}=-6,97 \mathrm{e}-08$, respectivamente. Portanto, há evidências em favor da hipótese testada neste estudo. Note-se que essa evidência sustenta os apontamentos teóricos feitos por Gomes e Paz (2008).

Estando a concavidade da parábola voltada para baixo $\left(\beta_{2}<0\right)$, a função que descreve a 
relação entre riqueza e risco de vitimização assume um valor máximo. Utilizando os coeficientes supracitados estima-se que o máximo risco de vitimização de furto/roubo a residência com relação ao nível de riqueza ocorre quando a despesa total domiciliar é aproximadamente 1.422 reais por pessoa. E, para furto/roubo a pessoa estima-se que o máximo risco ocorre quando ela é aproximadamente 3.423 reais por pessoa.

Para uma visualização gráfica da hipotética relação quadrática entre risco de vitimização e riqueza (aproximada pela despesa) não rejeitada neste estudo, mostram-se na Figura 4.2, os riscos de vitimização por tipo de crime para vários níveis de despesa. O cálculo aproximado foi feito a partir dos coeficientes estimados estatisticamente significativos, utilizando as médias amostrais das variáveis, $\bar{x}$, e variando somente a despesa.
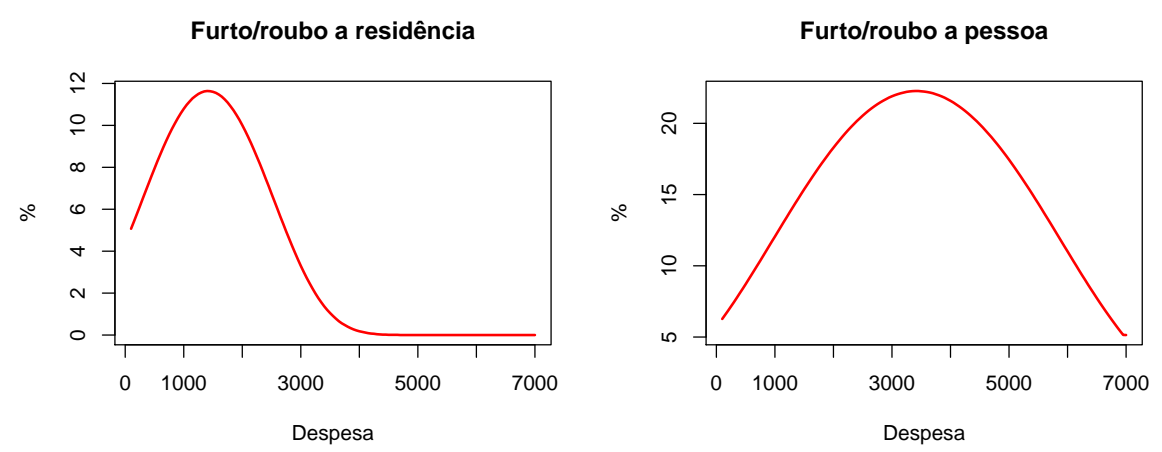

Figura 4.2 - Relação estimada entre riqueza (aproximada pela despesa) e risco de vitimização criminal à propriedade (\%)

Fonte: Elaborada pelo autor com as estimativas dos modelos

Infelizmente, a partir da distribuição de frequências da despesa reportada na Tabela 4.7, conclui-se que apenas uma pequena parcela dos cidadãos que compõem a amostra está na parte descendente dessas curvas estimadas. Especificamente, somente em torno de 3,17\% dos domicílios pesquisados tinham despesa superior a 1.422 reais, e somente $0,27 \%$ tinham despesa superior a 3.423 reais.

Na Tabela 4.8 reportam-se os resultados das regressões probit para crimes de furto/roubo a residência e furto/roubo a pessoa. Observe-se que os valores reportados são os efeitos marginais percentuais decorrentes de mudanças nos valores dos regressores avaliados em suas médias, $\bar{x}{ }^{13}$

Com relação aos determinantes da vitimização de furto/roubo a residência, conclui-se, ainda: a) que morar numa casa aumenta em cerca de 3,88 p.p o risco de vitimização comparativamente a morar num apartamento ou condomínio fechado; b) que o risco de vitimização é aproximadamente 1,67 p.p menor para os indivíduos que moram em favelas, próximo a favelas ou em conjuntos habitacionais comparativamente aos indivíduos que moram em locais onde não há favelas nas proximidades; c) que o risco de vitimização diminui em torno de 0,094 p.p. a cada ano de idade a mais.

\footnotetext{
${ }^{13} \mathrm{O}$ efeito marginal deve ser interpretado como a mudança na probabilidade para uma mudança infinitesimal numa variável explicativa contínua e uma mudança discreta nas variáveis binárias.
} 
Tabela 4.7 - Distribuição de frequências da despesa

\begin{tabular}{ccc}
\hline $\begin{array}{c}\text { Limites do estrato } \\
(\mathrm{R} \$ \text { de } 2003)\end{array}$ & $\begin{array}{c}\text { Frequência } \\
(n)\end{array}$ & $\begin{array}{c}\text { Frequência } \\
\text { relativa }(\%)\end{array}$ \\
\hline Menos de 400 & 4.253 & 76,18 \\
$400 \vdash 800$ & 835 & 14,96 \\
$800 \vdash 1.200$ & 237 & 4,25 \\
$1.200 \vdash 1.600$ & 81 & 1,45 \\
$1.600 \vdash 2.000$ & 79 & 1,42 \\
$2.000 \vdash 2.400$ & 42 & 0,75 \\
$2.400 \vdash 2.800$ & 27 & 0,48 \\
$2.800 \vdash 3.200$ & 12 & 0,21 \\
$3.200 \vdash 3.600$ & 2 & 0,04 \\
3.600 ou mais & 15 & 0,27 \\
\hline \multicolumn{3}{c}{ Total } \\
Nota: Foram utilizadas todas as observações das \\
duas pesquisas de vitimização concatenadas (ex- \\
clusive) os indivíduos que se recusaram a respo- \\
der ou que não sabiam a despesa total do domi- \\
cílio).
\end{tabular}

Esses resultados vão ao encontro dos resultados observados por Madalozzo e Furtado (2011) para o mesmo tipo de crime analisado, apenas diferindo em termos de magnitude dos efeitos marginais estimados. Considerando como grupo base os indivíduos que residiam dentro de favelas, esses autores concluíram que residir fora de uma favela (próximo a favelas ou longe de favelas) eleva o risco de o domicílio ser furtado/roubado em torno de 2,7 p.p.; morar em uma casa aumenta em torno de 1,6 p.p. o risco de vitimização comparativamente a morar em apartamento ou em casa dentro de condomínio fechado; o risco diminui em torno de 0,2 p.p. a cada aumento de um ano na média de idade dos moradores do domicílio. Peixoto et al. (2001) também encontraram efeitos estatisticamente significativos e positivos do tipo de residência (casa) e da idade no risco de vitimização de furto/roubo a residência. Concluíram que morar em uma casa eleva o risco de vitimização e que indivíduos mais velhos têm menor risco de ser vitimizados comparativamente aos mais jovens. Gomes (2011) também conclui que residir em casa eleva o risco de vitimização por crime de furto/roubo a residência, e que se a residência é localizada em uma favela, próximo a uma favela ou em um conjunto habitacional, o risco de vitimização por esse tipo de crime é menor comparativamente a residências distantes de favelas. Em Scorzafave et al. (2011) foram encontrados efeitos significativos negativo e positivo, respectivamente, para a idade do responsável pelo domicílio e para o tipo de residência (casa).

Com poucas exceções, morar em favelas, próximo a favelas ou em conjuntos habitacionais é sinal de baixa riqueza familiar. Pelo princípio da racionalidade do criminoso, criminosos escolhem para seus crimes as residências onde há mais riqueza para ser saqueada. Em outras palavras, em áreas mais "nobres" da cidade, os criminosos esperam obter maiores ganhos para cada crime cometido. Pelas análises preliminares dos dados feitas na seção 4.4 já suspeitávamos dessa possível relação, visto que o percentual de vítimas desse tipo de crime foi muito maior no 
Tabela 4.8 - Resultados das estimações, por tipo de crime

\begin{tabular}{|c|c|c|}
\hline \multirow[b]{2}{*}{ Variável } & \multicolumn{2}{|c|}{ Efeitos marginais (\%) } \\
\hline & $\begin{array}{l}\text { Furto/roubo } \\
\text { a residência }\end{array}$ & $\begin{array}{c}\text { Furto/roubo } \\
\text { a pessoa }\end{array}$ \\
\hline des & $\begin{array}{l}0,00881 * \\
(0,00237)\end{array}$ & $\begin{array}{l}0,00678 * \\
(0,00142)\end{array}$ \\
\hline$d e s^{2}$ & $\begin{array}{c}-3,10 \mathrm{e}-06 * * \\
(1,27 \mathrm{e}-06)\end{array}$ & $\begin{array}{c}-9,91 \mathrm{e}-07 * * \\
(4,58 \mathrm{e}-07)\end{array}$ \\
\hline cas & $\begin{array}{c}3,8765^{*} \\
(0,719)\end{array}$ & \\
\hline loc & $\begin{array}{c}-1,6685 * * \\
(0,7037)\end{array}$ & \\
\hline $\operatorname{tra}$ & & $\begin{array}{c}2,8616^{*} \\
(0,75)\end{array}$ \\
\hline$i d a$ & $\begin{array}{l}-0,09389 * \\
(0,02162)\end{array}$ & $\begin{array}{c}-0,2373 * \\
(0,0368)\end{array}$ \\
\hline $\operatorname{sex}$ & $\begin{array}{c}-0,0552 \\
(0,06783)\end{array}$ & $\begin{array}{c}-2,34 \\
(2,004)\end{array}$ \\
\hline$i d s$ & & $\begin{array}{l}-0,01569 \\
(0,05373)\end{array}$ \\
\hline cor & $\begin{array}{l}-1,0183 \\
(0,7097)\end{array}$ & $\begin{array}{c}0,7221 \\
(0,73547)\end{array}$ \\
\hline ano & $\begin{array}{l}-0,3955 \\
(0,6785)\end{array}$ & $\begin{array}{c}1,1 \\
(0,7352)\end{array}$ \\
\hline Pseudo $R^{2}$ & 0,0235 & 0,04 \\
\hline Teste de Wald $\chi^{2}$ (8 g.l.) & 51,21 & 113,52 \\
\hline Número de observações & 5.076 & 5.581 \\
\hline
\end{tabular}

Notas: os valores entre parênteses são os erros padrão robustos; * e ** denotam, respectivamente, significância a $1 \%$ e $5 \%$. A ausência de asterisco indica que o coeficiente estimado não foi estatisticamente significativo a pelos menos $10 \%$; as definições das variáveis estão na página 82. 
grupo formado por indivíduos que moravam em localidades em que não havia favelas nas proximidades. Portanto, o sinal negativo evidenciado para a variável loc corresponde à expectativa que se tinha sobre o efeito da localidade no risco de uma residência ser furtada/roubada.

Outro resultado que era esperado, sobretudo com base no senso comum, é o de que o risco de furto/roubo a residência é menor em se tratando de apartamentos ou casas em condomínios fechados comparativamente a casas comuns. Inegavelmente, furtar/roubar uma casa é mais fácil do que cometer tais crimes em apartamentos ou condomínios fechados. Portanto, considera-se que essa é mais uma evidência indireta de que criminosos agem racionalmente quando escolhem suas vítimas, avaliando os potenciais ganhos e o risco de fracasso no crime.

Para o crime de furto/roubo a pessoa os resultados indicam que o risco de vitimização é 2,86 p.p. maior para os indivíduos que exercem algum tipo de trabalho fora de casa comparativamente aos que não trabalham fora. Ainda, as estimativas indicam que cada ano de idade reduz o risco de ser vítima de crimes dessa natureza em torno de 0,24 p.p. Vale lembrar que para o crime de furto/roubo a residência esse efeito foi estimado em aproximadamente 0,094 p.p.

Considera-se plausível que o efeito da idade no risco de vitimização é maior para furto/roubo a pessoa do que para furto/roubo a residência. Em geral, os indivíduos mais jovens se expõem mais ao risco de furto/roubo a pessoa do que os indivíduos de idade mais avançada. Ressalte-se, ainda, que os indivíduos mais velhos tendem a adotar um comportamento ainda mais cauteloso se já foram alguma vez vitimizados. Some-se a isso o fato de que os indivíduos mais jovens se expõem muito mais aos criminosos do que os mais velhos por circularem mais frequentemente em locais e horários em que a probabilidade de fracasso do crime é menor.

Era esperado que o risco de vitimização de furto/roubo a pessoa fosse maior para indivíduos que trabalham fora de casa. Expectativa formada sobretudo pelo fato de que tais crimes geralmente ocorrem em locais públicos, que são mais frequentados por indivíduos que exercem alguma atividade laboral fora de casa, como, por exemplo, ruas e centros comerciais. Também nesse caso as evidências empíricas vão ao encontro do que foi visto nas análises preliminares. Naquela seção foi observado que os percentuais de vitimizados foi muito maior no grupo composto por indivíduos que trabalhavam fora de casa.

Observa-se que, independente do tipo de crime, não há efeitos estatisticamente significativos das variáveis de gênero, cor e tempo. Tais evidências de insignificância vão ao encontro da pouca ou quase nenhuma diferença observada nos percentuais de indivíduos vitimizados condicionais às categorias dessas variáveis. Mas, no que diz respeito ao gênero do indivíduo, não correspondem as nossas expectativas formadas com base no senso comum de que mulheres são vítimas mais fáceis para a execução de furtos/roubos a pessoa. Para furto/roubo a pessoa, também, não se rejeita a hipótese de nulidade de efeito da variável de interação entre gênero e idade, o que, a princípio, também não era esperado.

Vale dizer que, no tocante ao crime de furto/roubo a residência, a não significância das variáveis de gênero, cor e tempo já havia sido vista nas estimações feitas por Madalozzo e Furtado (2011). Peixoto et al. (2011) também encontraram efeito não significativo para cor e 
tempo, mas observaram um efeito significativo para o gênero. Nas inúmeras estimações feitas por Gomes (2011), a binária de tempo só é significativa em duas das três estimações em que se buscou controlar uma suposta correlação espacial entre as residências. Nas estimações feitas em Scorzafave et al. (2011), o gênero também não se revelou como um determinante do risco de vitimização. A variável de controle para cor só foi estatisticamente significativa a $10 \%$. A binária de tempo foi significativa, mas com uma magnitude muito pequena.

\subsection{Considerações Finais}

O desenvolvimento deste estudo foi norteado pela hipótese de que a riqueza influi no risco de um indivíduo ser vítima de crimes contra o seu patrimônio por meio de dois canais: atratividade econômica e capacidade de proteção. Em particular testou-se a hipótese de que a relação entre riqueza e risco de vitimização criminal à propriedade é caracterizada por uma parábola com concavidade voltada para baixo. Essa hipótese não foi rejeitada para nenhum dos dois tipos de crimes analisados: furto/roubo a residência e furto/roubo a pessoa. Evidências que sustentam os apontamentos teóricos feitos por Gomes e Paz (2008) sobre uma possível relação não monotônica entre renda e risco de vitimização criminal à propriedade.

Deduz-se que, indiretamente, a não rejeição da hipótese investigada neste estudo indica que os criminosos decidem racionalmente a execução de seus crimes, conforme postula a teoria econômica que trata das causas do comportamento criminoso. Segundo essa teoria, antes de cometer um crime, o criminoso avalia o retorno esperado, computando subjetivamente os potenciais ganhos e a probabilidade de fracasso no crime.

As evidências sobre o efeito não linear da riqueza no risco de vitimização, em particular caracterizado por uma parábola com concavidade voltada para baixo, é um forte indício de que a condição econômica das famílias não é apenas determinante dos ganhos do crime, mas também da capacidade de proteção ao crime.

A teoria da escolha racional prevê uma inequívoca relação positiva dos ganhos na atividade criminosa com a quantidade de ocorrências criminais, hipótese que tem sido testada empiricamente utilizando a renda familiar per capita como variável proxy (MENDONÇA et al., 2002; KUME, 2004; SANTOS; KASSOUF, 2007; SANTOS, 2009, e muitos outros). Frequentemente tem sido defendido que essa variável associa-se tanto aos ganhos esperados quanto ao custo de oportunidade do crime e, além disso, segundo Sjoquist (1973), a renda integra o custo de oportunidade se o criminoso for punido com prisão. No entanto, o primeiro efeito tem prevalecido nas análises empíricas de tal modo que, na maioria das vezes, tem sido diagnosticado um efeito positivo da renda sobre a criminalidade. Mas, as evidências encontradas neste estudo sinalizam que talvez seja mais adequado controlar um possível efeito não linear da renda nas taxas de crimes. Em outras palavras, com base nos resultados encontrados neste estudo, sugerimos a inclusão de um termo quadrático para a variável que mensura a renda familiar ou domiciliar. Isso porque ela determina tanto os ganhos esperados no crime quanto a possibilidade de gastos 
para prevenção ao crime. Devido à falta de dados adequados, em geral os gastos privados para causar dissuasão ao crime não são controlados nas estimações de modelos de oferta agregada de crimes. Portanto, a inclusão de um termo quadrático para a variável que busca controlar os ganhos esperados pelo criminoso pode ser uma boa alternativa para controlar indiretamente os esforços privados para dissuadir o comportamento criminoso.

Em termos de formulação de políticas públicas que visem reduzir os níveis de criminalidade, por um lado, as medidas adotadas pelo Estado devem focar em fatores que aumentem o custo de oportunidade do crime, desestimulando que mais indivíduos se tornem criminosos, e que presos após a soltura reincidam. Por outro lado, é imprescindível aumentar a probabilidade de fracasso dos criminosos contumazes na execução de seus crimes. Isso se faz por meio de políticas de segurança pública que aumentem a eficiência das instituições de segurança pública. É preciso, ainda, colocar em prática medidas que reduzam o sub-registro de crimes, pois o conhecimento da real taxa de crimes é fundamental para tomada de decisões por parte das autoridades competentes concernente à alocação dos recursos destinados à segurança pública. Por fim, se isso não for feito, caberá somente à sociedade o ônus para se prevenir das vitimizações adotando um comportamento cada vez mais cauteloso com relação ao risco de vitimização e gastando uma parcela de sua riqueza com a sua segurança, constitucionalmente uma obrigação do Estado.

\section{Detalhes computacionais}

Todos os procedimentos empíricos foram feitos no programa Stata, versão 11.0.

\section{Referências}

BEATO, F. C.; PEIXOTO, B. T.; ANDRADE, M. V. Crime, oportunidade e vitimização. Revista Brasileira de Ciências Sociais, São Paulo, v. 19, n. 55, p. 73-89, 2004.

BECKER, G. S. Crime and punishment: an economic approach. The Journal of Political Economy, Chicago, v. 76, n. 2, p. 169-217, 1968.

CAMERON, A. C.; TRIVEDI, P. K. Regression analysis of count data, Volume 1 of Econometric Society Monographs. New York: Cambridge University Press, 1998.

CAMERON, A. C.; TRIVEDI, P. K. Microeconometrics: methods and applications. New York: Cambridge University Press, 2005.

CAMERON, A. C.; TRIVEDI, P. K., P. K. Microeconometrics using stata. 2nd ed. College station: Stata Press, 2009. 
CARNEIRO, L. P. Violent crime in Latin America cities: Rio de Janeiro and São Paulo. São Paulo: USP, 2000. 129 p. (Research Report, 129)

CARVALHO, J. R.; LAVOR, S. C. Repeat criminal victimization and income inequality in Brazil. Economia (Selecta), Brasília, v. 9. n.4, p. 87-110, 2008.

CERQUEIRA, D.; LOBÃO, W. Determinantes da criminalidade: Arcabouços teóricos e resultados empíricos. Dados - Revista de Ciências Sociais, Rio de Janeiro, v. 47, n. 2, p. 233-269, 2004.

COHEN, L. E.; KLUEGEL, J. R.; LAND, K. C. Social inequality and predatory criminal victimization: an exposition and test of a formal theory. American Sociological Review, Washington, v. 46, n. 5, p. 505-524, 1981.

EHRLICH, I. The supply of illegimate activities. Unpublished manuscript, New York: Columbia University, 1967.

EHRLICH, I. Participation in illegitimate activities: a theoretical and empirical investigation. Journal of Political Economy, Chicago, v. 81, n. 3, p. 526-536, 1973.

FLEISHER, B. M. The effect of unemployment on juvenile delinquency. The American Economic Review, Nashville, v. 71, n. 6, p. 543-555, 1963.

FLEISHER, B. M. The effect of income on delinquency. The American Economic Review, Nashville, v. 61, n. 1, p. 118-137, 1966.

GAVIRIA, A.; PAGÉS, C. Patterns of crime victimization in Latin American cities. Journal of Development Economics, Amsterdam, v. 67, n.1, p. 181-203, 2002.

GOMES, F. A. R; PAZ, L. S. The determinants of criminal victimization in São Paulo State, Brazil. Brazilian Review of Econometrics, Rio de Janeiro, v. 28, n. 2, p. 217-238, 2008.

GOMES, F. A. R. Vitimização por roubo e furto em São Paulo: qual é a importância da dimensão espacial?. São Paulo: CPP-INSPER, 2011. 76 p. (Relatório de pesquisa).

HINDELANG, M. J.; GOTTFREDSON, M. R.; GAROFALO, J. Victims of personal crime: An empirical foundation for a theory of personal victimization. Cambridge: Ballinger Publishing Company, 1978. 
KUME, L. Uma estimativa dos determinantes da taxa de criminalidade brasileira: uma aplicação em painel dinâmico. In ENCONTRO NACIONAL DE ECONOMIA, XXXII, 2004, João Pessoa. Disponível em: http://www.anpec.org.br/encontro2004/artigos/A04A148.pdf. Acesso em: 30 dez. 2004.

LEVITT, S. D. The changing relationship between income and crime victimization. Economic Policy Review, New York, sep., p. 87-98, 1999.

MADALOZZO, R.; FURTADO, G. M. Um estudo sobre vitimização para a cidade de São Paulo. Revista de Economia Política, São Paulo, v. 31, n. 1, p. 160-180, 2011.

MEIER, R. F.; MIETHE, T. D. Understanding theories of criminal victimization. Crime and Justice, London, v. 17, p. 459-499, 1993.

MENDONÇA, M. J. C.; LOUREIRO, P. R. A.; SACHSIDA, A. Uma análise empírica a partir dos dados do Presídio da Papuda. Estudos Econômicos, São Paulo, v. 32, n. 4, p. 621-641, 2002.

MIETHE, T. D.; MCDOWALL, D. Contextual effects in models of criminal victimization. Social Forces, Chapel Hill, v. 71, n. 3, 741-759, 1993.

PEIXOTO, B.; SOUZA, L. G. de; LIMA, R. S. de. Uma análise sistêmica: Vitimização e políticas de segurança em São Paulo. São Paulo: CPP-INSPER, 2011. 36 p. (Relatório de pesquisa).

SANTOS, M. J. dos. Dinâmica temporal da criminalidade: mais evidências sobre o "efeito inércia" nas taxas de crimes letais nos estados brasileiros. Economia, Brasília, v. 10, n. 1, p. 169-194, 2009.

SANTOS, M. J. dos; KASSOUF, A. L. Uma investigação econômica da influência do mercado de drogas ilícitas sobre a criminalidade brasileira. Economia, Brasília, v. 8, n. 2, p. 187-210.

SANTOS, M. J. dos; KASSOUF, A. L. Estudos econômicos das causas da criminalidade no Brasil: Evidências e Controvérsias. Economia, Brasília, v. 9, n. 2, p. 343-373, 2008a.

SANTOS, M. J. dos; KASSOUF, A. L. Existe explicação econômica para o sub-registro de crimes contra a propriedade? Economia Aplicada, Ribeirão Preto, v. 12, n. 1, p. 5-27, 2008 b. 
e do sub-registro de crimes na cidade de São Paulo. São Paulo: CPP-INSPER, 2011. 47 p. (Relatório de pesquisa).

SJOQUIST, D. L. Property crime and economic behavior: Some empirical results. The American Economic Review, Nashville, v. 63, n. 3, p. 439-446, 1973.

SMIGEL-LEIBOWISTZ, A. Does crime pay? An economic analysis. 1965. Master's thesis - Columbia University, New York. 1965.

SPARKS, R. F. Multiple victimization: evidence, theory, and future research. Journal of Criminal Law and Criminology, Baltimore, v. 72, n. 2, p. 762-778, 1981.

WITTE, A. D. Estimating the economic model of crime with individual data. The Quarterly Journal of Economics, Cambridge, v. 94, n. 1, p. 57-84, 1980.

YBARRA, L. M. R.; LOHR, S. L. Estimates of repeat victimization using the national crime victimization survey. Journal of Quantitative Criminology, Dordrecht, v. 18, N.1, p. 1-21, 2002. 